\title{
RESRAD-BUILD: A Computer Model for Analyzing the Radiological Doses Resulting from the Remediation and Occupancy of Buildings Contaminated with Radioactive Material
}

\author{
RECEIVEO \\ JAN 264998 \\ OSTI
}

Environmental Assessment Division Argonne National Laboratory

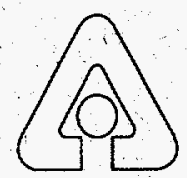

Operated by The University of Chicago, under Contract W-31-109-Eng-38, for the

United States Department of Energy

For Interim Use and Comment 


\section{Argonne National Laboratory}

Argonne National Laboratory, with facilities in the states of Illinois and Idaho, is owned by the United States Govemment, and operated by the University of Chicago under the provisions of a contract with the Department of Energy.

This technical memo is a product of Argonne's Environmental Assessment Division (EAD). For information on the division's scientific and engineering activities, contact:

Director, Environmental Assessment Division

Argonne National Laboratory

Argonne, Illinois 60439-4815

Telephone (630) 252-3107

Presented in this technical memo are preliminary results of ongoing work or work that is more limited in scope and depth than that described in formal reports issued by the EAD.

Publishing support services were provided by Argonne's Information : and Publishing Division (for more information, see IPD's home page: http://www.ipd.anl.gov/).

\section{Disclaimer}

This report was prepared as an accouint of work sponsored by an agency of

e the United States Government. Neither the United States Government nor any agency thereof, nor any of their employees, makes any warranty, express or implied, or assumes any leigal liability or responsibility for the accuracy, completeness, or usefulness of any information, apparatus, product, or process disclosed, or represents that its use would not infringe privately owned rights. Reference herein to any specific commercial product, process, or service by trade name, trademark, manufacturer, or otherwise, does not necessarily constitute or imply its endorsement, recommendation, or favoring by the United States Government or any agency thereof. The views and opinions of authors expressed herein do not necessarily state or reflect those of the United States Government or any agency thereof. 


\section{RESRAD-BUILD: A Computer Model for Analyzing the Radiological Doses Resulting from the Remediation and Occupancy of Buildings Contaminated with Radioactive Material}

by C. Yu, D.J. LePoire, C.O. Loureiro, ${ }^{\star}$ L.G. Jones, and S.Y. Chen

Environmental Assessment Division,

Argonne National Laboratory, 9700 South Cass Avenue, Argonne, Illinois 60439

November 1994

Work sponsored by United States Department of Energy,

Assistant Secretary for Environment, Safety and Health,

Office of Environmental Guidance,

Assistant Secretary for Environmental Restoration and Waste Management,

Office of Environmental Restoration

For Interim Use and Comment

BSTRIBUTION OF THS DOCUMENT IS UNLWMTED

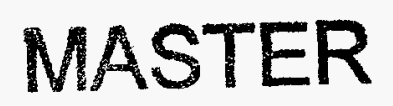

*Loureiro is associated with the School of Engineering of the University of Minas Gerais, Belo Horizonte, Brazil. 


\section{DISCLAIMER}

Portions of this document may be illegible electronic image products. Images are produced from the best available original document. 


\section{CONTENTS}

ACKNOWLEDGMENTS $\ldots \ldots \ldots \ldots \ldots \ldots \ldots \ldots \ldots \ldots \ldots \ldots \ldots$

AVAILABILITY OF COMPUTER SOFTWARE $\ldots \ldots \ldots \ldots \ldots \ldots$ vii

NOTATION $\ldots \ldots \ldots \ldots \ldots \ldots \ldots \ldots \ldots \ldots \ldots \ldots \ldots \ldots \ldots \ldots \ldots$

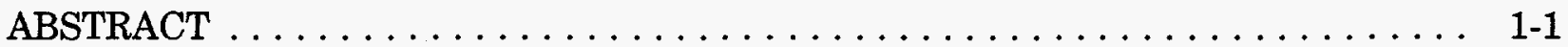

1 INTRODUCTION $\ldots \ldots \ldots \ldots \ldots \ldots \ldots \ldots \ldots \ldots \ldots \ldots \ldots \ldots \ldots \ldots$

2 DESCRIPTION OF BUILDING, SOURCES, AND RECEPTORS . . . . . . . 2-1

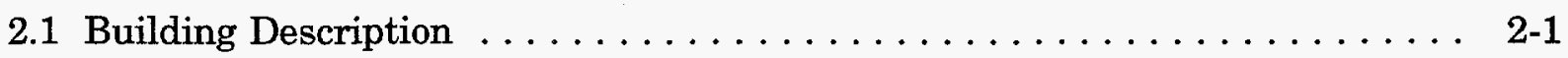

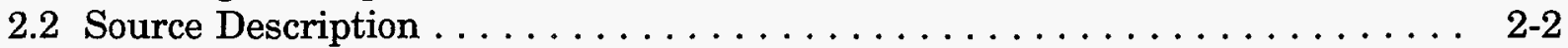

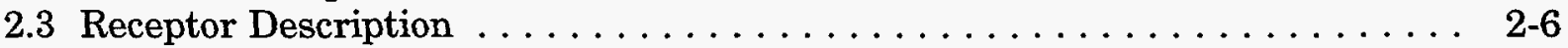

3 DESCRIPTION OF EXPOSURE SCENARIOS AND PATHWAYS $\ldots \ldots \ldots$. . . . $3-1$

3.1 Exposure Scenarios . . . . . . . . . . . . . . . . . . . . . 3-1

3.2 Exposure Pathways . . . . . . . . . . . . . . . . . . . $3-2$

$4 \quad$ USER'S GUIDE $\ldots \ldots \ldots \ldots \ldots \ldots \ldots \ldots \ldots \ldots \ldots \ldots \ldots \ldots \ldots \ldots \ldots . \ldots \ldots$

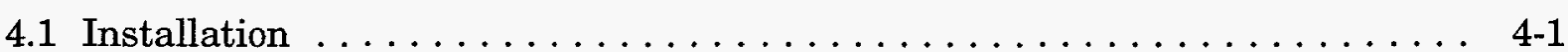

4.2 Program Execution $\ldots \ldots \ldots \ldots \ldots \ldots \ldots \ldots \ldots \ldots \ldots \ldots \ldots \ldots \ldots$

4.3 Input Data Requirements $\ldots \ldots \ldots \ldots \ldots \ldots \ldots \ldots \ldots \ldots \ldots \ldots \ldots \ldots$

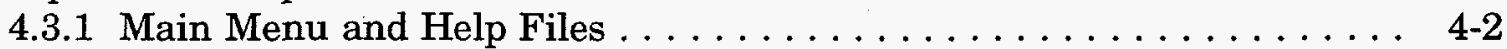

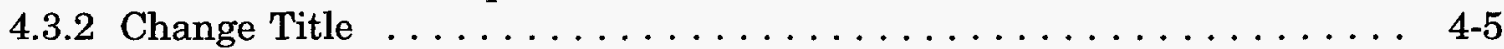

4.3 .3 Modify Data . . . . . . . . . . . . . . . . . . . . . . . 4-6

4.3.3.1 Occupancy Characteristics ................. 4-8

4.3.3.2 Building Characteristics . . . . . . . . . . . . . . . 4 4 9

4.3.3.3 Receptor Characteristics . . . . . . . . . . . . . . . . 4-11

4.3.3.4 Source Characteristics . . . . . . . . . . . . . . . . . 4-12

4.3.3.5 Shielding Characteristics . . . . . . . . . . . . . . 4-12

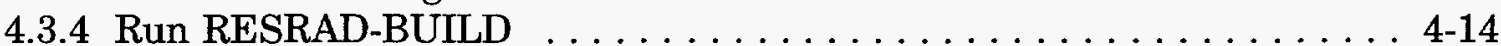

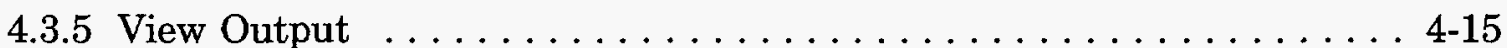

4.3.6 Reset Colors . . . . . . . . . . . . . . . . . . . . . . . . 4 4-15

4.3 .7 Modify Library . . . . . . . . . . . . . . . . . . . . . 4-15

4.3.7.1 Internal Dose Conversion Factors . . . . . . . . . . . . . 4 4-15

4.3.7.2 External Dose Conversion Factors . . . . . . . . . . . . 4-16

4.3 .8 Quit . . . . . . . . . . . . . . . . . . . 4 4-16

4.4 Technical Summary . . . . . . . . . . . . . . . . 4-17

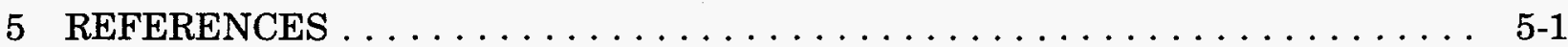




\section{CONTENTS (Cont.)}

APPENDIX A: Indoor Air Quality Model $\ldots \ldots \ldots \ldots \ldots \ldots \ldots \ldots \ldots \ldots$ A-1

APPENDIX B: Air Particulate Deposition $\ldots \ldots \ldots \ldots \ldots \ldots \ldots \ldots \ldots \ldots$ B-1

APPENDIX C: Radon and Its Progeny Concentration $\ldots \ldots \ldots \ldots \ldots \ldots$ C-1

APPENDIX D: Inhalation of Airborne Radioactive Dust $\ldots \ldots \ldots \ldots \ldots \ldots$ D-1

APPENDIX E: Ingestion of Radioactive Material $\ldots \ldots \ldots \ldots \ldots \ldots \ldots \ldots$

APPENDIX F: External Radiation Exposure $\ldots \ldots \ldots \ldots \ldots \ldots \ldots \ldots \ldots$ F-1

\section{TABLES}

C.1 Values of Rate Constants Used in the Radon Progeny Model $\ldots \ldots \ldots \ldots \ldots$ C-17

D.1 Committed Effective Dose Equivalent Conversion Factors

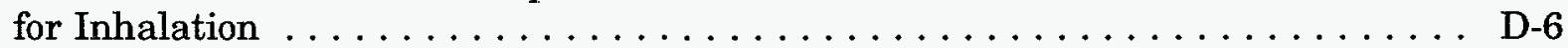

E.1 Committed Effective Dose Equivalent Conversion Factors for Internal Radiation from Ingestion $\ldots \ldots \ldots \ldots \ldots \ldots \ldots \ldots \ldots \ldots \ldots$

F.1 Effective Dose Equivalent Conversion Factors for External Exposure . . . . . . F-11

\section{FIGURES}

1 Vertical View of Possible Building Geometries for the

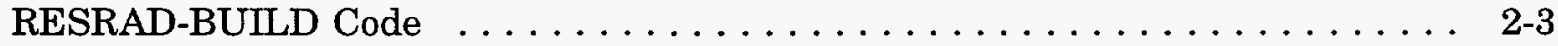

2 Coordinate System Used in the RESRAD-BUILD Code $\ldots \ldots \ldots \ldots \ldots \ldots 2-4$

3 Exposure Pathways Incorporated in the RESRAD-BUILD Code $\ldots \ldots \ldots \ldots$. $3-3$

4 RESRAD-BUILD Initial Banner Page $\ldots \ldots \ldots \ldots \ldots \ldots \ldots \ldots \ldots \ldots$

$5 \quad$ Main Menu for RESRAD-BUILD $\ldots \ldots \ldots \ldots \ldots \ldots \ldots \ldots \ldots \ldots \ldots \ldots \ldots \ldots$

6 Input Form for Title and User Data Files. . . . . . . . . . . $\ldots \ldots \ldots$

7 Modify Data Submenu $\ldots \ldots \ldots \ldots \ldots \ldots \ldots \ldots \ldots \ldots \ldots \ldots \ldots \ldots \ldots \ldots$

8 Input Form for Occupancy Characteristics. $\ldots \ldots \ldots \ldots \ldots \ldots \ldots \ldots$ 4-8 


\section{FIGURES (Cont.)}

9 Input Form for Building Characteristics. . . . . . . . . . . . . 4-10

10 Input Form for Receptor Characteristics. . . . . . . . . . . . . 4-11

11 Input Form for General Source Characteristics. . . . . . . . . . . . 4-13

12 Input Form for Volume Source Characteristics. . . . . . . . . . . . . 4-13

13 Input Form for Shielding Characteristics. . . . . . . . . . . . . 4-14

14 Input Form for Internal Dose Conversion Factors $\ldots \ldots \ldots \ldots \ldots \ldots \ldots$

15 Input Form for External Dose Conversion Factors $\ldots \ldots \ldots \ldots \ldots \ldots \ldots$. . . . . . .

A.1 Schematic Representation of the Three-Compartment Building, Showing the Inflow and Outflow of Air in Each Compartment . . . . . . . . A-4

B.1 Schematic Representation of a Compartment $i$ of the Building, Showing the Deposition of Dust Particulates onto the Projected Horizontal Surface . . . . . . . . . . . . . . . . . . . . . . B 4

C.1 Three-Dimensional Schematic Representation of a Volume Source . . . . . . C-5

C.2 One-Dimensional Schematic Representation of a Volume Source . . . . . . . C-5

C.3 Schematic Representation of the Three-Compartment Building . . . . . . . . C-13

C.4 Schematic Representation of the Interrelationships among the Several States of the Short-Lived Radon Decay Products . . . . . . . . . . . . C-15

F.1 Geometry for the Horizontal Displacement Factor $\ldots \ldots \ldots \ldots \ldots \ldots \ldots$

F.2 Geometry in the Line Source Model . . . . . . . . . . . . . . . . . F F-9 


\section{ACKNOWLEDGMENTS}

The authors would like to thank U.S. Department of Energy Program Managers Andy Wallo, Hal Peterson, and W. Alexander Williams for their guidance and encouragement throughout the project and for their review of the draft report. We also thank Emmanuel Gnanapragasam for his review of the report and for testing the code. We thank Scott Dovel for his contributions to the screen and interface program. Finally, we thank Margy Ortigara for editorial assistance and the Information and Publishing Division's Document Processing Center for document preparation. 
Electronic copies of the software described in this publication will be distributed with appropriate restrictions by:

Energy Science and Technology Software Center

P.O. Box 1020

Oak Ridge, Tennessee 37831-1020

For information regarding requests for software, call (615) 576-2606. 


\section{NOTATION}

The following is a list of the acronyms, initialisms, and abbreviations (including units of measure) used in this document.

\section{ACRONYMS, INITIALISMS, AND ABBREVIATIONS}

$\begin{array}{ll}\text { AEC } & \text { U.S. Atomic Energy Commission } \\ \text { AMAD } & \text { activity median aerodynamic diameter } \\ \text { AP } & \text { anterior-posterior } \\ \text { CEDE } & \text { committed effective dose equivalent } \\ \text { DOE } & \text { U.S. Department of Energy } \\ \text { DOS } & \text { disk operating system } \\ \text { GI } & \text { gastrointestinal } \\ \text { NRC } & \text { U.S. Nuclear Regulatory Commission } \\ \text { TEDE } & \text { total effective dose equivalent }\end{array}$

\section{UNITS OF MEASURE}

$\begin{array}{ll}\mathrm{h} & \text { hour(s) } \\ \text { in. } & \text { inch(es) } \\ \mathrm{K} & \text { kilobyte(s) } \\ \mathrm{MB} & \text { megabyte(s) } \\ \mathrm{MeV} & \text { megaelectron volt(s) } \\ \mathrm{m} & \text { meter(s) } \\ \mathrm{m}^{2} & \text { square meter(s) } \\ \mu \mathrm{m} & \text { micrometer(s) } \\ \text { pCi } & \text { picocurie(s) } \\ \text { WLM } & \text { working level month(s) }\end{array}$




\title{
RESRAD-BUILD: A COMPUTER MODEL FOR ANALYZING THE RADIOLOGICAL DOSES RESULTING FROM THE REMEDIATION AND OCCUPANCY OF BUILDINGS CONTAMINATED WITH RADIOACTIVE MATERIAL
}

by

C. Yu, D.J. LePoire, C.O. Loureiro, L.G. Jones, and S.Y. Chen

\begin{abstract}
The RESRAD-BUILD computer code is a pathway analysis model designed to evaluate the potential radiological dose incurred by an individual who works or lives in a building contaminated with radioactive material. The transport of radioactive material inside the building from one compartment to another is calculated with an indoor air quality model. The air quality model considers the transport of radioactive dust particulates and radon progeny due to air exchange, deposition and resuspension, and radioactive decay and ingrowth. A single run of the RESRAD-BUILD code can model a building with up to: three compartments, 10 distinct source geometries, and 10 receptor locations. A shielding material can be specified between each source-receptor pair for external gamma dose calculations. Six exposure pathways are considered in the RESRAD-BUILD code: (1) external exposure directly from the source; (2) external exposure to materials deposited on the floor; (3) external exposure due to air submersion; (4) inhalation of airborne radioactive particulates; (5) inhalation of aerosol indoor radon progeny; and (6) inadvertent ingestion of radioactive material, either directly from the sources or from materials deposited on the surfaces of the building compartments.
\end{abstract}




\section{INTRODUCTION}

Argonne National Laboratory has developed the computer code RESRAD for the U.S. Department of Energy (DOE) to evaluate residual radioactive material in soil (Yu et al. 1993). The RESRAD code implements the DOE requirements described in Chapter 4 of DOE Order 5400.5 (DOE 1990). Many sites that are contaminated with radioactive material in soil also have contamination inside the buildings on-site. DOE Order 5400.5 provides generic surface contamination guidelines that are applicable to building structures and equipment. These generic guidelines are generally consistent with standards of the U.S. Nuclear Regulatory Commission (NRC) and functionally equivalent to those listed in Regulatory Guide 1.86 (U.S. Atomic Energy Commission [AEC] 1974). Recently, the NRC studied the evaluation of building contamination on a generic screening basis (Kennedy and Strenge 1992). In the NRC study, certain important pathways such as radon progeny inhalation are not included; moreover, the contamination is limited to certain fixed thicknesses. Buildings (like soil) vary from site to site: the building structural material may be different; the size and air exchange rate of the building and rooms may be different; and the contamination inside the building may be different in size, thickness, and shape. Therefore, to properly evaluate building contamination, a detailed modeling of the transport of contaminants inside the building and the exposure pathways to the individual in the building is needed.

The RESRAD-BUILD computer code is a pathway analysis model developed to evaluate the potential radiological dose incurred by an individual who works or lives in a building contaminated with radioactive material. The radioactive material in the building structure can be released into the indoor air by mechanisms such as diffusion (radon gas), mechanical removal (decontamination activities), or erosion (removable surface 
contamination). The transport of radioactive material inside the building from one compartment to another is calculated with an indoor air quality model (see Appendix A). The air quality model evaluates the transport of radioactive dust particulates and radon progeny due to (1) air exchange between compartments and with outdoor air, (2) the deposition and resuspension of particulates, and (3) radioactive decay and ingrowth. RESRAD-BUILD can model up to three compartments in a building, making it possible to evaluate situations ranging from a one-room warehouse to a three-story house, for example.

The design of RESRAD-BUILD is similar to that of the RESRAD code: the user can construct the exposure scenario by adjusting the input parameters. Typical building exposure scenarios include long-term occupancy (resident and office worker) and short-term occupancy (remediation worker and visitor). Up to 10 receptor locations and 10 distinct source locations can be input into the RESRAD-BUILD code to calculate dose in a single run of the code. The calculated dose can be the total (individual) dose to a single receptor spending time at various locations or the total (collective) dose to a work force decontaminating the building. If a building is demolished, the RESRAD computer code may be used to evaluate the potential dose from the buried material.

The RESRAD-BUILD code considers six exposure pathways: (1) external exposure directly from the source; (2) external exposure to materials deposited on the floor; (3) external exposure due to air submersion; (4) inhalation of airborne radioactive particulates; (5) inhalation of aerosol indoor radon progeny (in the case of the presence of radon predecessors); and (6) inadvertent ingestion of radioactive material, either directly from the sources or from materials deposited on the surfaces of the building compartments. A detailed discussion of exposure scenarios and pathways is presented in Section 3.

The RESRAD-BUILD code can compute the attenuation due to a shielding material between each source-receptor combination when calculating the external dose. The user can 
select the shielding material from eight material types and input the thickness and density of shielding material. The user may also define the source as point, line, area, or volume source. Volume sources can comprise five layers of different materials, with each layer being porous, homogeneous, and isotropic.

The radionuclides included in the RESRAD-BUILD code are the same as those included in the RESRAD code version 5.05. Currently, 67 radionuclides are in the RESRADBUILD database, and additional radionuclides are being added. All these radionuclides have a half-life of six months or greater, and they are referred to as principal radionuclides. It is assumed that the short-lived decay products with half-lives of six months or less, referred to as the associated radionuclides, are in secular equilibrium with their parent (principal) radionuclides.

The information presented in this manual is organized as follows:

- Description of buildings, sources of contamination, and receptors exposed to radiation - Section 2;

- Exposure pathways and scenarios for building contaminationSection 3;

- Description of the RESRAD-BUILD code and instructions for its use - Section 4; and

- Models, formulas, and the database used in RESRAD-BUILD code Appendixes A through $\mathrm{F}$. 


\section{DESCRIPTION OF BUILDING, SOURCES, AND RECEPTORS}

The RESRAD-BUILD code is designed to evaluate the radiological doses to individuals who live or work inside a building that is contaminated with radioactive material. The contamination could be (1) on the surface of the floor, walls, or ceiling; (2) within the building material, such as drywall, concrete floor, steel I-beam, metal pipes, and wires; and (3) accumulated inside the building, such as in the air exchange filter or in the drain. RESRAD-BUILD can model up to three compartments in a building. A compartment can be one room or several rooms on the same floor with free air exchange among the rooms. External radiation penetrating the walls, ceilings, or floors is calculated on the basis of the user input of shielding material type, thickness, and density. Internal (inhalation and ingestion) exposures are calculated on the basis of an air quality model that considers the air exchange between rooms and with outdoor air.

The RESRAD-BUILD code can be applied to evaluate the potential exposure of an individual standing or working outside a contaminated building by assuming the outdoor space is a large room (compartment) adjacent to the contaminated building. The building, source of contamination, and receptors modeled in the RESRAD-BUILD code are discussed in detail in the following subsections.

\subsection{BUILDING DESCRIPTION}

In the RESRAD-BUILD model, the building is conceptualized as a structure composed of up to three compartments. It can be a one-room warehouse, a two-room office or apartment, a three-room ranch house, a three-story office building, or a two-story house with a basement. Air exchange is assumed between compartments 1 and 2 and compartments 2 and 3 but not between compartments 1 and 3 . All compartments can exchange air with the outdoor atmosphere. An air quality model was developed to calculate 
the contaminant concentration in each compartment. A detailed description of the air quality model is presented in Appendix A.

Typical building geometries that can be modeled by the RESRAD-BUILD code are illustrated in Figure 1. A coordinate system is used in RESRAD-BUILD to define the location of the sources and receptor points inside the building. The origin and axes of the coordinate system can be at any location and any direction, but the origin is usually located at the bottom left corner of the lowest level, with the $x$-axis measuring the horizontal distance to the right of the origin and coinciding with the bottom edge of the compartment (see Figure 2); the $y$-axis being perpendicular into the building; and the $z$-axis measuring the vertical distance and coinciding with the left edge of the building.

The user can specify the locations of the sources and receptors and time the receptor spends in each compartment, so the radiological dose to the receptor can be calculated for any type of building use including residential, commercial, or industrial. Therefore, the building model approach used in RESRAD-BUILD is quite flexible.

\subsection{SOURCE DESCRIPTION}

The building is assumed to be contaminated with radioactive materials located at a defined number of places within the structure of the building. Each contaminated location is considered a distinct source, and as many as 10 sources can be specified in a single run of RESRAD-BUILD. Depending on its geometric appearance, the source can be defined as a volume, area, line, or point source. The distinction between these types of sources is rather arbitrary and reflects the modeling objective of simplifying the overall configuration whenever justifiable. The proper classification of each source is left to the user's best judgment. 


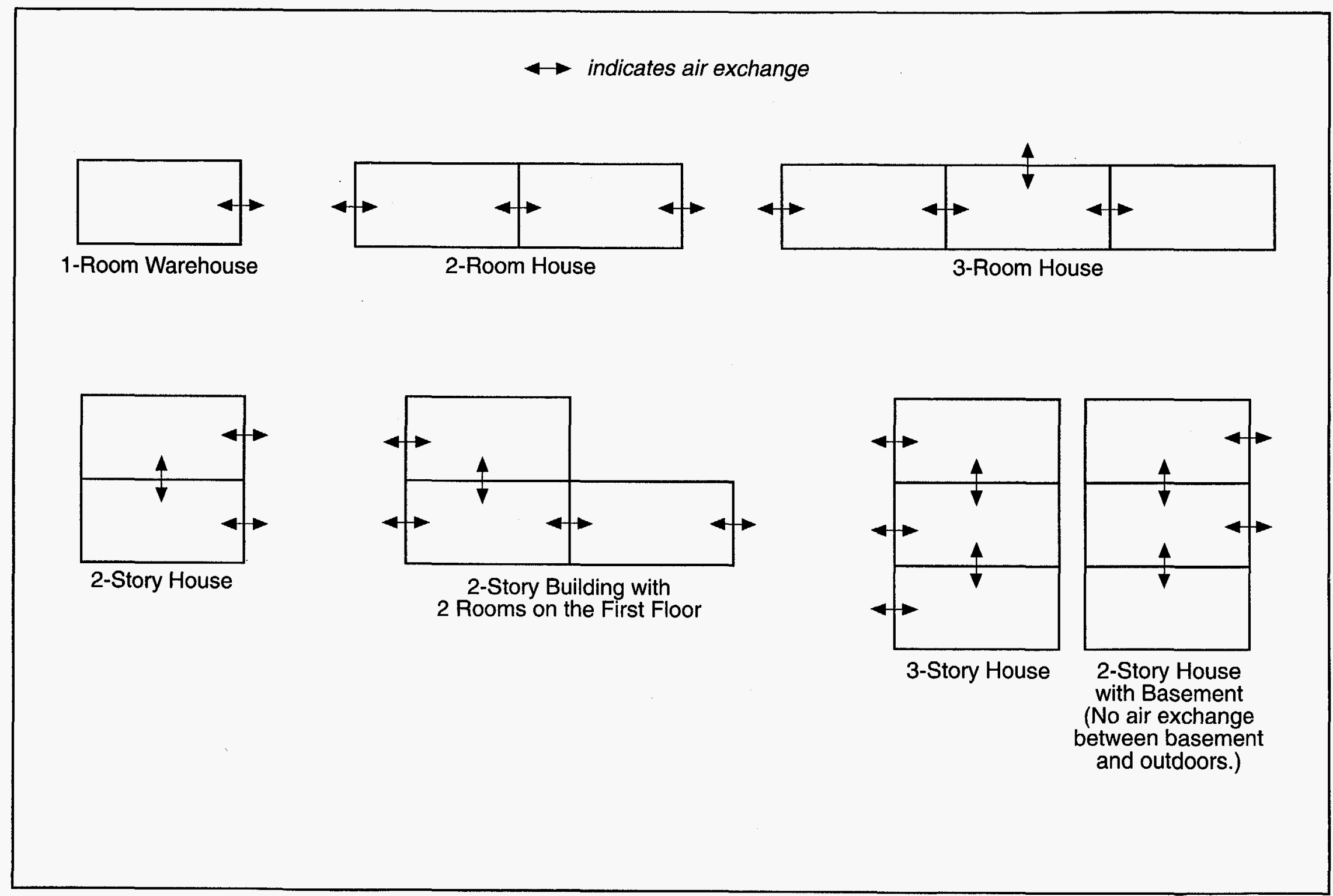




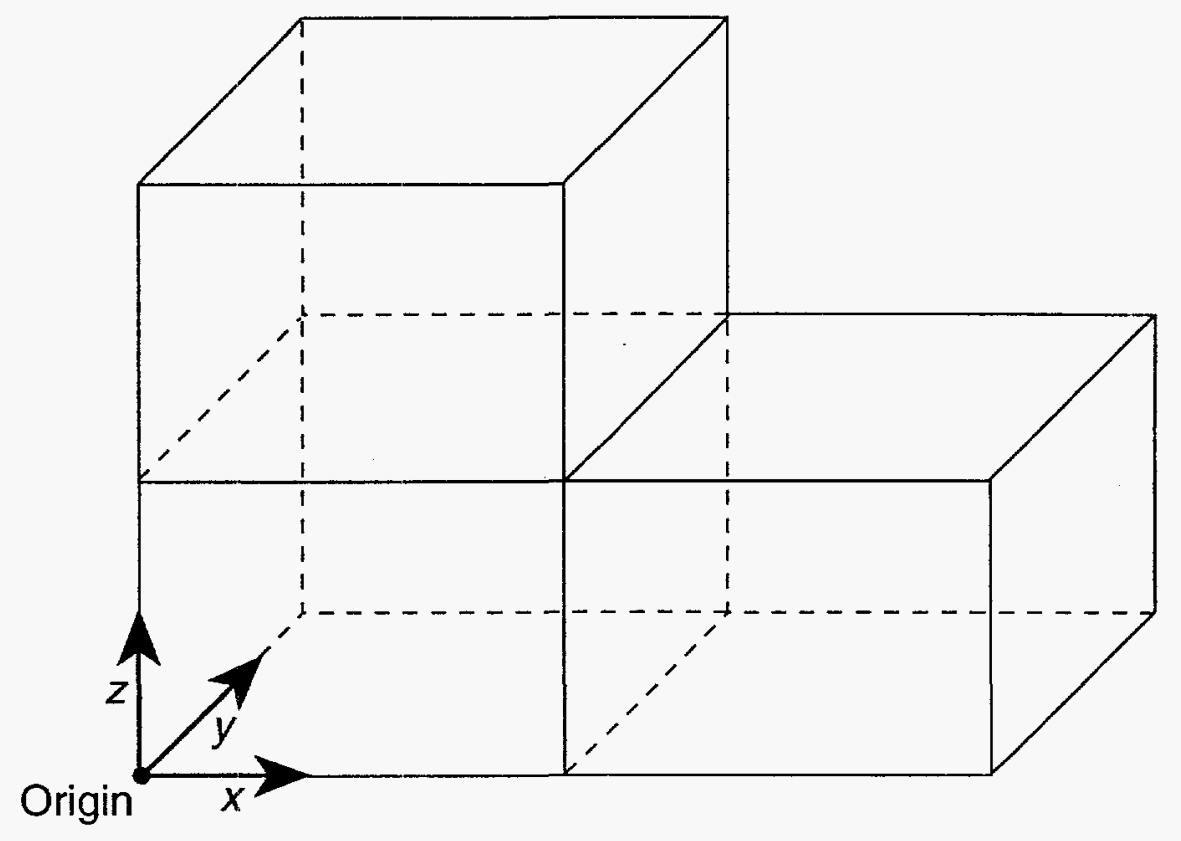

\section{FIGURE 2 Coordinate System Used in the RESRAD-BUILD Code}

In general, each source is initially characterized by defining its type, the compartment in which it is located, and the coordinates of its center, according to the system of coordinates used for the building compartments (see Figure 2). The number of different radionuclides and their initial total activities are also defined for each source. Depending on the type of the source, two other geometric parameters may also be defined: the area/length and the direction of the source. For either a volume or a surface source, the area is defined as the surface area of the source facing the open air; the area is assumed to be circular. Source direction is defined as the vector perpendicular to the exposed area. This direction should be coincident with one of the axes $(x, y$, or $z)$. For a line source, the length parameter is defined as the length of the segment of line forming the source, and direction is given by the direction of the line itself. Again, the direction of the line source must be coincident with an axis. For a point source, neither the direction nor the area or length parameter is used. 
Mechanical removal and erosion of the source material, when its surface is exposed to open air, will result in the transport of part of its mass directly into the indoor air environment, resulting in airborne contaminants. Because of the air exchange processes among all compartments of the building, the airborne particulates being loaded into the indoor air of the compartment are then transported to the indoor air of all compartments of the building.

A contaminated area in the building should be considered as a volume source if it can be clearly represented in a three-dimensional configuration. A segment of a wall in the building, contaminated with radioactive materials, is an example of a possible volume source. The volume source could be located entirely within one compartment, such as in an external wall, or it could be located at the boundaries of the compartment, such as in the floor/ceiling or in the wall separating two compartments. If located at the boundary between two compartments, the volume source could have two faces, one exposed to the open air of each compartment. In this case, the volume source could release radon to both compartments but contaminated particulates to the primary side only. In the RESRAD-BUILD model, the volume source can be defined with up to five distinct parallel regions (or layers) located along the direction parallel to the partition, each consisting of homogeneous and isotropic materials. Each layer is defined by its physical properties such as thickness, density, porosity, radon effective diffusion coefficient, radon emanation fraction, erosion rate (of the surface closest to the origin), and concentration of radioactive contaminants. The definition of a volume source must also identify which compartments the faces of the source are exposed to. Finally, the rate of inadvertent ingestion of loose materials directly from the source must be defined.

Definition of a surface source is considered in those cases of surface contamination in which the thickness of the contaminated layer is considerably smaller than the affected area exposed to open air. An example would be a spill of radioactive materials over an area 
of relatively large dimensions, with very little penetration of the spilled substance into the matrix of the contaminated medium. Each surface source is associated with a removable fraction, a time for source removal, a release fraction of material to the indoor air, and a direct ingestion rate. The unit of contamination for area source used in RESRAD-BUILD is $\mathrm{pCi} / \mathrm{m}^{2}$.

A line source can be defined for those cases in which one dimension, such as length, is clearly larger than any other dimension of the source. A pipe carrying radioactive materials, or the wall/floor joint edge with accumulated contaminated substances, could be considered a line source. Parameters used to characterize the line source are similar to those for the area source. The unit for line source is $\mathrm{pCi} / \mathrm{m}$.

Contaminated locations in the building where the radioactive materials are concentrated in regions of small dinnensions, compared to the dimensions of the compartment and the distance to the receptor, could be approximated as point sources. Parameters used to characterize point source are similar to those for the area and line sources. The unit for point source is $\mathrm{pCi}$.

\subsection{RECEPTOR DESCRIPTION}

The receptors considered in the RESRAD-BUILD model include office worker, resident, industrial worker, remediation worker, building visitor, or any individual spending some time inside the contaminated building. The RESRAD-BUILD code is designed with flexibility and simplicity in mind so that the model can simulate diverse exposure scenarios such as office work, building cleaning and maintenance work, building renovation, building visiting, and continuous residency. The exact location (coordinates) of the receptor is required to calculate external exposure. The receptor location should be the midpoint of the person. For example, if the receptor is standing on a contaminated floor, the receptor location should be $1 \mathrm{~m}$ above the floor. For other pathways, only the information about the room in which 
the receptor is located is required by the code because the air quality model assumed that the air is homogeneously mixed in each compartment. To calculate the external dose, the shielding material type and its density and thickness need to be input into the code in addition to the receptor location. The orientation of the receptor to the source can also be selected, that is, rotational or facing the source (anterior-posterior [AP]). The AP orientation will result in higher direct external dose than rotational orientation.

Up to 10 receptor points can be specified in the RESRAD-BUILD code. The time fraction spent at each receptor point needs to be input. The total time fraction can exceed unity. This allows RESRAD-BUILD to evaluate total (collective) worker dose as well as the total individual dose with a single run of the code. 
$2-8$ 


\section{DESCRIPTION OF EXPOSURE SCENARIOS AND PATHWAYS}

\subsection{EXPOSURE SCENARIOS}

Before a contaminated building can be released for use without radiological restrictions, the potential future use of the building must be evaluated. The potential future use of a building depends on many factors such as the current use of the building, age and conditions of the building, location and size of the building, and extent of contamination.

The potential uses of a building are referred to as exposure scenarios, which can be classified into two major categories: building occupancy and building remediation. Building occupancy scenarios include residential use and office worker. Building remediation scenarios include decontamination worker and building renovation worker. The building occupancy scenarios are usually rather long-term chronic exposures, whereas building remediation scenarios are usually short-term exposures. Building decontamination and renovation activities may result in a higher release of contaminants into the indoor air as compared to the building occupancy scenarios. The building occupancy scenarios may result in the release of contaminants into the air from normal use and cleaning of the building such as washing the wall and vacuuming the floor. Building remediation includes such activities as sanding a contaminated floor, chipping concrete, and removing or installing drywall.

The differences among these scenarios are the exposure duration, the amount and rate of contaminants released into air, and the pathways involved. The RESRAD-BUILD code is designed to model all these exposure scenarios. If the user inputs appropriate parameters for the exposure duration and the amount and rate of contaminants released into air and selects appropriate pathways, all scenarios can be modeled by RESRAD-BUILD. If a building is demolished, the dose to workers demolishing the building can be evaluated with 
the RESRAD-BUILD code. If the demolished building material is buried, the RESRAD computer code (Yu et al. 1993) can be used to evaluate the dose for future use of the site.

\subsection{EXPOSURE PATHWAYS}

The exposure pathways considered include external and internal exposure. Figure 3 illustrates all the pathways considered in the RESRAD-BUILD code:

- External exposure to penetrating radiation emitted directly from the sources,

- External exposure to penetrating radiation emitted from radioactive particulates deposited onto the floors of the compartments,

- External exposure to penetrating radiation due to submersion in airborne radioactive particulates,

- Inhalation of airborne radioactive particulates,

- Inhalation of aerosol indoor radon decay products,

- Inadvertent ingestion of radioactive material contained in removable material directly from the source, and

- Inadvertent ingestion of airborne radioactive particulates deposited onto the surfaces of the building.

The first three pathways would result in external exposure, and the others would result in internal exposure due to internal contamination of the exposed individual. In RESRAD-BUILD, the external radiation doses are evaluated as the deep effective dose, and the internal exposure is evaluated as the committed effective dose equivalent (CEDE). The total radiation dose, which is the sum of the external and internal exposures, is expressed as the total effective dose equivalent (TEDE).

Other possible exposure pathways to be considered in a radiological analysis of a contaminated building would include internal contamination due to puncture wounds and 
Source Transport Pathways / Models

Dose

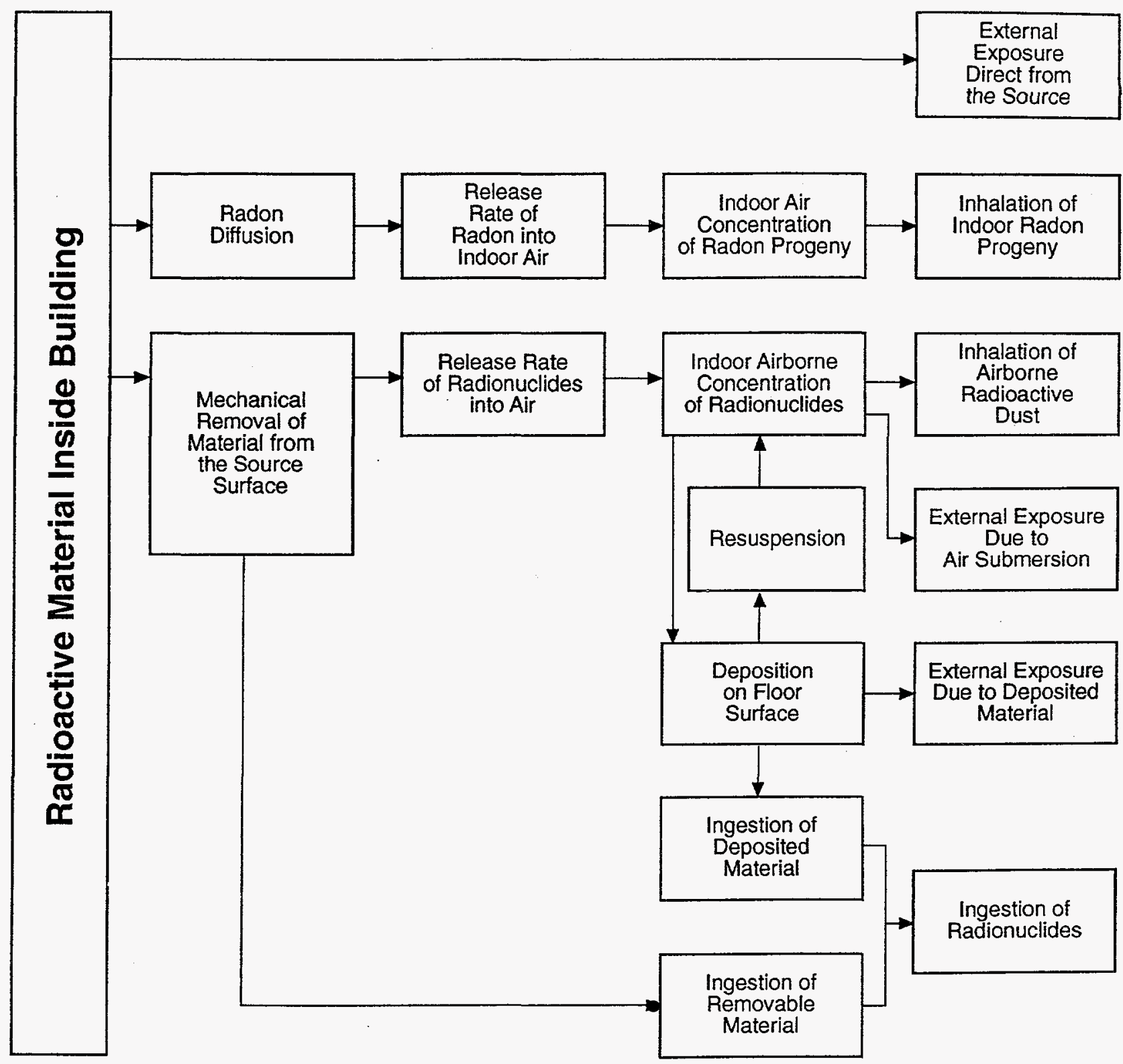

FIGURE 3 Exposure Pathways Incorporated in the RESRAD-BUILD Code 
dermal absorption of radionuclides deposited on the skin. However, the radiation doses caused from these two pathways would be much smaller than the doses caused by the other potential pathways already considered for most radionuclides (Kennedy and Strenge 1992). Therefore, dermal pathways are not included in the current version of RESRAD-BUILD. However, the dermal absorption of tritium is considered by increasing the inhalation dose conversion factor by $50 \%$. 


\section{USER'S GUIDE}

The computer code RESRAD-BUILD is designed to assess the radiological doses to an individual who lives or works in a building contaminated with radioactive material. The conceptual model, with its underlying assumptions, and descriptions of the building, sources, and receptors are presented in Section 2. Section 3 describes exposure scenarios and pathways. A more specific and detailed description of the model used in RESRAD-BUILD is presented in Appendixes A through F. This section describes the use of RESRAD-BUILD.

RESRAD-BUILD is designed for use on an IBM or IBM-compatible personal computer, with internal help files for information on input and output data. The code consists of several modules integrated into a single package that can be automatically executed, as needed, by the user. Instructions for installing and using the code are presented in the following subsections.

\subsection{INSTALLATION}

An IBM or IBM-compatible microcomputer with a 3.1 or higher disk operating system (DOS), a hard disk drive, and approximately 400 kilobytes (K) of free memory are required to run the code. A printer capable of 132-column output is desirable. Most personal computer printers have a condensed print option (17 characters per inch) that is satisfactory. A mathematical coprocessor, a color monitor, and a mouse are optional but recommended; however, a mouse may not work with all monitor/graphics cards used in IBM or clone configurations. No problems have occurred with the Microsoft Bus Mouse, the Logitech Bus Mouse, or the Mouse Systems PS/2 Mouse. Any hardware problems encountered should be reported to the contact address on the final RESRAD-BUILD screen.

The RESRAD-BUILD code is available on a single 1.44-megabyte (MB), 3.5-in. or 1.2-MB, 5.25-in. diskette. To install the program, insert the installation diskette, set the 
default drive to this diskette drive, and issue the command INSTALL. A few prompts will ask the desired location of the installed files. Approximately 1.0 MB of hard disk space is needed. The installation program will create new directories as needed. The installation procedure can be repeated any number of times.

\subsection{PROGRAM EXECUTION}

If the RESRAD-BUILD execution files are located in the subdirectory C: IRESRAD-B, the prompts (in boldface) and responses for starting RESRAD-BUILD are as follows:

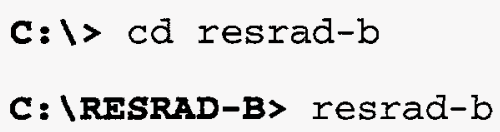

An optional command line argument containing the name of the initial site-specific data file may also be included. The default file for this purpose is RESRAD-B.DEF.

After the program is started, an initial banner page appears on the screen with a brief description of the code (Figure 4). If a mouse is available, the banner screen is followed by instructions for using the mouse that are specific to RESRAD-BUILD. Although optional, a mouse provides three unique advantages for data entry: (1) direct access to any menu item, (2) instant review of a parameter's default value, and (3) automatic restoration of a parameter's default value. The next screen is the main menu.

\subsection{INPUT DATA REQUIREMENTS}

\subsubsection{Main Menu and Help Files}

The true starting point for using RESRAD-BUILD is the main menu (Figure 5). This screen appears as soon as the preliminary output described in Section 4.2 is completed. The main menu is also the return point after the computations performed in the code have 


\section{R E S R A - B U I I D 1.50}

A U.S. Department of Energy Computer Model for Analyzing the Radiological Doses Resulting from the Remediation and Occupancy of Buildings Contaminated with Radioactive Materials

Developed at the Environmental Assessment Division of Argonne National Laboratory

for the U.S. DEPARTMENT OF ENERGY

Office of Environmental Guidance and

Office of Environmental Restoration

FIGURE 4 RESRAD-BUILD Initial Banner Page

RESRAD-BUILD Version 1.50

\begin{tabular}{|l|}
\hline Change title \\
\hline Modify data \\
\hline Run RESRAD-BUILD \\
\hline View output \\
\hline Reset colors \\
\hline Modify library \\
\hline Quit \\
\hline
\end{tabular}

Press

"Fl" or "F2"

for HELP
Current data file: SAMPLE.DAT Current library: NUCDCF.DAT 
been completed. Instructions for interactive use of the code are provided in help files that can be displayed on the screen by pressing the F1 or F2 function keys. ${ }^{1}$ The F1 help screen contains information for positioning the cursor and selecting options. Descriptions of data to be input and general information are given in the F2 help files.

The main menu provides the primary options for running RESRAD-BUILD. Many of the options have associated submenus that define the user's options more explicitly. A menu option is selected by highlighting the field and pressing the Enter or F10 key or the mouse button. An alternative selection method is to press the highlighted letter key in the desired option field. The seven main menu options are discussed in Sections 4.3.2 through 4.3.7.

If a submenu appears, additional help information is always available via the F2 function key. The main menu is active when it is the only menu displayed; if a submenu shares the screen, the submenu then becomes the active one. The Esc key can always be used to return to the main menu; however, other methods, depending on the submenu, may also be available. To exit RESRAD-BUILD (back to DOS), a two-key combination is used as a safety feature. Press the Esc key so the main menu appears alone on the screen with the Quit option highlighted, and then press the Enter key. Another method is to press the highlighted Q key.

The main menu offers seven options:

1. Change title,

2. Modify data,

1 The F1 and F2 function-key help files are used throughout all interactive phases of RESRADBUILD; however, the exact screen information will vary according to the specific item being requested. The F1 help screen always contains cursor and display information that remains constant until a major phase change occurs. The F2 screens concern data input, and usually the information is keyed to the current active menu field (cursor position). In addition, the last line of every menu is a brief help message for the current field. 
3. Run RESRAD-BUILD,

4. View outputs,

5. Reset colors,

6. Modify library, and

7. Quit.

The primary main-menu data-entry options are "change title" and "modify data." These fullscreen submenus have identical keystrokes for data entry, but the keystrokes differ somewhat from those used in the main menu and other submenus. The F1 help file provides a complete keystroke list. Pressing the F10 function key records all data fields and can be used to exit the menu; the Esc key can also be used to exit (as always) but cancels all changes made on the form.

\subsubsection{Change Title}

Change title is a single, full-screen, data-entry submenu. The screen contains fields for the title of the current RESRAD-BUILD run, the initial (template) and final site-specific data files for RESRAD-BUILD input, and the destination for RESRAD-BUILD printer output. The change title default form is shown in Figure 6; the blank gray line at the bottom will contain the help message associated with the current cursor position.

The title field, which is used to identify the run, can include up to 70 alphabetic or numeric characters. The title field is part of the header for every page of RESRAD-BUILD output. The other three fields correspond exactly to the three optional command line arguments that can be used to start RESRAD-BUILD. Input to these fields overrides the command line arguments. If the initial site-specific data file is to be changed, this should be done first, and then the F10 key should be pressed before any other changes are made. This procedure applies to all modify data forms. The new data file is input and overrides all previous values as soon as the F10 key is pressed. 
RESRAD-BUILD: Title and Data File Parameters

ReraD-Burid : Titie and Data File Paraneters

Ti.tle: Befautt Case for RESRAD - BUTLD

Site-specific data file (initial):

Site-specific data file (final):

Printer output (LPTI or file):

1.PT?

Press "F1" or "F2" for HELP, or "EsC" to IGNORE CHANGES and return to main menu. Press "Elo" to SAVE DATA AND CONTINUE.

FIGURE 6 Input Form for Title and User Data Files

Before entering text-string data, it is usually best to clear the field with the Del key. The "*" and "?" DOS wild-card characters can be used in the file names. RESRAD-BUILD will then produce an appropriate directory listing(s) from which the user can input the desired data file name.

After each RESRAD-BUILD execution and return to the main menu, the initial sitespecific data file is replaced with the final site-specific data file of the run just completed. The final site-specific data file and the printer output file remain unchanged, which allows the parameter input of the previous run to serve as the template for the next execution. The user, of course, can alter these automatic selections at any time.

\subsubsection{Modify Data}

The first portion of the modify data main-menu option is the submenu shown in Figure 7. This is the starting and return point for a series of five data-entry screens that are 


$$
\begin{aligned}
& \text { RESRAD-BUILD Version } 1.50 \\
& \text { Current data file: SAMPLE.DAT } \\
& \text { Current library: NUCDCF.DAT } \\
& \begin{array}{|l}
\hline \text { Change title } \\
\hline \text { Modify data } \\
\hline \text { Run RESRAD-BU } \\
\hline \text { View output } \\
\hline \text { Reset colors } \\
\hline \text { Modify librar } \\
\hline \text { Quit } \\
\hline \\
\text { "FI" or "F2" } \\
\text { for HELP }
\end{array}
\end{aligned}
$$

FIGURE 7 Modify Data Submenu (with Main Menu)

the primary data entry forms for RESRAD-BUILD. The submenus can be selected repeatedly in any order by highlighting the appropriate field and pressing Enter, F10, or the mouse button. Pressing the highlighted letter/number key will also select a screen. Initial values for all data on the forms were obtained from the initial site-specific data file (Section 4.3.2). The current values on any form can be reviewed and changed as desired.

Parameters pertaining to suppressed pathways are blanked out in the data-entry screens because they are not used in the RESRAD-BUILD calculations. This action eases data entry and ensures that only variables pertinent to the calculations are subject to modification.

Pressing the F2 key will give specific help information for the current active field (cursor position) for all forms in this group. If a mouse is available, pressing the left button while within a numeric data field will display the field's default value, and pressing the right button will replace the data item with the default value. Exiting from a form is accomplished by either pressing F10, which saves all data on the screen, or by pressing the Esc key, which 
ignores all changes. RESRAD-BUILD input parameters are briefly discussed in

Sections 4.3.3.1 through 4.3.3.5.

\subsubsection{Occupancy Characteristics}

The first input form in the modify data series is for occupancy characteristics (Figure 8). The data fields in this form are general parameters related to the occupancy characteristics of the building.

The dose received at each receptor location is the product of the dose rate at the time specified and the time spent at the receptor location. The time spent at a receptor location is the product of three input parameters: total time on-site, fraction of time in the building, and fraction of time at the receptor location. The first two parameters are independent of the receptor and therefore are input on this menu. The fraction of time at the receptor location is input on the receptor menu. The dose reported is the dose rate at the time specified

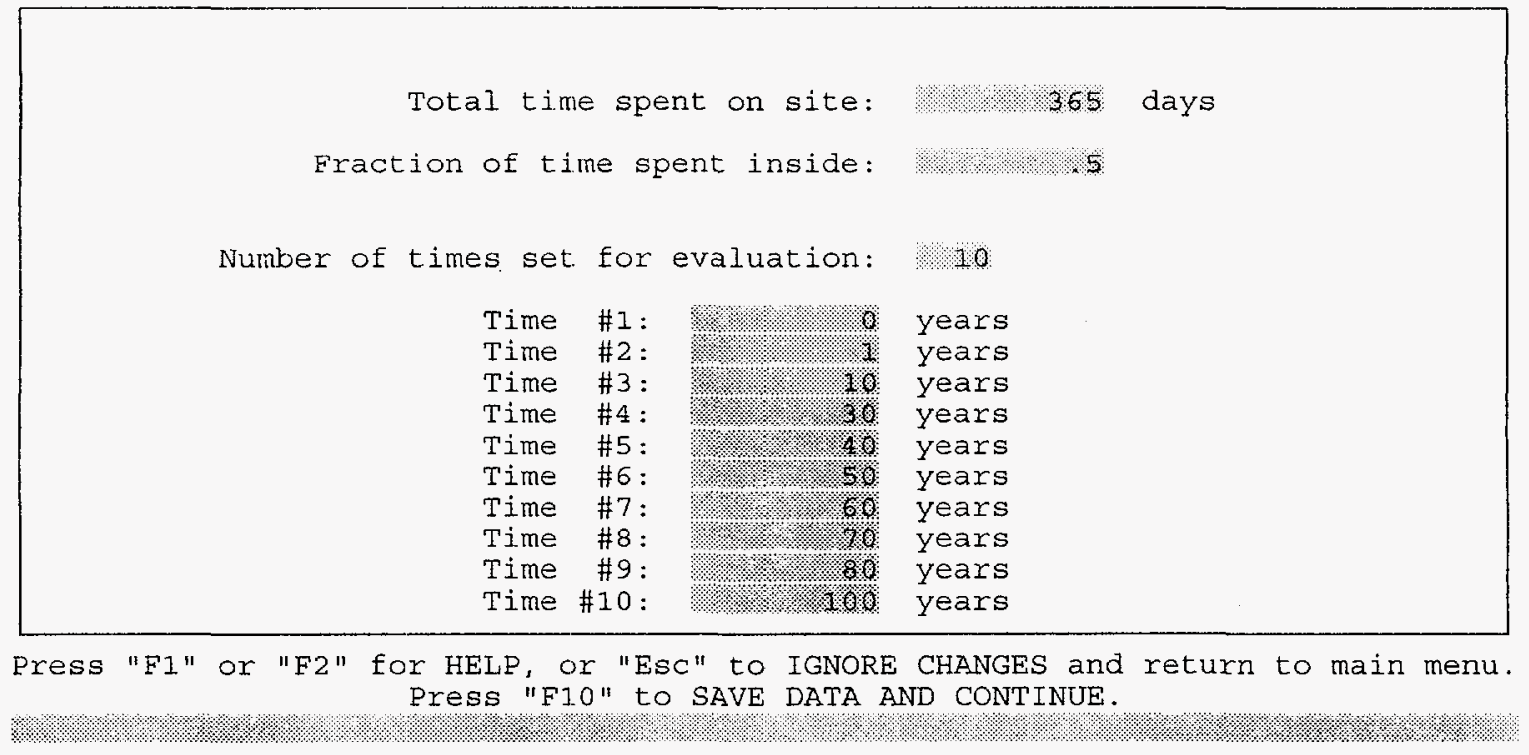

FIGURE 8 Input Form for Occupancy Characteristics 
multiplied by the exposure time. This version makes no attempt to calculate the time-integrated dose; however, the user can estimate this dose by splitting the exposure time into smaller segments and entering more times for evaluation.

The total time spent on-site is specified either in days or in days per year. In the first case, the calculated radiological doses would represent the total absolute dose received during the exposed time. In the second case, the results would represent the dose rate in units of dose per year.

The fraction of time spent inside is a dimensionless parameter representing the fraction of the total time on-site in which the individual stays inside the building.

The number of times set for evaluation is an integer parameter representing the number of points along the time domain in which the calculations should be evaluated. The user can select up to 10 points in time to be evaluated.

The "Time \#" parameter consists of the times, in years, following the initial time zero, in which the calculations will be performed. All times must be input in ascending order.

\subsubsection{Building Characteristics}

The second input form in the modify data series represents the characteristics of the building (Figure 9). The conceptual building model consists of one to three rooms. The user must enter the area and the ceiling height of each room. These parameters will be used in the air quality model. To solve the air quality model, the user must enter the average building air-exchange rate and three additional parameters for each additional room: the room air-exchange rate, the outdoor inflow rate, and the net flow between two rooms. It is assumed that no direct airflow occurs between rooms 1 and 3 . To solve the deposition model, a deposition velocity and resuspension rate are required, which are assumed to be the same in each room. 
RESRAD-BUILD: Building Characteristics

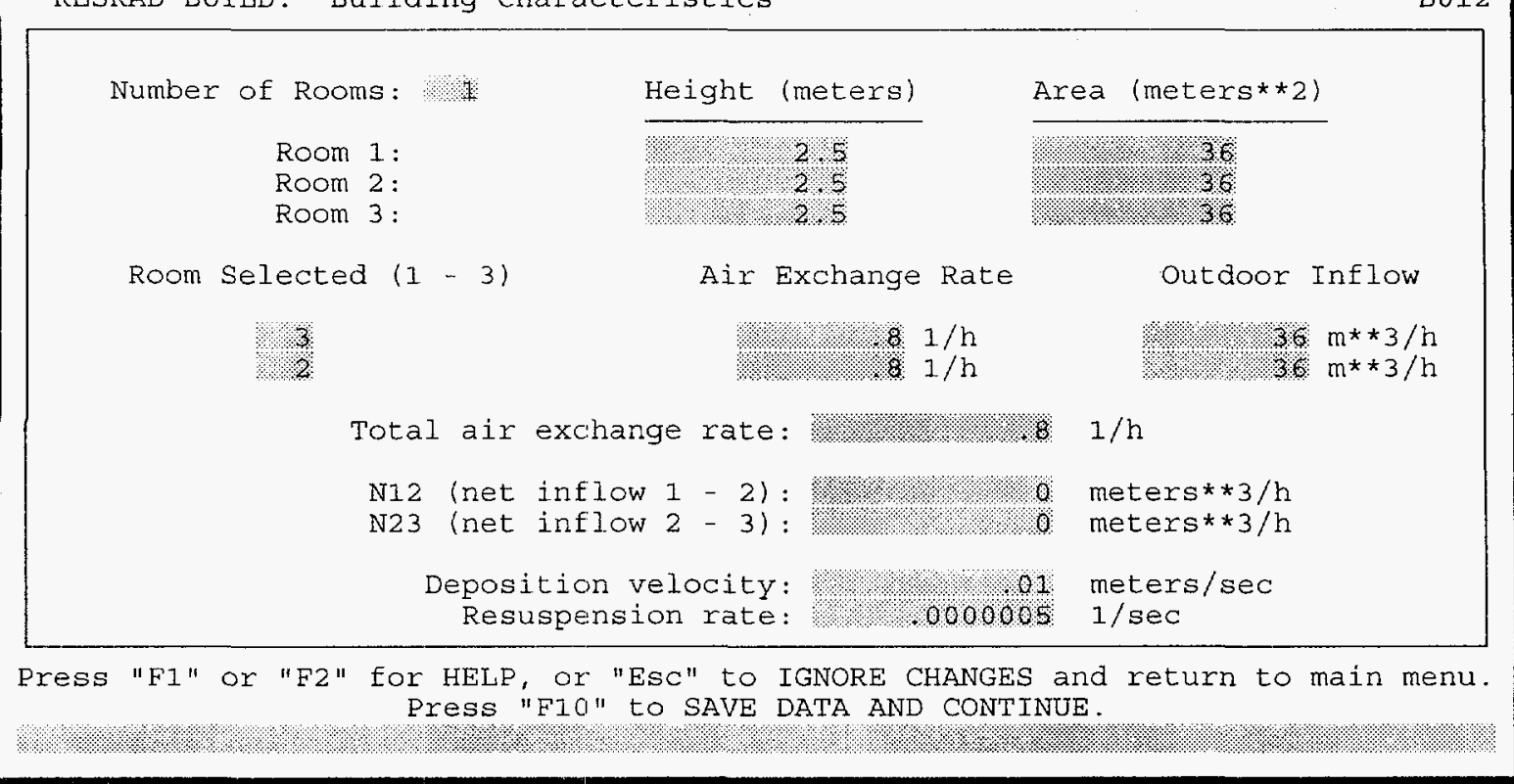

FIGURE 9 Input Form for Building Characteristics

For a one-room model, the only airflow parameter necessary is the total air-exchange rate. For a two-room model, the airflow parameters necessary are the total air-exchange rate, the air-exchange rate in one of the rooms, the outdoor inflow in that room, and the net flow between that room and the other. The full airflow then can be solved if the parameters entered satisfy certain conditions that guarantee a positive exchange of air between the rooms. These conditions are discussed in the air quality model in Appendix A.

For a three-room model, the airflow parameters necessary are the total air-exchange rate, the air-exchange rate in two of the rooms, the outdoor inflow in those rooms, and the net flow between the rooms. It is assumed that there is no direct airflow between room 1 and room 3. The full airflow then can be solved if the parameters entered satisfy certain conditions that guarantee a positive exchange of air between the rooms. These conditions are discussed in the air quality model in Appendix A. 


\subsubsection{Receptor Characteristics}

The receptor characteristics form (Figure 10) allows the user to specify the exposure characteristics of an individual. The dose to one individual is calculated by the code. That individual can be represented by many receptor points. Each receptor point is specified by the location and the fraction of the time that an individual spends at each location. An additional parameter is needed to implement one of the ingestion pathways. If the individual accidentally eats deposited dust, this ingestion rate must be entered. The default surface dust ingestion rate is $0.0001 \mathrm{~m}^{2} / \mathrm{h}$.

The location of the receptor is the absolute coordinate of the receptor midpoint location according to some origin chosen by the user. For example, the receptor location should be $1 \mathrm{~m}$ above the absolute location on the floor where the receptor is standing. This reference origin must be used to specify the location of the sources also. This information is important for the direct external exposure pathway only. The other pathways only require the room location of the receptor and the source.

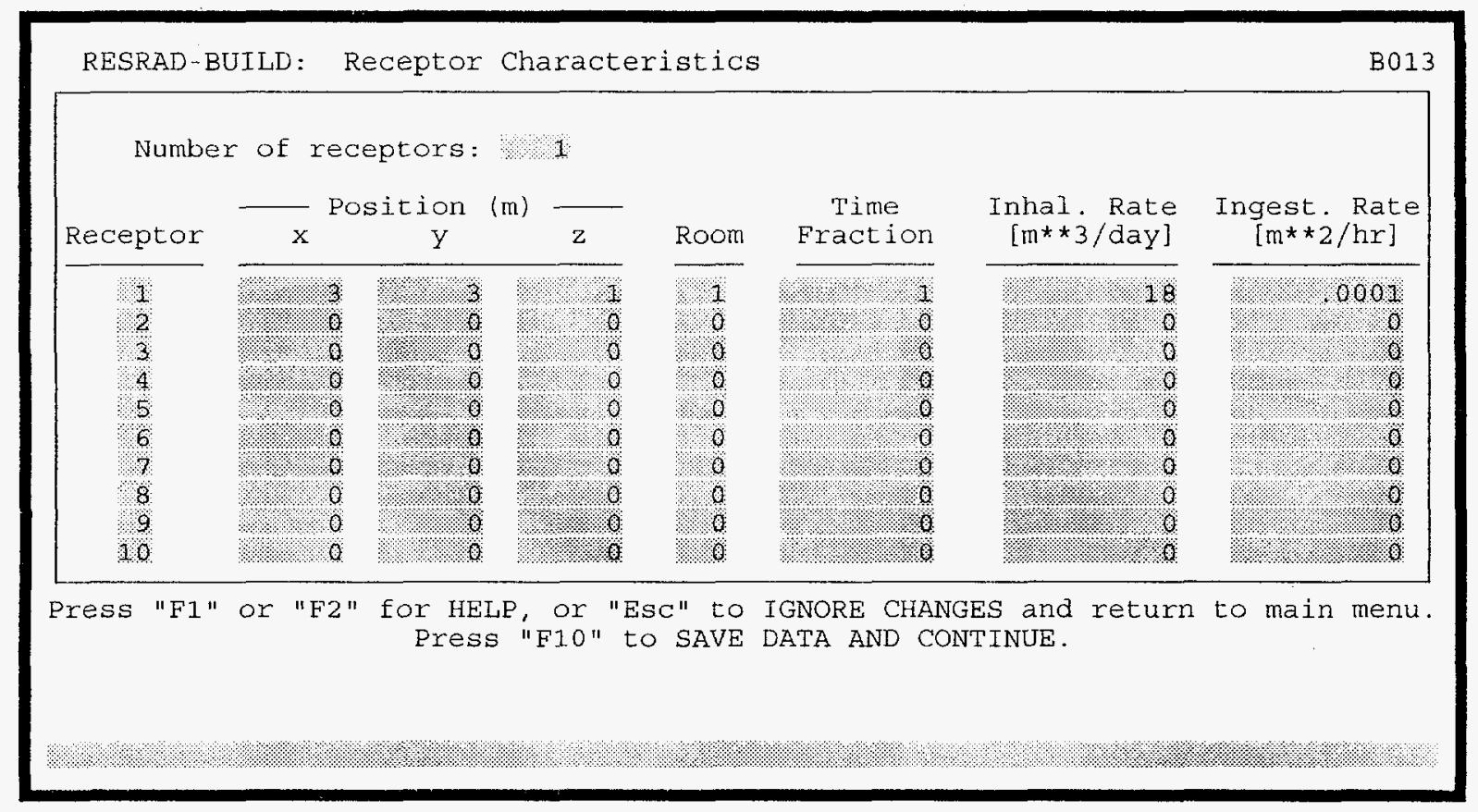




\subsubsection{Source Characteristics}

One main form requests data for all types of sources (Figure 11), and an additional form is for the volume sources (Figure 12). The main source form requests the position, direction, size, radon release (if applicable), source type, removable fraction, air release fraction, and radionuclide contamination of the source. The location of the source includes the room and the coordinates of the center point of the source. An ingestion parameter specifies how much of the source is accidentally ingested per unit of time. For volume sources, a second room corresponds to the other side of the contaminated wall. For external-dose calculations, the volume and area sources are assumed to be circular. For nonvolume sources with a radon source present, the radon release fraction is required.

The location of the source center point is the absolute coordinate according to some origin chosen by the user. This reference origin must be used to specify the receptor locations also. This information is important for the direct external-exposure pathway only. The other pathways only require the room location of the receptor and the source.

For the volume sources, an additional form needs to be completed about the properties of the source. The source is modeled as a number of distinct regions. The properties of each region include density, porosity, radon emanation fraction, radon diffusion coefficient, thickness, and fraction of the total contamination within the region. If there is more than one region, Region 1 is defined as the region closest to the origin.

\subsubsection{Shielding Characteristics}

Although the locations of the source and receptor points are known, the external pathway also requires information about shielding between them. This information is gathered in the form for the shielding characteristics (Figure 13). The RESRAD-BUILD 


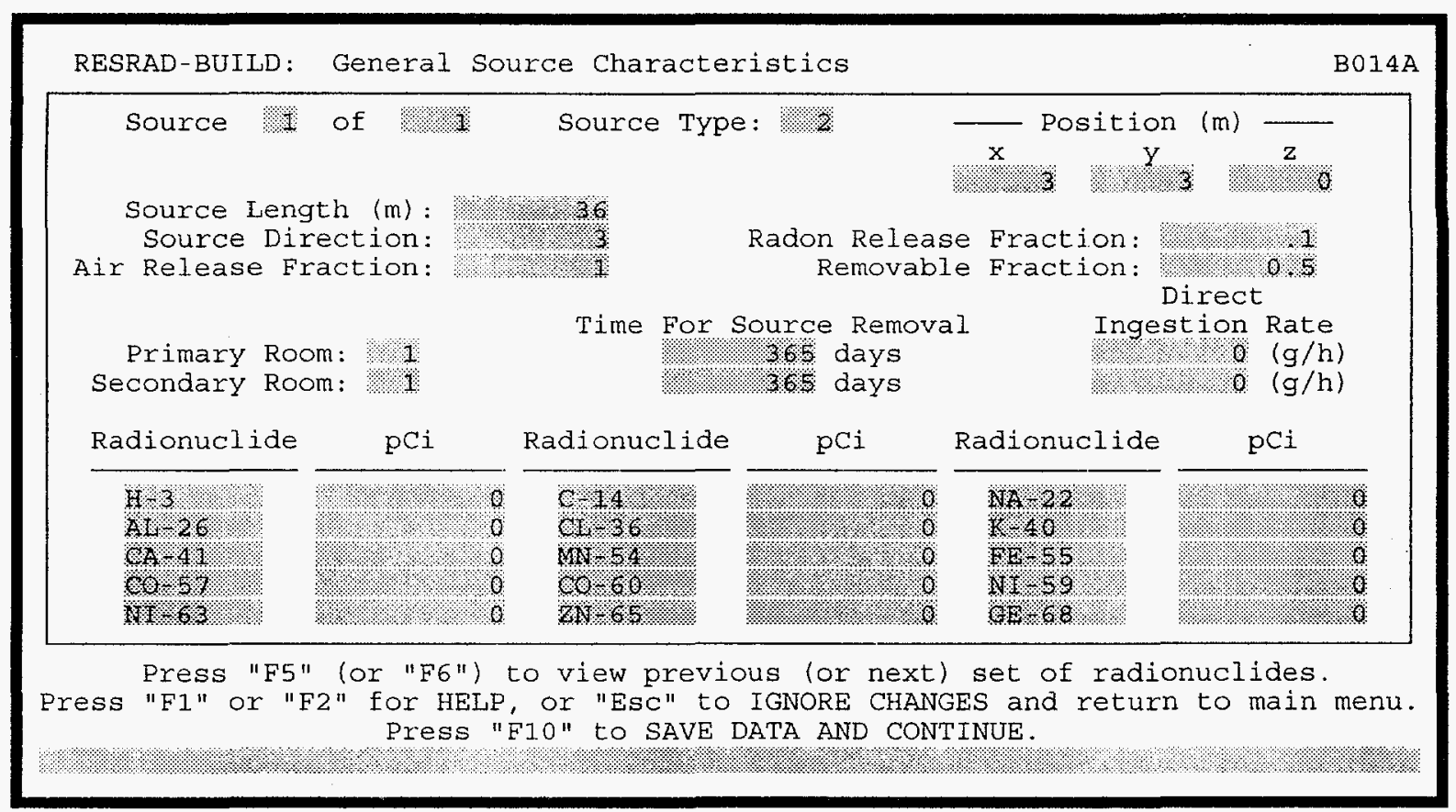

FIGURE 11 Input Form for General Source Characteristics

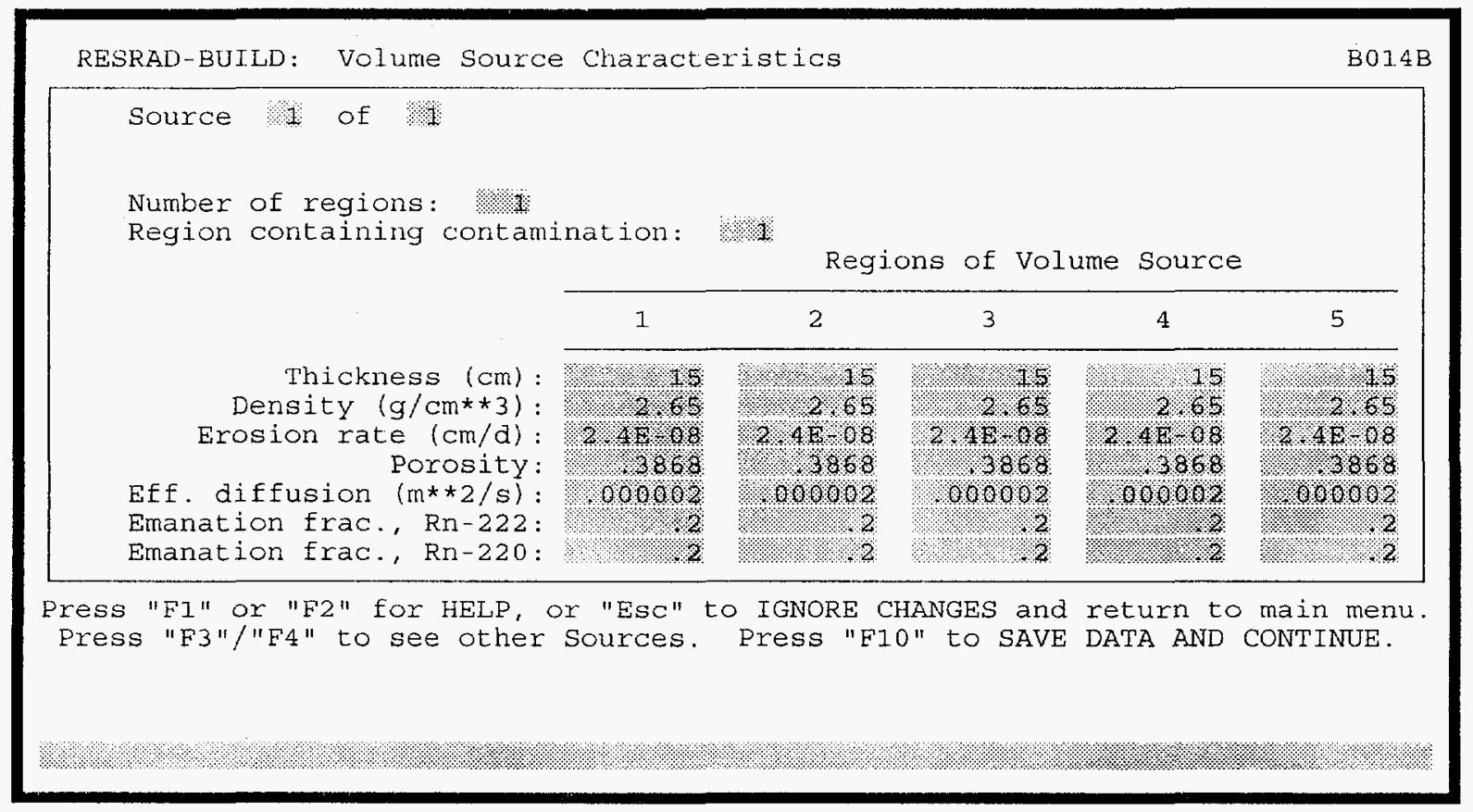

FIGURE 12 Input Form for Volume Source Characteristics 
RESRAD-BUILD: Volume-Source Shielding Characteristics

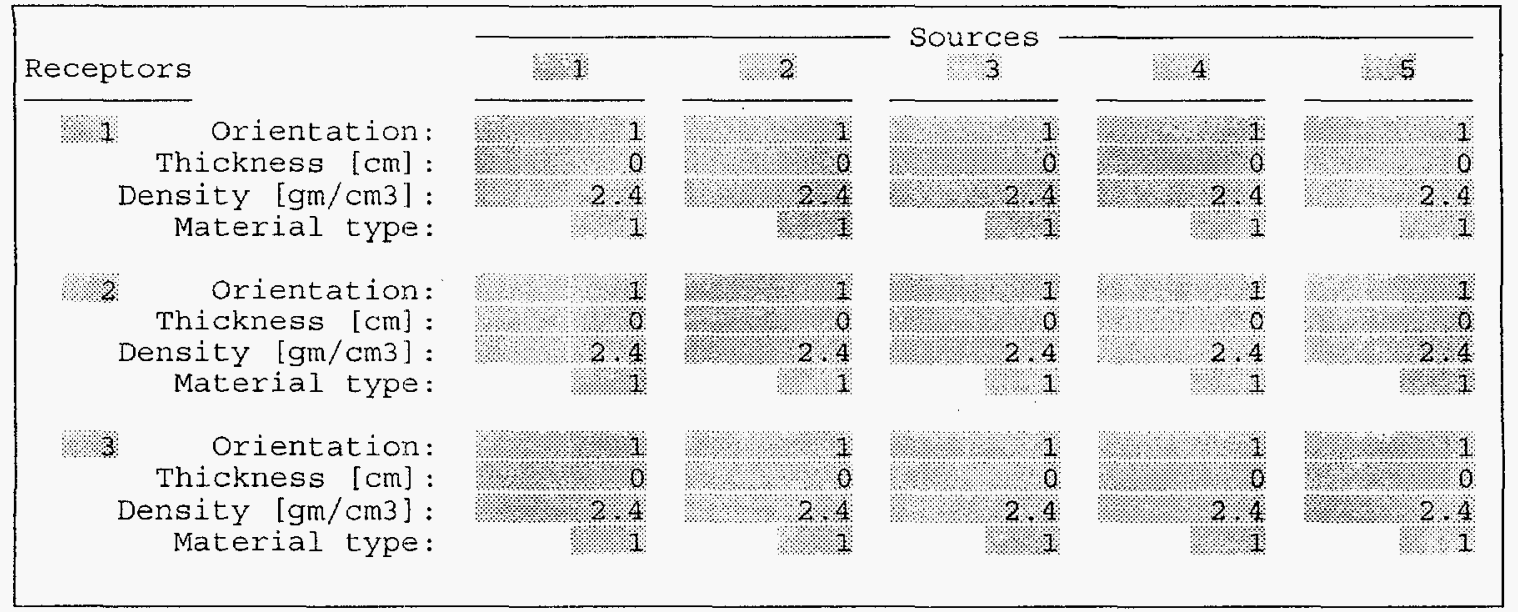

Press "F5"/"F6" to see other Sources. Press "F7"/"F8" to view other Receptors. Press "Fl" or "F2" for HELP, cr "Esc" to IGNORE CHANGES and return to main menu. Press "F10" to SAVE DATA AND CONTINUE.

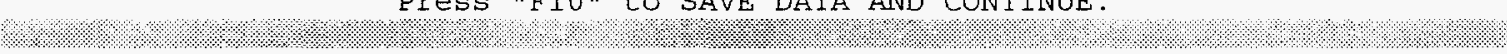

FIGURE 13 Input Form for Shielding Characteristics

model is simplified so that the user specifies just one average shield between each source-receptor point pair. This shield is characterized by a material type, a thickness, and a density. The other parameter on this form pertains to the orientation of the receptor to the source. The possible material types include concrete, water, aluminum, iron, copper, tungsten, lead, and uranium.

\subsubsection{Run RESRAD-BUILD}

This main-menu option starts RESBMAIN, the computational and report-generating phase of RESRAD-BUILD. During the execution of RESBMAIN, a series of brief status reports will appear on the screen indicating the progress of the execution through the userspecified times for calculation.

The successful completion of RESBMAIN is marked by the following display line: RESBMAIN regular output complete. The RESBMAIN output consists of a tabular report file, RESRADB.RPT. The user can view or obtain a hard copy of the text (or both) by using the View Output option of the main menu discussed in Section 4.3.5. 


\subsubsection{View Output}

A report file named RESRADB.RPT is generated each time RESRAD-BUILD is executed. This file can be accessed by choosing the view output option of the main menu. Choosing view text on the submenu and view RESRADB.RPT on the next submenu will display the most recent output report. This report can be printed by hitting the F7 key while the file is being displayed. This will lead to further prompts for printer setup and printer control over the extent of what is printed.

\subsubsection{Reset Colors}

This submenu allows the user to experiment with the monitor display and, if desired, to save the new color selections as the permanent RESRAD-BUILD default. The submenu is also a convenient method of resetting the default for a monochrome monitor.

\subsubsection{Modify Library}

This collection of submenus allows the user to select and modify the dose conversion factors that are used in the RESRAD-BUILD calculations. The factors are contained in two dose factor libraries. One library (NUCDCF.DAT) contains the RESRAD-BUID default dose conversion factors. The second library (NUCDCF.USR) is user-defined. The dose factors in this library can be modified via two data entry screens similar to the data entry screens described in the modify data option of the main menu (Section 4.3.3). Each screen contains parameters for all of the radionuclides available in RESRAD-BUILD.

\subsubsection{Internal Dose Conversion Factors}

The internal dose conversion factors for ingestion and inhalation are accessible in the data entry form shown in Figure 14. Any changes to these factors will be included in the user-defined library (NUCDCF.USR). 


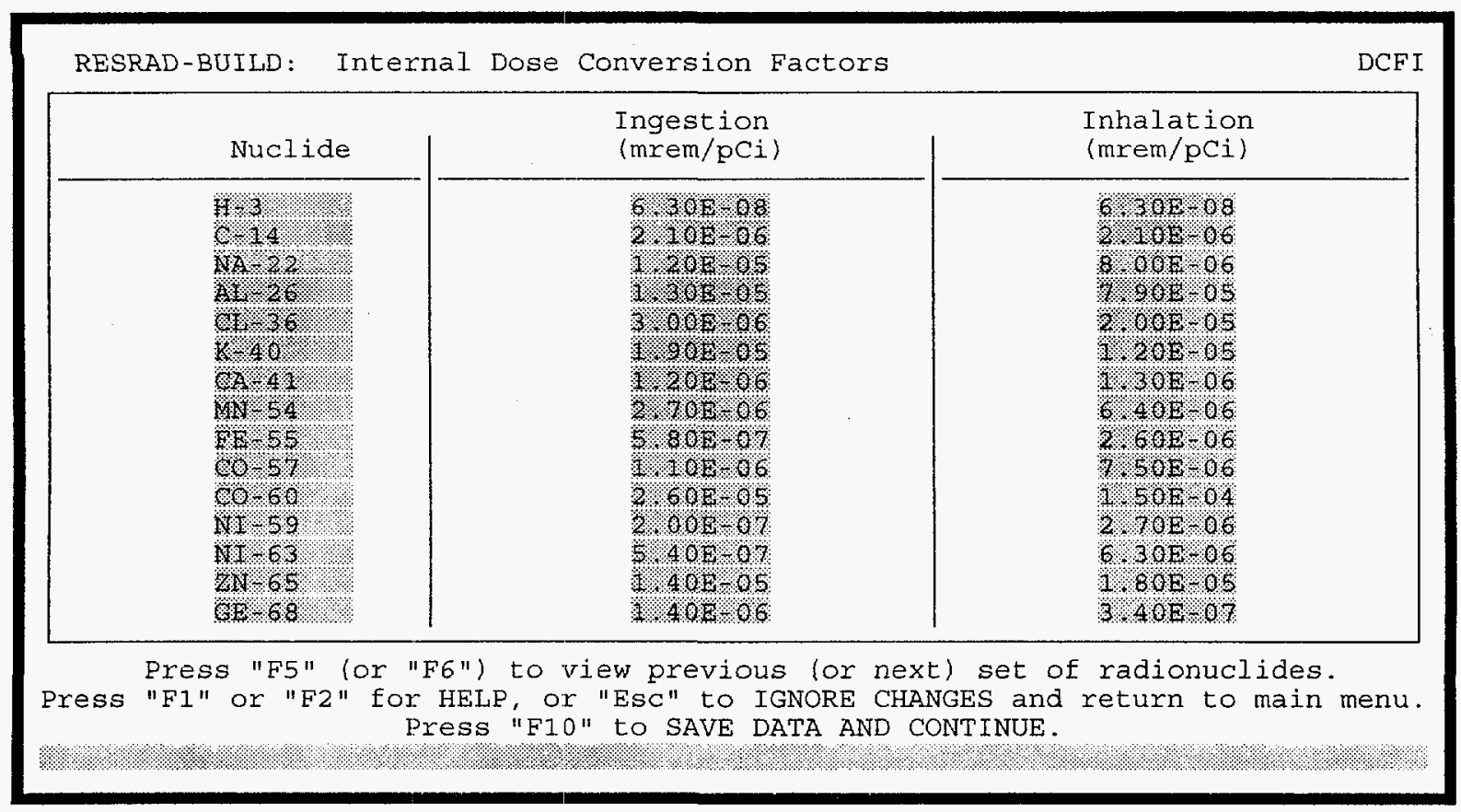

FIGURE 14 Input Form for Internal Dose Conversion Factors

\subsubsection{External Dose Conversion Factors}

A second data entry form contains dose conversion factors used in calculating dose from external exposure to gamma radiation (Figure 15). Three factors are available for each radionuclide. These correspond to surface contamination, volume contamination, and air submersion. As with the internal dose conversion factors screen, any changes to these factors will be included in a user-defined library that is available for use in subsequent RESRAD-BUILD calculations.

\subsubsection{Quit}

The final submenu option terminates RESRAD-BUILD and returns the screen to the DOS prompt. When the main menu is alone on the screen, the Enter key must be pressed 


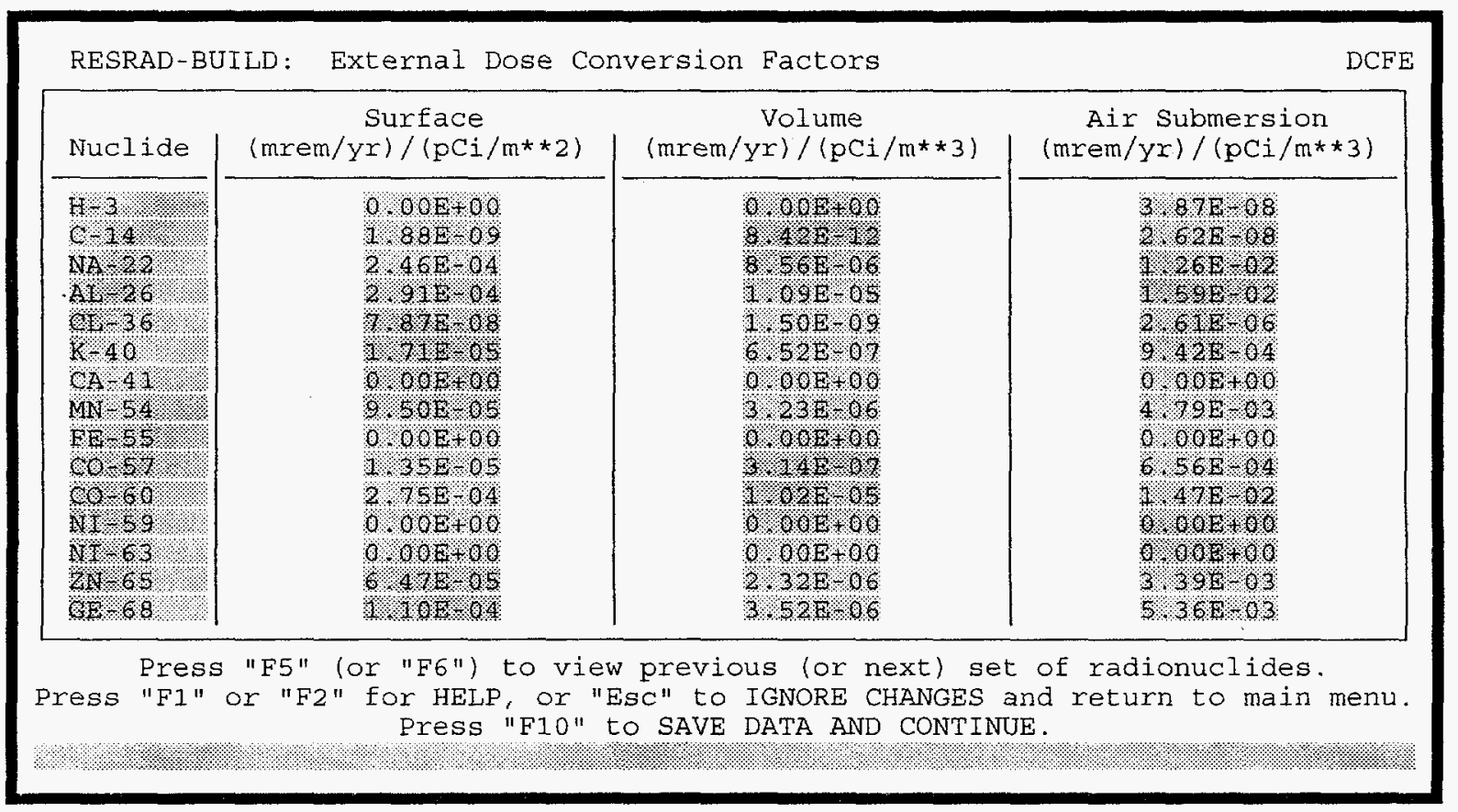

\section{FIGURE 15 Input Form for External Dose Conversion Factors}

with the Quit field highlighted. Repeatedly pressing the Esc key is not sufficient; Enter must also be pressed. An alternative is to press the $Q$ key. This multikey sequence guards against accidental termination of a RESRAD-BUILD session.

\subsection{TECHNICAL SUMMARY}

It is not the intent of this manual to include a programmer's guide, but a brief technical summary should be useful. RESRAD-BUILD consists of two main programs: RESBMAIN and RESB_BAS. RESB_BAS is a set of compiled BASIC programs (Microsoft BASIC 7.1) that enables most user interaction with RESRAD-BUILD. RESBMAIN is the FORTRAN code (Lahey F77L 5.0) that does the actual computations and generates the output tables.

RESB_BAS is loaded first (via RESRAD-B.BAT, NEXT.ORI, and NEXT.BAT). Within RESB_BAS, the user may input selected site-specific data files, review and/or modify parameters, select printer hardware parameters, save the data in a selected file, view and/or 
print selected results from the last RESRAD-BUILD computation, or run RESBMAIN for a new computation. After RESBMAIN completes the computations, RESB_BAS is reloaded automatically. The user may then continue with any of the RESB_BAS options. 


\section{REFERENCES}

Kennedy, W.E., Jr., and D.L. Strenge, 1992, Residual Radioactive Contamination from Decommissioning, Technical Basis for Translating Contamination Levels to Annual Total Effective Dose Equivalent, Vol. 1, NUREG/CR-5512, PNL-7994, prepared for U.S. Nuclear Regulatory Commission by Pacific Northwest Laboratory, Richland, Wash., Oct.

U.S. Atomic Energy Commission, 1974, "Termination of Operating Licenses for Nuclear Reactors," Regulatory Guide 1.86, June.

U.S. Department of Energy, 1990, "Radiation Protection of the Public and the Environment," DOE Order 5400.5, Feb.

Yu, C., et al., 1993, Manual for Implementing Residual Radioactive Material Guidelines Using RESRAD, Version 5.0, ANL/EAD/LD-2, Argonne National Laboratory, Argonne, Ill., Sept. 
5-2 
A-1

\section{APPENDIX A:}

INDOOR AIR QUALITY MODEL 
A-2 


\section{APPENDIX A:}

\section{INDOOR AIR QUALITY MODEL}

An indoor air quality model has been developed to simulate the transport of radiological contaminants inside a building with air exchange between compartments and with outdoor air. The air quality model assumes that particulates in the indoor air of any compartment are well mixed; therefore, the pollutant concentration is the same for every point in the air within the compartment. The air exchange and ventilation of building compartments are discussed in Section A.1; the models used to calculate the radionuclide concentrations in the indoor air are presented in Section A.2. The adaptation of the air quality model to calculate airborne concentrations of radionuclides, including radon and its progeny, is presented in Section A.3.

\section{A.1 BUILDING VENTILATION AND INFILTRATION}

Consider a three-compartment building represented by the schematic configuration shown in Figure A.1. From the principle of conservation of mass, applied at any building compartment $i$ and assuming a steady-state condition, we can write the following general expression:

$$
\sum_{\frac{j=0}{(j \neq i)}}^{3} Q_{i j}=\sum_{\frac{j=0}{(j \neq i)}}^{3} Q_{j i}
$$

where

$Q_{i j}=$ flow from compartment $i$ to compartment $j$ (in $\mathrm{m}^{3} / \mathrm{s}$ ); and

$i$ or $j=$ compartment index, representing the outdoor air and the first, second, and third compartment for $i=0,1,2$, and 3 , respectively.

The net inflow rate, $N_{i j}$, from compartment $i$ to compartment $j$ is defined as:

$$
N_{i j}=Q_{i j}-Q_{j i}
$$




\section{Outdoor (Compartment 0)}

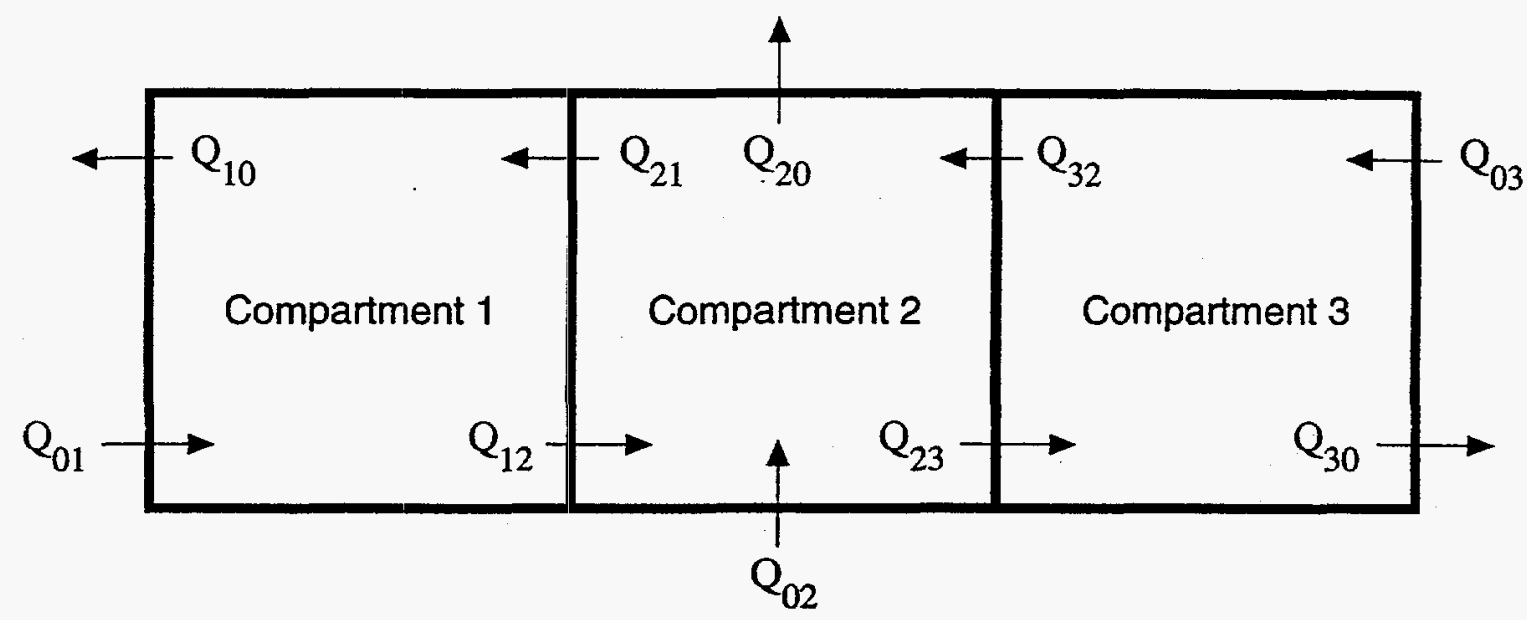

FIGURE A.1 Schematic Representation of the Three-Compartment Building, Showing the Inflow and Outflow of Air in Each Compartment

The value of $N_{i j}$ can be negative, meaning that the net air flow is from compartment $j$ into compartment $i$.

Now, applying Equation A.1 to compartment number $1(i=1)$ yields:

$$
Q_{10}+Q_{12}+Q_{13}=Q_{01}+Q_{21}+Q_{31}
$$

The RESRAD-BUILD model assumes that compartment 1 is not adjacent to compartment 3 and, thus, does not communicate directly with compartment 3. Therefore, the following expression applies:

$$
Q_{13}=Q_{31}=0
$$

Equations A.3 and A.4 yield:

$$
Q_{10}+Q_{12}=Q_{01}+Q_{21}
$$

That is, the total inflow of air to compartment 1 is equal to the total outflow of air from compartment 1 . 
Similarly, applying Equation A.1 to compartment $2(i=2)$ yields:

$$
Q_{20}+Q_{21}+Q_{23}=Q_{02}+Q_{12}+Q_{32}
$$

Finally, applying Equation A.1 to compartment number $3(i=3)$, and considering Equation A.4, yields:

$$
Q_{30}+Q_{32}=Q_{03}+Q_{23}
$$

Note that summing Equations A.5, A.6, and A.7 yields:

$$
Q_{10}+Q_{20}+Q_{30}=Q_{01}+Q_{02}+Q_{03}
$$

which expresses the fact that the total outflow of air from inside the building is equal to the total inflow of air from outside.

The ventilation (or air exchange) rate of a building (or a compartment) is defined as the number of the total volume of air contained in the building (or the compartment) that is being exchanged with outside air (or air from other compartments) per unit of time. For example, a building with a ventilation rate of $1 \mathrm{~h}^{-1}$ has its volume of air replaced once each hour. The air exchange rate $\lambda_{i}^{a}$ for compartment $i$ can be calculated as:

$$
\lambda_{i}^{a}=\frac{\sum_{\frac{j=0}{(j \neq i)}}^{3} Q_{j i}}{V_{i}}=\frac{\sum_{\frac{j=0}{(j \neq i)}}^{3} Q_{i j}}{V_{i}},
$$

where $V_{i}$ is the volume of compartment $i$.

The building air exchange rate $\lambda^{a}{ }_{b}$ is:

$$
\lambda_{b}^{a}=\frac{\sum_{i=1}^{3} Q_{i 0}}{\sum_{i=1}^{3} V_{i}}=\frac{\sum_{i=1}^{3} Q_{0 i}}{\sum_{i=1}^{3} V_{i}} .
$$

The measurement methodology and ranges of air exchange rate are discussed by Yu et al. (1993) and Nero (1988). 


\section{A.2 INDOOR AIR CONCENTRATION}

Assuming that the pollutant in the indoor air is well mixed within a generic compartment $i$, the mass balance of a pollutant within the volume $V_{i}$, due to the contribution of one specific source, can be expressed as:

$$
V_{i} \frac{d C_{i}^{n}}{d t}=\lambda_{r n} V_{i} C_{i}^{(n-1)}+\sum_{\frac{j=0}{(j \neq i)}}^{3}\left(Q_{j i} C_{j}^{n}\right)-C_{i}^{n} \sum_{\frac{j=0}{(j \neq i)}}^{3} Q_{i j}+I_{i}^{n}-S_{i}^{n}
$$

where

$i=$ compartment index $(i=0,1,2$, and 3$)$ representing, respectively, the outdoor air (0th compartment) and the first, second, and third compartments;

$C^{n}{ }_{i}=$ concentration of a radionuclide of order $n$ in its radioactive decay series, present in the air of compartment $i\left(\mathrm{pCi} / \mathrm{m}^{3}\right)$;

$\lambda_{r n}=$ radioactive decay constant of radionuclide $n$;

$Q_{i j}=$ flow of air from compartment $i$ to compartment $j(i \neq j)\left(\mathrm{m}^{3} / \mathrm{h}\right)$;

$I^{n}{ }_{i}=$ injection rate of the radionuclide $n$ into the air of compartment $i$ $(\mathrm{pCi} / \mathrm{h})$;

$V_{i}=$ volume of compartment $i(i=1,2$, and 3$)\left(\mathrm{m}^{3}\right)$; and

$S^{n}{ }_{i}=$ sink term for radionuclide $n$ in compartment $i(\mathrm{pCi} / \mathrm{h})$.

Each term of Equation A.11 represents the variation in time of a part of the mass of the material within the volume $V_{i}$, due to some specific process. The term at the left side of the equation represents the net change (accumulation or depletion) of the pollutant within volume $V_{i}$ per unit of time. The first term at the right-hand side of the equation represents the generation of the principal radionuclide of order $n$ due to the radioactive decay of its predecessor of order $(n-1)$. The second term at the right side represents the total contribution due to the inflow of air from the neighbor compartments. The third term represents the loss 
of material in the compartment $i$ due to the total outflow of air into the neighbor compartments. The sink term $S^{n}{ }_{i}$ represents the loss of mass of airborne material due to radioactive decay, $S_{r i}^{n}$, and deposition, $S_{d i}^{n}$, and can be expressed as:

$$
S_{i}^{n}=S_{r i}^{n}+S_{d i}^{n}
$$

where

$$
\begin{aligned}
S_{r i}^{n} & =\lambda_{r n} V_{i} C_{i}^{n} ; \\
S_{d i}^{n} & =\lambda_{d i} V_{i} C_{i}^{n} ; \\
\lambda_{d i} & =\left(\frac{u_{d} A_{i}}{V_{i}}\right) ; \\
\lambda_{r n} & =\text { radioactive decay constant of radionuclide } n\left(\mathrm{~h}^{-1}\right) ; \\
\lambda_{d i} & =\text { deposition rate }\left(\mathrm{h}^{-1}\right) ; \\
u_{d} & =\text { deposition velocity }(\mathrm{m} / \mathrm{h}) ; \text { and } \\
A_{i} & =\text { horizontal area of compartment } i\left(\mathrm{~m}^{2}\right)
\end{aligned}
$$

Therefore, from Equations A.12, A.13, and A.14, the sink term $S_{i}^{n}$ can be expressed as:

$$
S_{i}^{n}=\left(\lambda_{r n}+\lambda_{d i}\right) V_{i} C_{i}^{n}
$$

The term $I_{i}^{n}$ in Equation A.11 represents the total injection of material (radionuclide $n$ ) into the air of compartment $i$ due to the source present within the compartment, $I_{S i}^{n}$, and due to resuspension of the material deposited on the floor, $I_{R i}^{n}$. It can be expressed as:

$$
I_{i}^{n}=I_{S i}^{n}+I_{R i}^{n}
$$

where $I_{S i}^{n}$ is the source-dependent term representing the direct injection rate of radioactive material into the indoor air. It depends on the mechanical removal or erosion rate of the 
source (or on the radon diffusion process, for the case of radon source) and must be evaluated specifically for each defined source and operational scenario. The resuspension term, $I_{R i}^{n}$, depends on the resuspension rate, $\lambda_{R}$, and the deposition velocity, $u_{d}$, and can be expressed as (see Appendix B):

$$
\begin{gathered}
I_{R i}^{n}=\left(\frac{\lambda_{R} u_{d} A_{i}}{\lambda_{r n}+\lambda_{R}}\right) C_{i}^{n}, \\
I_{R i}^{n}=\left(\frac{\lambda_{R}}{\lambda_{r n}+\lambda_{R}}\right)\left(\frac{u_{d} A_{i}}{V_{i}}\right) V_{i} C_{i}^{n},
\end{gathered}
$$

or

$$
I_{R i}^{n}=\left(\frac{\lambda_{R} \lambda_{d i}}{\lambda_{r n}+\lambda_{R}}\right) V_{i} C_{i}^{n}
$$

Therefore, from Equations A.17 and A.20, the injection rate $I_{i}^{n}$ can be expressed as:

$$
I_{i}^{n}=I_{S i}^{n}+\left(\frac{\lambda_{R} \lambda_{d i}}{\lambda_{r n}+\lambda_{R}}\right) V_{i} C_{i}^{n} .
$$

Substituting Equations A.16 and A.21 into Equation A.11 yields the following general mass balance equation:

$$
\begin{aligned}
V_{i} \frac{d C_{i}^{n}}{d t}= & \lambda_{r n} V_{i} C_{i}^{(n-1)}+\sum_{\frac{j=0}{j \neq i}}^{3}\left(Q_{j i} C_{j}^{n}\right)-C_{i}^{n} \sum_{\frac{j=0}{j \neq i}}^{3} Q_{i j}+I_{S i}^{n} \\
& +\left(\frac{\lambda_{R} \lambda_{d i}}{\lambda_{r n}+\lambda_{R}}\right) V_{i} C_{i}^{n}-\left(\lambda_{r n}+\lambda_{d i}\right) V_{i} C_{i}^{n} .
\end{aligned}
$$


Now, substituting the steady-state compartment mass balance Equation A.1 into A.22, and assuming steady-state conditions, Equation A.22 becomes (for each compartment $i$ ):

$$
\begin{gathered}
\lambda_{r n} V_{i} C_{i}^{(n-1)}+\sum_{\frac{j=0}{j \neq i}}^{3}\left(Q_{j i} C_{j}^{n}\right)-C_{i}^{n} \sum_{\frac{j=0}{j \neq i}}^{3} Q_{j i}+I_{S i}^{n} \\
+\left(\frac{\lambda_{R} \lambda_{d i}}{\lambda_{r n}+\lambda_{R}}\right) V_{i} C_{i}^{n}-\left(\lambda_{r n}+\lambda_{d i}\right) V_{i} C_{i}^{n}=0 \\
{\left[\left(\lambda_{r n}+\lambda_{d i}-\frac{\lambda_{R} \lambda_{d i}}{\lambda_{r n}+\lambda_{R}}\right) V_{i}+\sum_{\frac{j=0}{j \neq i}}^{3} Q_{j i}\right] C_{i}^{n}} \\
-\sum_{\frac{j=0}{j \neq i}}^{3}\left(Q_{j i} C_{j}^{n}\right)=I_{S i}^{n}+\lambda_{r n} V_{i} C_{i}^{(n-1)} .
\end{gathered}
$$

Applying Equation A.24 to all three internal compartments of the building $(i=1,2,3)$ generates a system of three equations related to the three unknowns $C^{n}{ }_{1}, C^{n}{ }_{2}$, and $C^{n}{ }_{3}$, which can then be solved. So, applying Equation A.24 for compartments 1, 2, and 3 yields, respectively:

$$
\begin{gathered}
{\left[\left(\lambda_{r n}+\lambda_{d 1}-\frac{\lambda_{R} \lambda_{d 1}}{\lambda_{r n}+\lambda_{R}}\right) V_{1}+\sum_{\frac{j=0}{j \neq 1}}^{3} Q_{j 1}\right] C_{1}^{n}-Q_{21} C_{2}^{n}-Q_{31} C_{3}^{n}} \\
=I_{S 1}^{n}+Q_{01} C_{0}^{n}+\lambda_{r n} V_{1} C_{1}^{(n-1)} ; \\
-Q_{12} C_{1}^{n}+\left[\left(\lambda_{r n}+\lambda_{d 2}-\frac{\lambda_{R} \lambda_{d 2}}{\lambda_{r n}+\lambda_{R}}\right) V_{2}+\sum_{\frac{j=0}{j \neq 2}}^{3} Q_{j 2}\right] C_{2}^{n}-Q_{32} C_{3}^{n} \\
=I_{S 2}^{n}+Q_{02} C_{0}^{n}+\lambda_{r n} V_{2} C_{2}^{(n-1)} ;
\end{gathered}
$$




$$
\begin{gathered}
-Q_{13} C_{1}^{n}-Q_{23} C_{2}^{n}+\left[\left(\lambda_{r n}+\lambda_{d 3}-\frac{\lambda_{R} \lambda_{d 3}}{\lambda_{r n}+\lambda_{R}}\right) V_{3}+\sum_{\frac{j=0}{j \neq 3}}^{3} Q_{j 3}\right] C_{3}^{n} \\
=I_{S 3}^{n}+Q_{03} C_{0}^{n}+\lambda_{r n} V_{3} C_{3}^{(n-1)} .
\end{gathered}
$$

Using a matrix notation, the system of equations represented by Equation A.20 can be rewritten as:

$$
\boldsymbol{A} \times x=b,
$$

where $A$ is a systematic coefficient matrix of order 3 that can be written as:

$$
\mathbf{A}=\left[\begin{array}{ccc}
\left(\lambda_{r n}+\lambda_{d 1}-\frac{\lambda_{R} \lambda_{d 1}}{\lambda_{r n}+\lambda_{R}}\right) V_{1}+\sum_{j \neq 1}^{3} Q_{j 1} & -Q_{21} & -Q_{31} \\
-Q_{12} & \left(\lambda_{r n}+\lambda_{d 2}-\frac{\lambda_{R} \lambda_{d 2}}{\lambda_{r n}+\lambda_{R}}\right) V_{2}+\sum_{j \neq 0}^{3} Q_{j 2} & -Q_{32} \\
-Q_{13} & -Q_{23} & \left(\lambda_{r n}+\lambda_{d 3}-\frac{\lambda_{R} \lambda_{d 3}}{\lambda_{r n}+\lambda_{R}}\right) V_{3}+\frac{\sum_{j=0}^{3}}{j \neq 3} Q_{j 3}
\end{array}\right]
$$

The vectors of the unknown variables and the independent terms, $\boldsymbol{x}$ and $\boldsymbol{b}$, are written respectively as:

$$
\boldsymbol{x}=\left[\begin{array}{c}
C_{1}^{n} \\
C_{2}^{n} \\
C_{3}^{n}
\end{array}\right] ; \quad \boldsymbol{b}=\left[\begin{array}{c}
I_{s 1}^{n}+Q_{01} C_{0}^{n}+\lambda_{r n} V_{1} C_{1}^{(n-1)} \\
I_{s 2}^{n}+Q_{02} C_{0}^{n}+\lambda_{r n} V_{2} C_{2}^{(n-1)} \\
I_{s 3}^{n}+Q_{03} C_{0}^{n}+\lambda_{r n} V_{3} C_{3}^{(n-1)}
\end{array}\right]
$$


Equation A.28 is a general expression representing the air quality model. It can be solved for the concentrations $C^{n}{ }_{1}, C_{2}^{n}$, and $C_{3}^{n}$ of a radionuclide $n$. Compartments 1 and 3 are assumed to be separated, and no air flows between them. Therefore, $Q_{13}=Q_{31}=0$. In the current version of RESRAD-BUILD, the outdoor air concentration $C^{n}{ }_{0}$ is assumed to be zero.

\section{A.3 ADAPTATION OF THE AIR QUALITY MODEL}

This air quality model can be used to calculate the airborne concentration of a radionuclide of order $n$ in its radioactive decay series or the concentration of radon and its decay progeny in the air of compartments 1,2 , and 3 . Use of the model to simulate these cases would require the following adaptation.

Case 1 - Airborne concentration of a radionuclide of order $n$ :

- The injection rate $I_{S i}^{n}$ is evaluated according to the behavior of the source, such as source erosion rate (see Appendix D).

- The concentration $C^{(n-1)}$ is given by the concentration of the predecessor radionuclide in the series. If $n=1$, then $C_{i}^{(n-1)}$ is made equal to zero.

Case 2-Airborne radon concentration:

- The rate of radon injection, $I_{S i}^{n}$, from the source into the indoor air of compartment $i$ is evaluated by solving the radon transport equation within the source (see Appendix C).

- The order number $n$ is made equal to 1 .

- The precursor concentration $C^{0}{ }_{i}$ is equal to the concentration of radium-226 (for the case of radon-222) or thorium-228 (for the case of radon-220) in the air of compartment $i$, due to a direct release from the source. $C_{i}^{0}$, which will be used for the radon calculations, can be calculated according to Case 1 . 
- In most cases, the radon calculations could be performed by neglecting the contribution from the indoor air precursor concentration $C^{0}$. However, this point should be investigated (tested) further.

- The deposition velocity for the radon gas is negligible; therefore, $\lambda_{d i}=0$.

Case 3-Airborne concentration of radon progeny:

- The order number $n$ is made equal to 2,3 , and 4 .

- $C^{1}{ }_{i}=C^{R n}{ }_{i}$ for each $i$. Note that $C^{1}{ }_{i}$ is calculated according to Case 2 .

- The concentration of the radon progeny is determined by solving Equation A.28 sequentially with $n=2,3$, and 4 .

- The injection rate is $I^{n}{ }_{S i}=0$ for all $i$ and $n$.

- Specific details are shown in Appendix C.

\section{A.4 REFERENCES}

Nero, A.V., 1988, "Radon and Its Decay Products in Indoor Air: An Overview," in Radon and Its Decay Products in Indoor Air, W.W. Nazaroff and A.V. Nero (editors), John Wiley \& Sons, New York, N.Y.

Yu, C., et al., 1993, Data Collection Handbook to Support Modeling the Impacts of Radioactive Material in Soil, ANL/EAIS-8, prepared by Argonne National Laboratory, Argonne, Ill., for U.S. Department of Energy, April. 
B-1

\section{APPENDIX B:}

\section{AIR PARTICULATE DEPOSITION}


B-2 


\section{APPENDIX B:}

\section{AIR PARTICULATE DEPOSITION}

The objective of the deposition model is to evaluate the surface contamination, $C^{n} d i$, of the principal radionuclide of order $n$ in the decay series, at each compartment $i$ of the building, as a function of the respective airborne concentration in the indoor air of compartment $i$. For the derivation of the deposition model, consider the schematic representation of a generic compartment $i$, as shown in Figure B.1.

Thus, from a mass balance principle applied to the projected plane surface of compartment $i$, the following expression can be derived:

$$
A_{i} \frac{d C_{d i}^{n}}{d t}=u_{d} A_{i} C_{i}^{n}-\lambda_{r n} A_{i} C_{d i}^{n}-\lambda_{R} A_{i} C_{d i}^{n}
$$

where

$C_{d i}^{n}=$ surface concentration of principal radionuclide of order $n$ in the radioactive decay series, due to deposition at the projected horizontal surface of compartment $i\left(\mathrm{pCi} / \mathrm{m}^{2}\right)$;

$C^{n}{ }_{i}=$ airborne concentration of radionuclide $n$, in the indoor air of compartment $i\left(\mathrm{pCi} / \mathrm{m}^{3}\right)$;

$u_{d}=$ average deposition velocity of the airborne radioactive dust particulates $(\mathrm{m} / \mathrm{h})$;

$\lambda_{r n}=$ radioactive decay constant of radionuclide $n(1 / \mathrm{h}) ;$

$\lambda_{R}=$ resuspension rate of deposited dust particulates into the air, or the fraction of the deposited dust particulates that is resuspended into the indoor air per unit of time $(1 / \mathrm{h})$; and $A_{i}=$ surface area of the floor of compartment $i\left(\mathrm{~m}^{2}\right)$. 


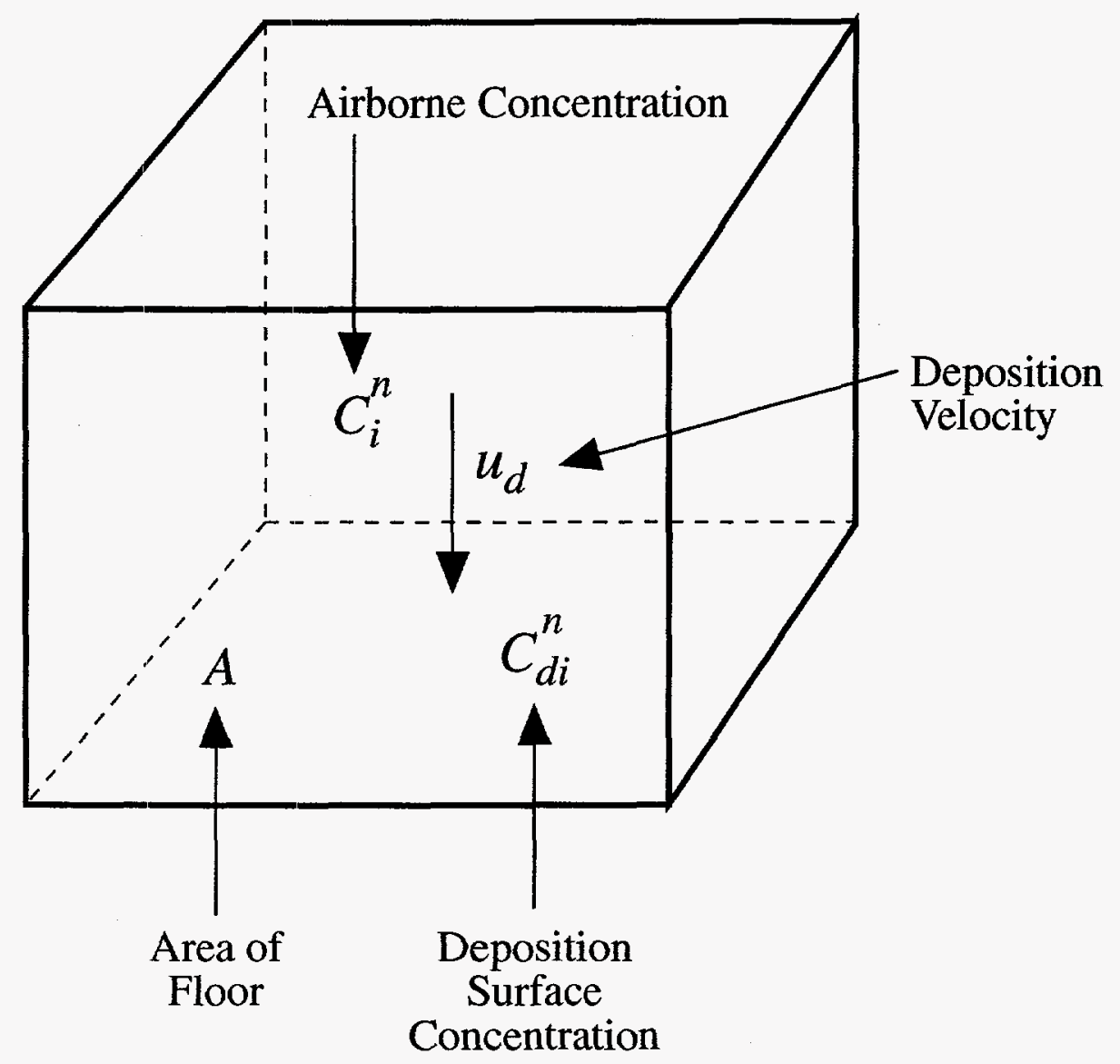

FIGURE B.1 Schematic Representation of a Compartment $i$ of the Building, Showing the Deposition of Dust Particulates onto the Projected Horizontal Surface

Each term in Equation B.1 represents the variation of mass (activity) on the projected plane surface, per unit of time, due to different processes. The term on the left-hand side represents the total accumulation/depletion of mass (activity) on the surface. The first term on the right-hand side represents the addition of mass due to the deposition of dust particulates. The second term represents the loss of mass due to radioactive decay. Finally, the third term represents the loss of mass due to the resuspension of deposited dust particulates back into the indoor air.

Assuming a steady-state condition, the mass balance Equation B.1 yields:

$$
u_{d} C_{i}^{n}-\lambda_{r n} C_{d i}^{n}-\lambda_{R} C_{d i}^{n}=0
$$


or

$$
C_{d i}^{n}=\left(\frac{u_{d}}{\lambda_{r n}+\lambda_{R}}\right) C_{i}^{n}
$$

Equation B.3 is used to calculate $C_{d i}^{n}$, at each compartment $i$, as a function of the respective airborne concentration $C_{i}^{n}$. The contribution for the total injection rate at each compartment $i$, due to resuspension, can be evaluated from the last term of Equation B.1. That is:

$$
I_{R i}^{n}=\lambda_{R} A_{i} C_{d i}^{n}
$$

where $I_{R i}^{n}$ is the rate of injection of radionuclide $n$ into the indoor air of compartment $i$, due to resuspension of deposited dust particulates (pCi/h). Substituting Equation B.3 into B.4 yields:

$$
I_{R i}^{n}=\left(\frac{\lambda_{R} u_{d} A_{i}}{\lambda_{r n}+\lambda_{R}}\right) C_{i}^{n}
$$

Equation B.5 is used in the air quality model (see Appendix A) to represent the component of the injection rate due to resuspension. 


$$
\text { B- } 6
$$


C-1

APPENDIX C:

RADON AND ITS PROGENY CONCENTRATION 
C-2 


\section{APPENDIX C:}

\section{RADON AND ITS PROGENY CONCENTRATION}

\section{C.1 RADON FLUX}

The airborne radon concentration in the indoor air of compartment $i$ is calculated by using the generic air quality model, as described in Appendix A. Yet, to apply the air quality model, it is necessary to evaluate the radon injection rate $I_{S i}^{R n}$ directly from the source into the indoor air of compartment $i$. The rate of radon injection into the indoor air depends on the concentration of the radon parent within the source and on the geometric and physical properties of the source. Therefore, $I^{R n}{ }_{S i}$ is defined for each type of source: surface, line, point, and volume. For surface, line, and point sources, $I_{S i}^{R n}(\mathrm{pCi} / \mathrm{s})$ is calculated as:

$$
I_{S i}^{R n}=F^{R n} \lambda A_{\text {total }}^{p}
$$

where

$$
\begin{aligned}
F^{R n}= & \text { fraction of radon generated within the source that escapes from } \\
& \text { the source and is injected into the air (dimensionless); } \\
\lambda= & \text { radon decay constant }\left(\mathrm{s}^{-1}\right) ; \text { and } \\
A_{\text {total }}^{p}= & \text { total amount of the radon parent radionuclide present within the } \\
& \text { source }(\mathrm{pCi}) .
\end{aligned}
$$

For a volume source, the radon injection rate, $I_{S i}^{R n}$, is evaluated differently, according to the following:

$$
I_{S i}^{R n}=A_{s} J
$$

where

$A_{s}=$ surface area of the face of the volume source that is exposed to the indoor air of compartment $i\left(\mathrm{~m}^{2}\right)$; and 
$J=$ flux density of radon activity (or radon flux, for short) through the exposed face of the volume source $\left(\mathrm{pCi} \times \mathrm{m}^{-2} \times \mathrm{s}^{-1}\right)$.

The variables $F^{R n}$ and $A^{p}$ total are given as input parameters to the model. Therefore, the calculation of $I_{S i}^{R n}$ for surface, line, and point sources is a straightforward procedure, based directly on Equation C.1. Yet, for volume sources, the radon flux is not given as an input parameter and must be evaluated specifically for each case. Sections C.1.1 to C.1.3 describe the model for calculating the radon flux $J$ for the cases in which the volume sources are defined.

\section{C.1.1 Mathematical Model}

Consider initially a three-dimensional configuration of a volume source composed of up to five distinct regions, as shown in Figure C.1. The present conceptual model assumes that, due to geometric considerations, the total flow of radon activity from the lateral (smaller) faces of the volume source is negligible compared with the total flow through the larger faces that are exposed to the indoor air. This assumption implies that, if the lateral flux is neglected, the distribution of radon concentration in the lateral (boundary) zones within the source could be assumed invariable. Neglecting the value of $J_{l a t}$ increases the calculated values of $J_{i}$ and $J_{j}$, resulting in a conservative estimation of indoor radon concentration. Under these assumptions, the three-dimensional configuration in Figure C.1 can be further simplified and represented by a five-zone, one-dimensional configuration according to Figure C.2.

The general mass balance equation for radon activity in a two-phase porous system composed of solid phase and gas phase (no moisture content) in any region represented in Figure C.2 can be expressed as:

$$
\frac{\partial(n C)}{\partial t}=-\vec{\nabla} \times \vec{J}-n R+n S,
$$




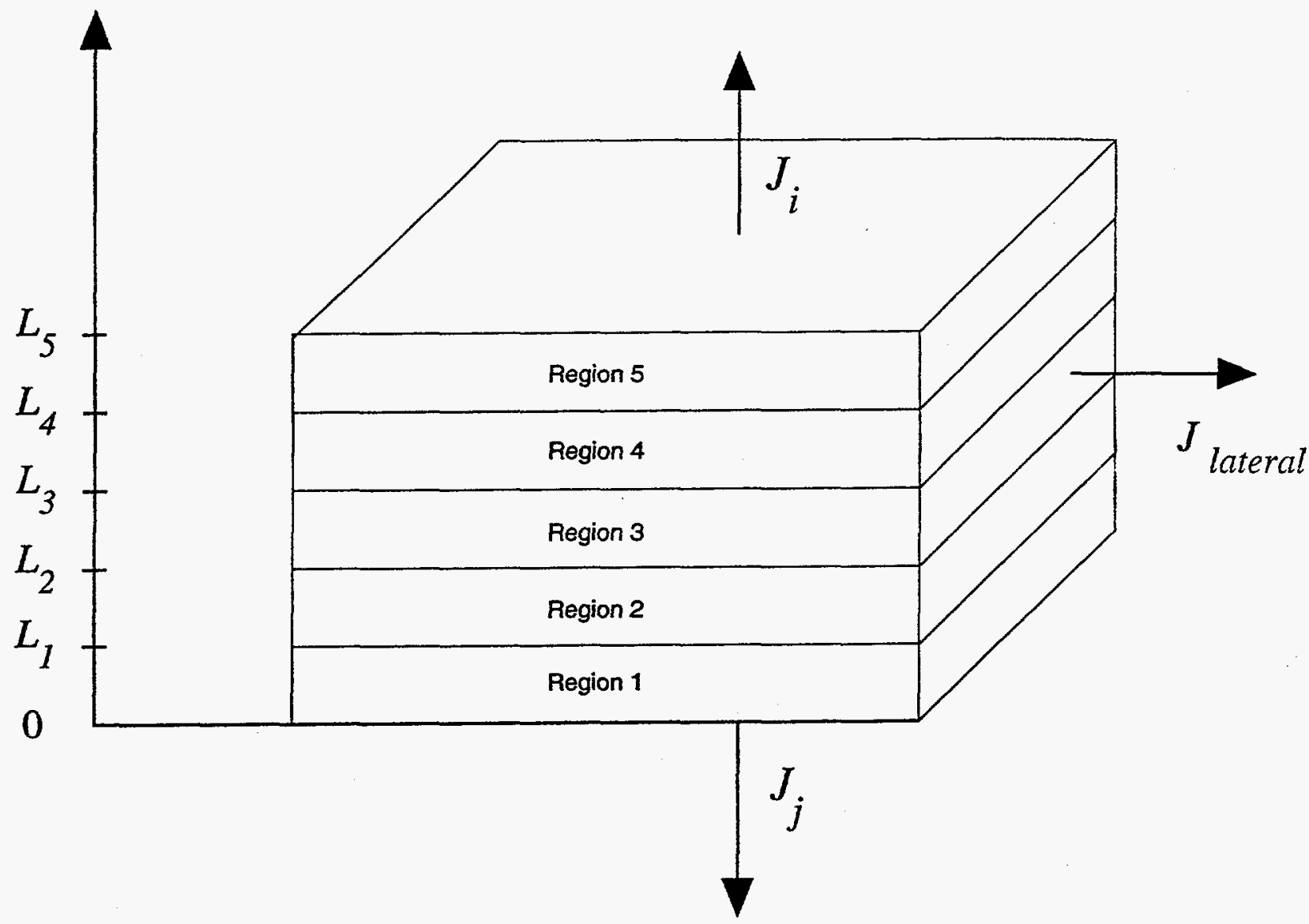

FIGURE C.1 Three-Dimensional Schematic Representation of a Volume Source (showing its five distinct regions and the radon flux densities at the surfaces of the source)

\section{Regions}

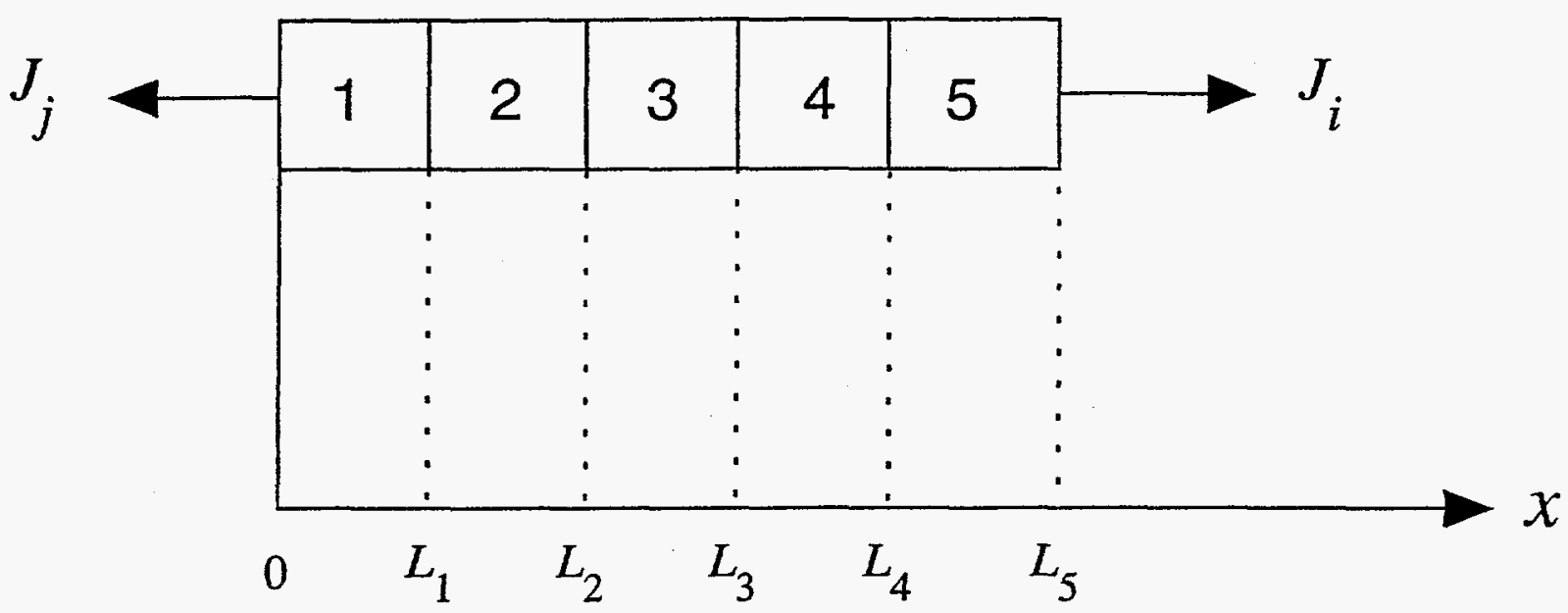

FIGURE C.2 One-Dimensional Schematic Representation of a Volume Source (showing its five distinct regions and radon flux densities at the surfaces of the source) 
where

$$
\begin{aligned}
C= & \text { radon activity concentration in the pore space }\left(\mathrm{pCi} / \mathrm{m}^{3}\right) ; \\
J= & \begin{array}{l}
\text { bulk flux density of radon activity through the matrix } \\
\left(\mathrm{pCi} \times \mathrm{m}^{-2} \times \mathrm{s}^{-1}\right) ;
\end{array} \\
R= & \text { radon sink term }\left(\mathrm{pCi} \times \mathrm{m}^{-3} \times \mathrm{s}^{-1}\right) ; \\
S= & \text { radon source term }\left(\mathrm{pCi} \times \mathrm{m}^{-3} \times \mathrm{s}^{-1}\right) ; \text { and } \\
n= & \text { total (volumetric) porosity. }
\end{aligned}
$$

Each term of Equation C.3 expresses the variation of radon activity per unit of total volume and per time.

In the absence of convective flow of the gaseous phase in the porous medium, the bulk flux density of radon activity, $J$, can be expressed by the Fickian diffusion equation:

$$
\vec{J}=-n D_{e} \vec{\nabla} C
$$

where $D_{e}$ is the effective diffusion coefficient of radon in the porous medium $\left(\mathrm{m}^{2} \cdot \mathrm{s}^{-1}\right)$.

The source of radon activity into the pore volume of the porous medium can be evaluated by the following expression:

$$
S=\varepsilon \rho_{s} C^{p} \lambda\left(\frac{1-n}{n}\right)
$$

where

$\epsilon=$ radon emanating factor;

$\rho_{s}=$ density of solid phase of the porous medium $\left(\mathrm{kg} / \mathrm{m}^{3}\right)$;

$C^{p}=$ concentration of the radon parent radionuclide in the solid phase $(\mathrm{pCi} / \mathrm{kg})$

$\lambda=\operatorname{radon}$ decay constant $(1 / \mathrm{s}) ;$ and

$n=$ total porosity of the medium.

The decay of radon activity (the sink term) in the pore volume can be expressed as:

$$
R=+\lambda C
$$


Now, considering the steady-state condition in the one-dimensional configuration and the constitutive expressions above, the general mass balance equation for radon becomes:

$$
\begin{gathered}
-\frac{d}{d x}\left(n D_{e} \frac{d C}{d x}\right)+n \lambda C=n S, \\
-n D_{e} \frac{d^{2} C}{d x^{2}}+n \lambda C=n S,
\end{gathered}
$$

or

$$
-D_{e} \frac{d^{2} C}{d x^{2}}+\lambda C=S
$$

where the porosity $n$ and the diffusion coefficient $D_{e}$ are assumed invariable with distance.

Equation C.7a is a nonhomogeneous, linear (constant coefficients), second-order, ordinary differential equation representing the transport of radon activity in a one-dimensional porous medium configuration. The general solution for the nonhomogeneous transport equation above can be expressed as:

$$
C=K_{1} e^{r x}+K_{2} e^{-r x}+\frac{S}{\lambda},
$$

or

$$
C=K_{1} e^{\frac{x}{L_{D}}}+K_{2} e^{-\frac{x}{L_{D}}}+\frac{S}{\lambda}
$$

where $K_{1}$ and $K_{2}$ are linear coefficients to be determined from the boundary conditions and $r$ represents the inverse of the diffusion length, $L_{D}$, and is given by:

$$
r=\frac{1}{L_{D}}=\sqrt{\frac{\lambda}{D_{e}}}
$$

where $L_{D}$ is the diffusion length $(\mathrm{m})$. 
Equation C.8 represents the profile of radon activity concentration, $C$, within a specific one-dimensional region where all the parameters (such as $D_{e}, \varepsilon, S, \rho_{s}$, and $n$ ) are assumed to be constant and the coefficients $K_{1}$ and $K_{2}$ are calculated on the basis of the boundary conditions imposed on the defined region of the domain. Equation C. 8 can also be used to represent the profile of $C$ in a multiple-region, one-dimensional configuration, if each defined region has constant and homogeneous properties. In this case, the constants $K_{i 1}$ and $K_{i 2}$, for each region $i$, must be evaluated on the basis of the boundary conditions imposed on the external boundaries of the domain and on each interface between two defined regions.

\section{C.1.2 General Boundary Conditions}

Two types of physical boundaries need to be considered in solving a problem of radon diffusion in a one-dimensional porous medium configuration: (1) at the interface between the porous medium and open air (either outdoor atmosphere or indoor air) and (2) at the interface between two defined porous medium regions of the domain.

Different boundary conditions are imposed at these boundaries. Thus, at the open-air/porous-medium interface, the radon activity concentration is assumed to be substantially smaller than the values of $C$ inside the medium, where the radon source is present. Therefore, as an approximation, the value of $C=0$ is assumed at this boundary. That means, at values of $x=0$ and $x=L_{5}$, this boundary condition would be expressed as:

$$
C_{(x=0)}=0,
$$

and

$$
C_{\left(x=L_{5}\right)}=0 \text {. }
$$

At the interfaces between two different regions in the porous medium domain, the principle of continuity is applied as a boundary condition. That means at an interface $i$, 
located at a generic point $x_{i}$, the values of radon activity concentration, $C$, and the bulk flux density of radon activity, $J$, should satisfy the following limit expressions:

$$
C_{\left(x=x_{i}-\right)}=C_{\left(x=x_{i}+\right)},
$$

and

$$
\left[n D_{e} \frac{d C}{d x}\right]_{\left(x=x_{i}-\right)}=\left[n D_{e} \frac{d C}{d x}\right]_{\left(x=x_{i}+\right)} .
$$

\section{C.1.3 Analytical Solution: General Multilayer Configuration}

The general solution for the one-dimensional radon diffusion equation, Equation C.8, can be applied to represent the profile of radon activity concentration and flux density along a multiregion, one-dimensional configuration representing the source within the wall.

To simplify the equations, a three-layer source will be considered as an example here. Thus, consider a one-dimensional physical configuration of three porous layers, with thicknesses $l_{1}, l_{2}$, and $l_{3}$ and homogeneous properties within each layer. Also, assume the system of coordinates at the origin of the configuration. The boundaries of the system will be located at the distances $x=0, L_{1}, L_{2}$, and $L_{3}$. Applying Equation C.8 into this configuration results in the following system of equations:

$$
\begin{aligned}
& C(x)=K_{11} e^{r_{1} x}+K_{12} e^{-r_{1} x} \cdot \frac{S_{1}}{\lambda}, \quad 0 \leq x \leq L_{1}, \\
& C(x)=K_{21} e^{r_{2} x}+K_{22^{2}} e^{-r_{2} x}+\frac{S_{2}}{\lambda}, \quad L_{1} \leq x \leq L_{2}, \\
& C(x)=K_{31} e^{r_{3} x}+K_{32} e^{-r_{3} x}+\frac{S_{3}}{\lambda}, \quad L_{2} \leq x \leq L_{3} .
\end{aligned}
$$


This set of equations involves six $(2 n=6)$ unknown parameters $K_{i j}$, where $i=1,2$, 3 and $j=1,2$. The values of these parameters specify a defined physical system. A threelayer configuration has two $(n-1=2)$ internal boundaries, which, from the boundary conditions represented by Equation C.11, generate four $(2 n-2=4)$ equations. The two external boundaries provide the other two needed equations for solving the system. The conditions imposed on these external boundaries can be represented by Equation C.10a or C.10b.

Thus, applying the condition represented by Equation C.10 on the first boundary of the system (at $x=0$ ) yields:

$$
K_{11}+K_{12}=-\frac{S_{1}}{\lambda}
$$

Then, applying the condition represented by Equation C.11 on an internal boundary between region $i$ and region $(i+1)$ at the distance $\left(x=L_{i}\right)$ of the system yields:

$$
\left(e^{r_{i} L_{i}}\right) K_{i 1}+\left(e^{-r_{i} L_{i}}\right) K_{i 2}+\frac{S_{i}}{\lambda}=\left(e^{r_{i+1} L_{i}}\right) K_{(i+1) 1}+\left(e^{-r_{i+1} L_{i}}\right) K_{(i+1) 2}+\frac{S_{i+1}}{\lambda}
$$

and

$$
\begin{aligned}
& \left(n_{i} D_{e_{i}} r_{i} e^{r_{i} L_{i}}\right) K_{i 1}-\left(n_{i} D_{e_{i}} r_{i} e^{-r_{i} L_{i}}\right) K_{i 2}= \\
& \left(n_{i+1} D_{e_{i+1}} r_{i+1} e^{r_{i+1} L_{i}}\right) K_{(i+1) 1}-\left(n_{i+1} D_{e_{i+1}} r_{i+1} e^{-r_{i+1} L_{i}}\right) K_{(i+1) 2}
\end{aligned}
$$

For the last boundary of the system, or the external boundary of the third layer, the condition imposed there could be represented by the following expression:

$$
\left(e^{r_{3} L_{3}}\right) K_{31}+\left(e^{-r_{3} L_{3}}\right) K_{32}=-\frac{S_{3}}{\lambda}
$$

The system of equations represented by Equations C.13a through C.13d contains six $(2 n=6)$ equations related to the six unknowns, $K_{i j}$. It can be represented by the following matrix equation: 


$$
A \times k=b,
$$

where $A$ is a pentadiagonal coefficient matrix that can be written as:

$$
A=\left[\begin{array}{cccccc}
1 & 1 & 0 & 0 & 0 & 0 \\
e^{r_{1} L_{1}} & e^{-r_{1} L_{1}} & -e^{r_{2} L_{1}} & -e^{-r_{2} L_{1}} & 0 & 0 \\
D_{1} r_{1} e^{r_{1} L_{1}} & -D_{1} r_{1} e^{-r_{1} L_{1}} & -D_{2} r_{2} e^{r_{2} L_{1}} & D_{2} r_{2} e^{-r_{2} L_{1}} & 0 & 0 \\
0 & 0 & e^{r_{2} L_{2}} & e^{-r_{2} L_{2}} & -e^{r_{3} L_{2}} & -e^{-r_{3} L_{2}} \\
0 & 0 & D_{2} r_{2} e^{r_{2} L_{2}} & -D_{2} r_{2} e^{-r_{2} L_{2}} & -D_{3} r_{3} e^{r_{3} L_{2}} & D_{3} r_{3} e^{-r_{3} L_{2}} \\
0 & 0 & 0 & 0 & e^{r_{3} L_{3}} & e^{-r_{3} L_{3}}
\end{array}\right]
$$

To save space in writing the matrix identity above, the product $n_{i} D_{e_{i}}$ was substituted by the bulk diffusion coefficient $D_{i}$. By definition, the product of porosity times the effective diffusion coefficient is equal to the bulk diffusion coefficient. That is,

$$
n_{i} D_{e_{i}}=D_{i}
$$

The vectors of the unknown variables and the independent terms $k$ and $b$ are written respectively as:

$$
k=\left[\begin{array}{l}
K_{11} \\
K_{12} \\
K_{21} \\
K_{22} \\
K_{31} \\
K_{32}
\end{array}\right]
$$

and

$$
b=\left[\begin{array}{c}
-\frac{S_{1}}{\lambda} \\
\left(\begin{array}{c}
S_{2}-S_{1} \\
\lambda
\end{array}\right) \\
0 \\
\left(\begin{array}{c}
S_{3}-S_{2} \\
\lambda
\end{array}\right) \\
0 \\
-\frac{S_{3}}{\lambda}
\end{array}\right] .
$$


The solution of Equation C.14 provides for the values of the coefficients $K_{i j}$, which could then be used in Equation C.12 to represent the profile of radon activity concentration throughout the multilayer configuration.

The flux density of radon activity at both extremities of the system (at $x=0$ and $\left.x=L_{3}\right)$ could then be derived from Equations C.4 and C.12. Thus, at $(x=0)$ the flux $J(x=0)$ is given by:

$$
\begin{aligned}
J_{(x=o)} & =-n_{1} D_{e_{1}} \nabla C_{(x=0)} \\
& =-n_{1} D_{e_{1}}\left(r_{1} K_{11} e^{r_{1} x}-r_{1} K_{12} e^{-r_{1} x}\right)_{(x=0)},
\end{aligned}
$$

or

$$
J_{(x=o)}=-n_{1} D_{e_{1}} r_{1}\left(K_{11}-K_{12}\right) .
$$

Similarly, for $X=L_{3}$, the flux density $J\left(x=L_{3}\right)$ is given by:

$$
J_{\left(x=L_{3}\right)}=-n_{3} D_{e_{3}} r_{3}\left(K_{31} e^{r_{3} L_{3}}-K_{32} e^{-r_{3} L_{3}}\right) .
$$

Finally, after calculating $J_{i}$ from Equations C.16 and C.17, the radon injection rate from each face of the volume source into the indoor air of the respective compartment $i$ can be calculated from Equation C.2. This methodology is implemented in the RESRAD-BUILD code for up to five regions of different material.

\section{C.2 RADON PROGENY}

The objective of the radon dosimetry model is to evaluate the effective dose equivalent due to inhalation of the airborne radon progeny. The model presented here is an adaptation of the radon dosimetry model currently used in the RESRAD computer code (Yu et al. 1993). 
Consider a three-compartment building shown in Figure C.3. The terms shown in the figure are defined as follows. $F_{\text {out }}$ is the fraction of time spent outside the building (dimensionless); $F_{i n}$ is the fraction of time spent inside the building (dimensionless); $F_{i}$ is the fraction of all the time spent inside the building, in which the individual stays in the compartment $i$ (with $i=1,2,3$ for the first, second, and third compartment, respectively) (dimensionless); $C_{i}^{n}$ is the indoor air concentration of radon decay products $(n=2,3,4)$ for either radon-222 or radon-220 progeny in the compartment $i(i=1,2,3)\left(\mathrm{pCi} / \mathrm{m}^{3}\right) ; W L_{i}$ is the working level concentration of radon decay products for either radon-222 or radon-220 progeny in the indoor air of compartment $i(i=1,2,3)$ (in units of WL); $W L M_{i}$ is the exposure to the indoor air concentration of radon decay products for either radon-222 or radon-220, in the compartment $i\left(i=1,2,3\right.$ ) (in units of Working Level Month [WLM]); and $D^{R n}{ }_{i}$ is the

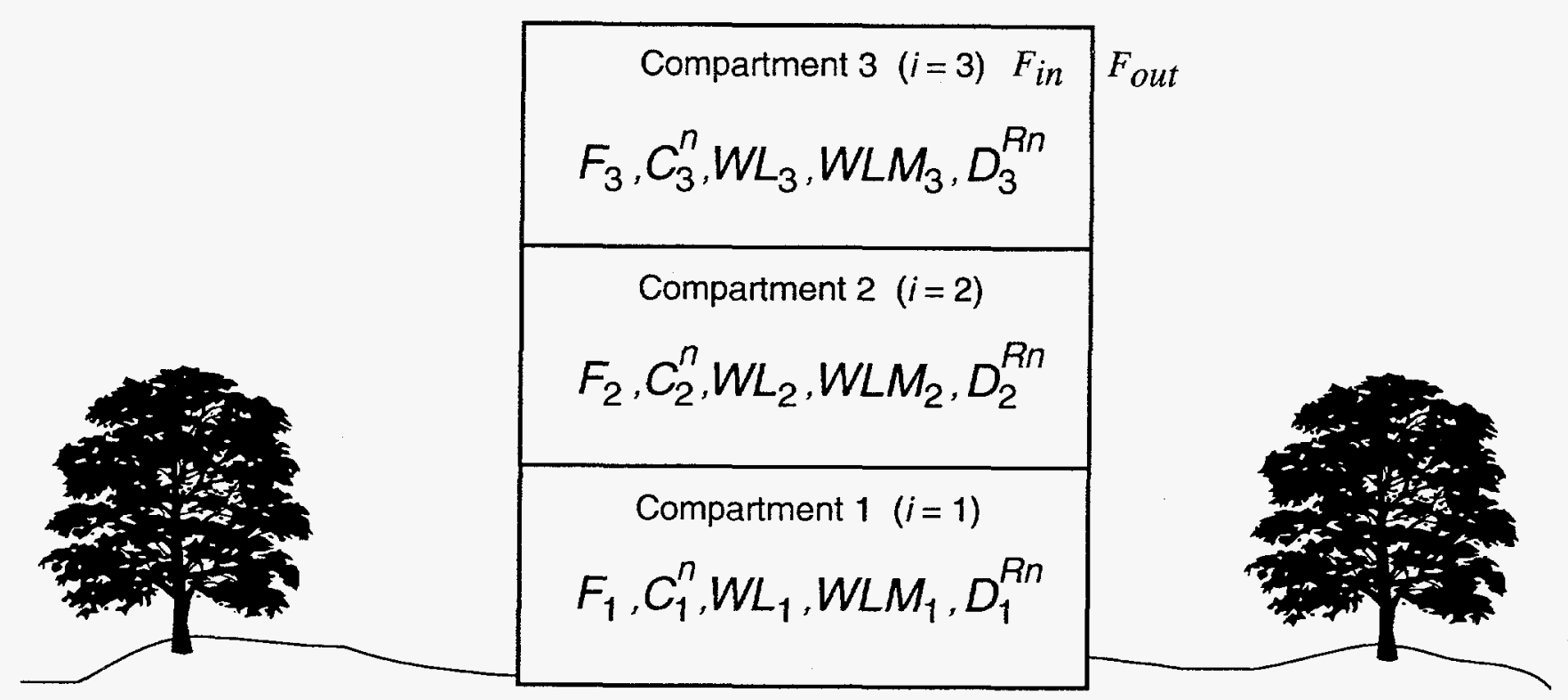

FIGURE C.3 Schematic Representation of the Three-Compartment Building 
effective dose equivalent due to the inhalation of radon decay products in the indoor air of compartment $i(i=1,2,3)(\mathrm{mrem} / \mathrm{yr})$.

The algorithm to calculate the radon decay product dosimetry can be summarized in the following four steps:

(1) Calculate $C_{i}^{n}$, the indoor air concentration of radon and its decay products (obtained by applying the air quality model, Appendix A);

(2) Calculate the $W L_{i}$, based on the values of $C_{i}^{n}$;

(3) Calculate the exposure $\left(W L M_{i}\right)$ to the radon decay products, based on the $W L_{i}$ and the exposure time; and

(4) Calculate the effective dose equivalent $D_{i}^{R n}$, based on the $W L M_{i}$ and the related dose conversion factors (see Section C.5).

\section{C.2.1 Airborne Radon Progeny Concentration}

The calculation of the airborne concentration of the radon short-lived decay products in the indoor air of compartment $i$ is based on a variation of the model proposed by Jacobi (1972) and extended by Porstendörfer (1984) and Bruno (1983). Figure C.4 schematically represents the main interactions among the different stages of the radon decay products, as addressed in the model. According to the adopted notation, the radon progeny is designated by the index $n$, where $n$ is equal to $1,2,3$, and 4 for radon and its first, second, and third decay products, respectively. For convenience, the first, second, and third radon decay products are designated, in general, as elements $A, B$, and $C$, respectively. For example, in the case of the radon-222 family, the $n$ index would represent radon-222, polonium-218, lead-214, and bismuth-214, for $n$ equal to $1,2,3$, and 4 , respectively. In this case, polonium-218, lead-214, and bismuth-214 are described as elements $A, B$, and $C$, respectively. 
Free State

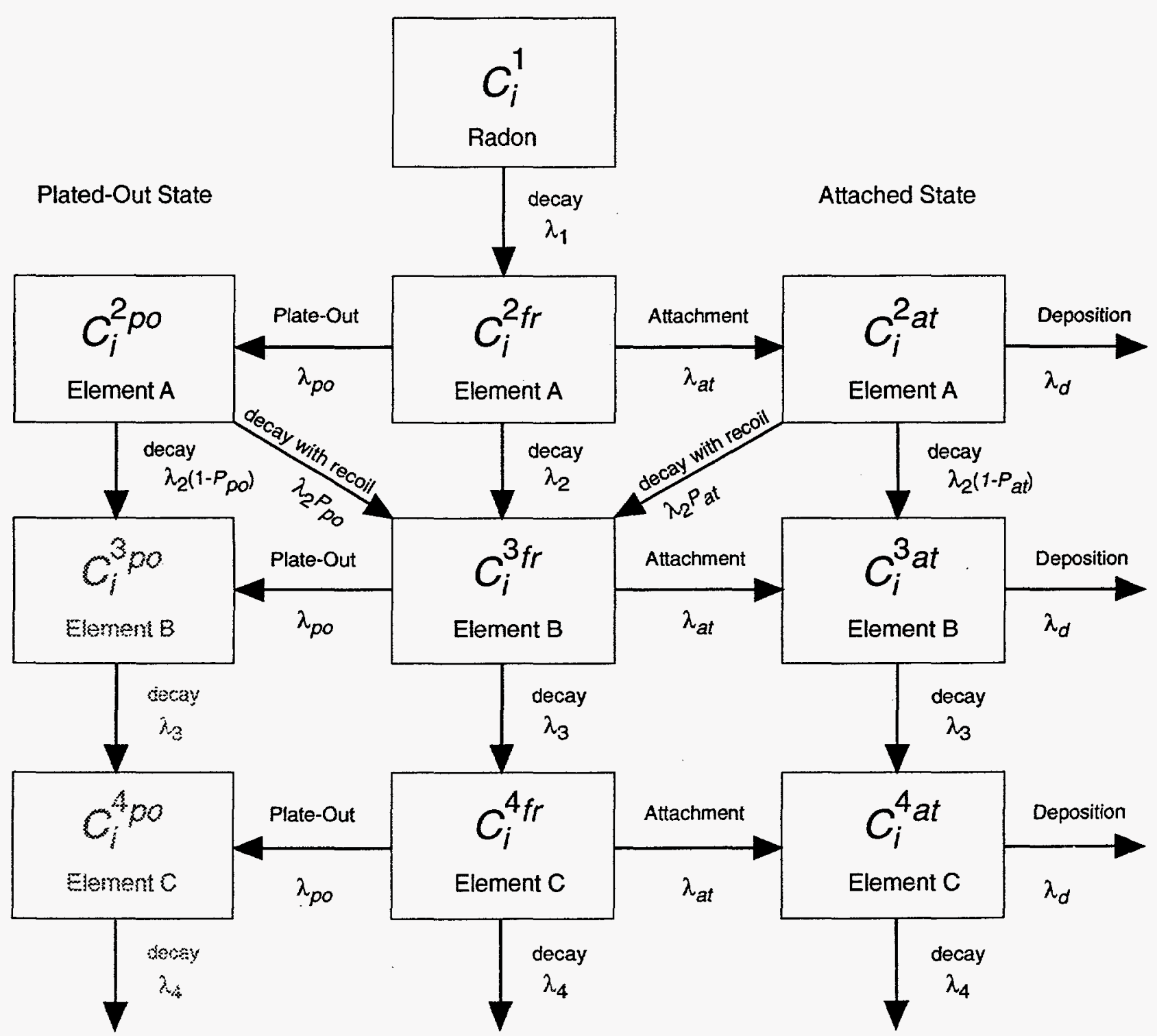

FIGURE C.4 Schematic Representation of the Interrelationships among the Several States of the Short-Lived Radon Decay Products (The superscripts 1, 2, 3, and 4 represent radon and its three first decay products, respectively.) 
Similarly, for the case of the radon-220 family, the $n$ index would represent radon-220, polonium-216, lead-212, and bismuth-212, respectively. The subscripts $f r$, at, and po designate, respectively, the free, attached, and plated-out states in which the radon decay products may exist.

The atom of element $A$ is formed as a free ion as a result of the decay of a radon atom. Soon after being formed, the ions of element $A$ join with other ions, forming an ionized molecular cluster. The molecular cluster and the ions recently formed are usually considered together in what is denominated the "free state" (fr) of the decay product. This state is represented by the second block from the top, in the center of Figure C.4. At this free state, the atom of element $A$ may follow several possible courses: (1) attach to airborne particulates (one block at right in Figure C.4); (2) plate out to exposed surfaces such as walls within the compartment (one block at left); (3) decay to the free stage of element $B$ (one block below, in Figure C.4); or (4) be ventilated out of compartment $i$.

At the "attached state" (at), the atoms of element $A$ are attached to the airborne dust particulates and may have the following fate: (1) decay to element $B$ and remain attached to the surface of the airborne dust particulate; (2) decay to element $B$ and be ejected out of the host particle, due to the recoil energy from the alpha-decay process ${ }^{1}$; (3) deposit onto the floor surface, together with the deposition of the air particulates; or (4) be ventilated out of compartment $i$.

At the "plated-out state" (po), the atoms of element $A$ are plated onto exposed surfaces in the compartment and, consequently, are removed from the indoor air. However, the atoms of element $B$ generated from the radioactive decay of element $A$ in the plated-out location can be reintroduced, as a free state atom, into the indoor air due to the recoil energy from the alpha-decay process. ${ }^{1}$

1 The recoil process is usually only considered for polonium-218 because of the substantial recoil energy $(6 \mathrm{MeV})$ associated with alpha decay. 
The atoms of element $B$ are faced with almost the same destiny as described for

element $A$. Yet, because the recoil energy from beta-decay is not sufficient to promote detachment, the atoms of element $C$ formed from the decay of element $B$ mostly remain attached to their host.

The rate constant for the decay pathway of radon and its progeny is simply the radioactive decay constant, $\lambda_{n}$, where $n$ is equal to $1,2,3$, and 4 , representing radon and the elements $A, B$, and $C$, respectively. The rate constant for the decay of element $A$, either in the attached or plated-out state, followed by detachment and the generation of element $B$ in a free state, is equal to the decay constant, $\lambda_{2}$, multiplied by the appropriate probability that a free atom will be created due to recoil. $P_{a t}$ and $P_{p o}$ are the probabilities that a free atom of element $B$ will be created due to recoil and detachment from attached and plated-out atoms of element $A$, respectively. The rate constant for the attachment pathway is denominated the attachment rate, $\lambda_{a t}$. It depends mainly on the airborne particle concentration and size distribution (Bruno 1983). Similarly, the rate constant for the plate-out pathway is denominated the plate-out rate, $\lambda_{p o}$. It depends on the surface-to-volume ratio of the compartment and on the transport properties of the free atoms within the air in the compartment. A list of the range of measured and reported values for the constants discussed above, as reported by Bruno (1983), is presented in Table C.1.

TABLE C.1 Values of Rate Constants Used in the Radon Progeny Model (Source: Bruno 1983)

\begin{tabular}{clcc}
\hline \multicolumn{1}{c}{ Name } & Value & Unit \\
\hline$\lambda_{a t}$ & Attachment rate & $6.0 \times 10^{-3}-5.0 \times 10^{-2}$ & $\mathrm{~s}^{-1}$ \\
$\lambda_{p o}$ & Plate-out rate & $3.0 \times 10^{-4}-6.0 \times 10^{-2}$ & $\mathrm{~s}^{-1}$ \\
$P_{a t}$ & Probability of detachment from particles & 0.50 & - \\
$P_{p o}$ & Probability of detachment from surfaces & 0.25 & - \\
\hline
\end{tabular}


The airborne concentration of radon progeny will be calculated sequentially by applying the mass balance equation (as described in Appendix A) to find the radon concentration first and, then, to each block of Figure C.4 to find the concentration of the radon progeny at each state. Therefore, in relation to the radon progeny calculations, the air quality model will be applied in eight consecutive steps to calculate (1) the radon concentration; (2) the concentrations of element $A$ in the free, attached, and plated-out states; (3) the concentrations of element $B$ in the free and attached states; and (4) the concentrations of element $C$ in the free and attached states. Finally, the airborne concentration of each radon decay product will be evaluated as a sum of the respective concentrations in the free and attached states.

\section{C.2.1.1 Mass Balance of Element $A$ (Free State)}

Under steady-state conditions, a mass balance of element $A$ in the free state within compartment $i$ yields (see Equation A.23 in Appendix A):

$$
0=\lambda_{2} V_{i} C_{i}^{1}+\sum_{\frac{j=0}{j \neq i}}^{3} Q_{j i} C_{j}^{2 f r}-C_{i}^{2 f r} \sum_{\frac{j=0}{j \neq i}}^{3} Q_{j i}-\left(\lambda_{2}+\lambda_{a t}+\lambda_{p o}\right) V_{i} C_{i}^{2 f r}
$$

where the terms related to the injection rate and the deposition-resuspension are neglected. Equation C.18 can be rewritten in the appropriate format to be used in the indoor air quality model as:

$$
\left[\left(\lambda_{2}+\lambda_{a t}+\lambda_{p o}\right) V_{i}+\sum_{\substack{j=0 \\ j \neq i}}^{3} Q_{j i}\right] C_{i}^{2 f r}-\sum_{\frac{j=0}{j \neq i}}^{3} Q_{j i} C_{j}^{2 f r}=\lambda_{2} V_{i} C_{i}^{1}
$$




\section{C.2.1.2 Mass Balance of Element A (Attached State)}

A mass balance of element $A$ in the attached state within compartment $i$ yields:

$$
\begin{aligned}
0 & =\lambda_{a t} V_{i} C_{i}^{2 f r}+\sum_{\frac{j=0}{j \neq i}}^{3} Q_{j i} C_{j}^{2 a t}-C_{i}^{2 a t} \sum_{\frac{j=0}{j \neq i}}^{3} Q_{j i}-\lambda_{2} V_{i} C_{i}^{2 a t}-\lambda_{d i} V_{i} C_{i}^{2 a t} \\
& +\left(\frac{\lambda_{R} \lambda_{d i}}{\lambda_{2}+\lambda_{R}}\right) V_{i} C_{i}^{2 a t}
\end{aligned}
$$

or

$$
\left\{\left[\lambda_{2}+\lambda_{d i}\left(1-\frac{\lambda_{R}}{\lambda_{2}+\lambda_{R}}\right)\right] V_{i}+\sum_{\frac{j=0}{j \neq i}}^{3} Q_{j i}\right\} C_{i}^{2 a t}-\sum_{\substack{j=0 \\ j \neq i}}^{3} Q_{j i} C_{j}^{2 a t}=\lambda_{a t} V_{i} C_{i}^{2 f r}
$$

\section{C.2.1.3 Mass Balance of Element A (Plated-Out State)}

A mass balance of element $A$ in the plated-out state within compartment $i$ yields:

$$
0=\lambda_{p o} V_{i} C_{i}^{2 f r}-\lambda_{2} V_{i} C_{i}^{2 p o},
$$

or

$$
C_{i}^{2 p o}=\left(\frac{\lambda_{p o}}{\lambda_{2}}\right) C_{i}^{2 f r}
$$

\section{C.2.1.4 Mass Balance of Element $B$ (Free State)}

A mass balance of element $B$ in the free state within compartment $i$ yields:

$$
\begin{aligned}
0 & =\lambda_{3} V_{i} C_{i}^{2 f r}+P_{a t} \lambda_{3} V_{i} C_{i}^{2 a t}+P_{p o} \lambda_{3} V_{i} C_{i}^{2 p o}+\sum_{\frac{j=0}{j \neq i}}^{3} Q_{j i} C_{j}^{3 f r} \\
& -C_{i}^{3 f r} \sum_{\frac{j=0}{j \neq i}}^{3} Q_{j i}-\left(\lambda_{3}+\lambda_{a t}+\lambda_{p o}\right) V_{i} C_{i}^{3 f r}
\end{aligned}
$$


or

$$
\begin{aligned}
& {\left[\left(\lambda_{3}+\lambda_{a t}+\lambda_{p o}\right) V_{i}+\sum_{\frac{j=0}{j \neq i}}^{3} Q_{j i}\right] C_{i}^{3 f r}-\sum_{\frac{j=0}{j \neq i}}^{3} Q_{j i} C_{j}^{3 f r}} \\
& =\lambda_{3} V_{i} C_{i}^{2 f r}+P_{a t} \lambda_{3} V_{i} C_{i}^{2 a t}+P_{p o} \lambda_{3} V_{i} C_{i}^{2 p o} .
\end{aligned}
$$

\section{C.2.1.5 Mass Balance of Element $B$ (Attached State)}

A mass balance of element $B$ in the attached state within compartment $i$ yields:

$$
\begin{aligned}
0 & =\left(1-P_{a t}\right) \lambda_{3} V_{i} C_{i}^{2 a t}+\lambda_{a t} V_{i} C_{i}^{3 f r}+\sum_{\frac{j=0}{j \neq i}}^{3} Q_{j i} C_{j}^{3 a t}-C_{i}^{3 a t} \sum_{\frac{j=0}{j \neq i}}^{3} Q_{j i}-\lambda_{3} V_{i} C_{i}^{3 a t} \\
& -\lambda_{d i} V_{i} C_{i}^{3 a t}+\left(\frac{\lambda_{R} \lambda_{d i}}{\lambda_{3}+\lambda_{R}}\right) V_{i} C_{i}^{3 a t},
\end{aligned}
$$

or

$$
\begin{gathered}
\left\{\left[\lambda_{3}+\lambda_{d i}\left(1-\frac{\lambda_{R}}{\lambda_{3}+\lambda_{R}}\right)\right] V_{i}+\sum_{\frac{j=0}{j \neq i}}^{3} Q_{j i}\right\} C_{i}^{3 a t}-\sum_{\frac{j=0}{j \neq i}}^{3} Q_{j i} C_{j}^{3 a t} \\
=\left(1-P_{a t}\right) \lambda_{3} V_{i} C_{i}^{2 a t}+\lambda_{a t} V_{i} C_{i}^{3 f r}
\end{gathered}
$$

\section{C.2.1.6 Mass Balance of Element $C$ (Free State)}

A mass balance of element $C$ in the free state within compartment $i$ yields:

$$
0=\lambda_{4} V_{i} C_{i}^{3 f r}+\sum_{\substack{j=0 \\ j \neq i}}^{3} Q_{j i} C_{j}^{4 f r}-C_{i}^{4 f r} \sum_{\substack{j \neq i \\ j \neq i}}^{3} Q_{j i}-\left(\lambda_{4}+\lambda_{a t}+\lambda_{p o}\right) V_{i} C_{i}^{4 f r}
$$

or

$$
\left[\left(\lambda_{4}+\lambda_{a t}+\lambda_{p o}\right) V_{i}+\sum_{\frac{j=0}{j \neq i}}^{3} Q_{j i}\right] C_{i}^{4 f r}-\sum_{\frac{j=0}{j \neq i}}^{3} Q_{j i} C_{j}^{4 f r}=\lambda_{4} V_{i} C_{i}^{3 f r}
$$




\section{C.2.1.7 Mass Balance of Element $C$ (Attached State)}

A mass balance of element $C$ in the attached state within compartment $i$ yields:

$$
\begin{gathered}
0=\lambda_{4} V_{i} C_{i}^{3 a t}+\lambda_{a t} V_{i} C_{i}^{4 f r}+\sum_{\frac{j=0}{j \neq i}}^{3} Q_{j i} C_{j}^{4 a t}-C_{i}^{4 a t} \sum_{\frac{j=0}{j \neq i}}^{3} Q_{j i} \\
-\lambda_{4} V_{i} C_{i}^{4 a t}-\lambda_{d i} V_{i} C_{i}^{4 a t} \cdot\left(\frac{\lambda_{R} \lambda_{d i}}{\lambda_{4}+\lambda_{R}}\right) V_{i} C_{i}^{4 a t}
\end{gathered}
$$

or

$$
\begin{gathered}
\left\{\left[\lambda_{4}+\lambda_{d i}\left(1-\frac{\lambda_{R}}{\lambda_{4}+\lambda_{R}}\right)\right] V_{i}+\sum_{\frac{j=0}{j \neq i}}^{3} Q_{j i}\right\} C_{i}^{4 a t}-\sum_{\frac{j=0}{j \neq i}}^{3} Q_{j i} C_{j}^{4 a t} \\
=\lambda_{4} V_{i} C_{i}^{3 a t}+\lambda_{a t} V_{i} C_{i}^{4 f r} .
\end{gathered}
$$

\section{C.3 WORKING LEVEL}

Calculation of the $W L_{i}$ value associated with different radon isotopes follows a different formulation depending on the radionuclide being considered. Thus, the $W L_{i}$ value in the compartment $i$ for an indoor atmosphere containing a mixture of radon (radon-222) progeny can be evaluated as:

$$
W L_{i}^{\mathrm{Rn}-222}=\left(1.03 \times 10^{-6}\right) C_{i}^{2}+\left(5.07 \times 10^{-6}\right) C_{i}^{3}+\left(3.73 \times 10^{-6}\right) C_{i}^{4},
$$

where $C^{2}{ }_{i}, C^{3}{ }_{i}$, and $C^{4}{ }_{i}$ are the concentrations of polonium-218, lead-214, and bismuth-214, respectively, in the indoor air of compartment $i\left(\mathrm{pCi} / \mathrm{m}^{3}\right)$. Similarly, for thoron (radon-220), the $W L_{i}$ value is evaluated as:

$$
W L_{i}^{\mathrm{Rn}-220}=\left(9.48 \times 10^{-10}\right) C_{i}{ }^{2}+\left(1.23 \times 10^{-4}\right){C_{i}}^{3}+\left(1.17 \times 10^{-5}\right) C_{i}{ }^{4},
$$

where $C_{i}^{\prime 2}, C_{i}^{\prime 3}$, and $C_{i}^{\prime 4}$ are the concentrations of polonium-216, lead-212, and bismuth-212, respectively, in the indoor air of compartment $i\left(\mathrm{pCi} / \mathrm{m}^{3}\right)$. 


\section{C.4 WORKING LEVEL MONTH}

The normalized exposure to the radon progeny concentration is measured in units of working level month (WLM), which for each compartment $i$ can be calculated as:

$$
W L M_{i}=\left(\frac{8,760}{170}\right) F_{i n} F_{i} W L_{i}
$$

where

$$
\begin{aligned}
8,760 & =\text { number of hours per year }(\mathrm{h} / \mathrm{yr}), \text { and } \\
170 & =\text { number of working hours per month }(\mathrm{h}) .
\end{aligned}
$$

The fractions of time in Equation C.34 are defined in Section C.2. The indoor time fraction $F_{\text {in }}$ and the outdoor time fraction $F_{\text {out }}$ should sum up to 1 . That is:

$$
F_{\text {in }}+F_{\text {out }}=1.0
$$

The time fraction in compartment $i, F_{i}$, can be less than, equal to, or greater than 1 in the RESRAD-BUILD code. When $F_{i}$ is greater than 1 , it can be used to calculate collective dose.

The total exposure to the indoor airborne radon decay products is then evaluated by summing Equation C.34 from all three compartments. That is:

$$
W L M=\sum_{i=1}^{3} W L M_{i}=\left(\frac{8,760}{170}\right) F_{i n} \sum_{i=1}^{3}\left(F_{i} W L_{i}\right) .
$$

Note that Equations C. 34 and C.36 can be used for calculating the $W L M$ from exposure to either radon-222 or radon-220 progenies.

\section{C.5 RADON PROGENY DOSIMETRY}

The effective dose equivalent due to the exposure to radon decay products in the indoor air of each compartment $i$ can be evaluated as:

$$
D_{i}=K W L M_{i} D C F,
$$


where

$$
\begin{aligned}
D_{i}= & \text { effective dose equivalent due to exposure to radon decay products } \\
& \text { (from either radon-222 or radon-220) in compartment } i \text { (mrem/yr); } \\
D C F= & \text { dose conversion factor for the inhalation of radon decay products } \\
& (\text { mrem } / W L M) ; \text { and } \\
K= & \text { multiplication factor to account for the extrapolation of doses from } \\
& \text { uranium mines to homes. }
\end{aligned}
$$

For the radon-222 decay products, the values of the $D C F$ and the $K$ factor are equal to 1,000 (mrem/WLM) and 0.76 (dimensionless), respectively. Similarly, for the radon-220 decay products, the values of the $D C F$ and the $K$ factor are equal to $350(\mathrm{mrem} / W L M)$ and 0.42 (dimensionless), respectively.

The total effective dose equivalent resulting from the inhalation of airborne radon decay products is then given by summing the contribution from the occupancy of each compartment of the building. That is:

$$
D=\sum_{i=1}^{3} D_{i}=K W L M D C F
$$

If both radon-222 and radon-220 progenies are present in the indoor air, the final calculated effective dose equivalent should be the sum of the contribution from each decay series. That is:

$$
D_{\text {total }}=D_{\mathrm{Rn}-222}+D_{\mathrm{Rn}-220}
$$

\section{C.6 REFERENCES}

Bruno, R.C., 1983, "Verifying a Model of Radon Decay Product Behavior Indoors," Health Physics 45:471.

Jacobi, W., 1972, "Activity and Potential Alpha Plan Energy of Radon 222 and Radon 220 Daughters in Different Air Atmosphere," Health Physics 22:331. 
Porstendörfer, J., 1983, "Behavior of Radon Daughter Products in Indoor Air," Radiation Protection Dosimetry 7:107.

Yu, C., et al., Manual for Implementing Residual Radioactive Material Guidelines Using RESRAD, Version 5.0, ANL/EAD/LD-2, prepared by Argonne National Laboratory, Argonne, Ill., for the U.S. Department of Energy, Sept. 


\section{APPENDIX D:}

\section{INHALATION OF AIRBORNE RADIOACTIVE DUST}


D-2 


\section{APPENDIX D: \\ INHALATION OF AIRBORNE RADIOACTIVE DUST}

\section{D.1 DUST RELEASE RATE}

The inhalation pathway can be included in the building contamination model by performing three sets of calculations:

- The mechanical removal of material from the source and the rate of release of radionuclides into the indoor air of each compartment,

- The indoor airborne concentration of the radionuclides released into the air (using the indoor air quality model), and

- The inhalation of airborne radioactive dust and the associated effective dose equivalent.

For a volume source, the release rate of a principal radionuclide $n$ into the compartment $i$ is calculated by:

$$
I_{S i}^{n}=\frac{f E A_{s} \rho_{b s} C_{s}^{n}}{8,760}
$$

where

$$
\begin{aligned}
I_{S i}^{n}= & \text { injection rate of radionuclide } n \text { into the indoor air of compartment } \\
& i(\mathrm{pCi} / \mathrm{h}) ; \\
f= & \text { fraction of mechanically removed or eroded material that becomes } \\
& \text { indoor dust; } \\
E= & \text { source removal or erosion rate }(\mathrm{m} / \mathrm{yr}) ; \\
A_{s}= & \text { effective surface area of the source }\left(\mathrm{m}^{2}\right) ; \\
P_{b s}= & \text { bulk density of the source material }\left(\mathrm{kg} / \mathrm{m}^{3}\right) ; \\
C_{s}^{n}= & \text { radionuclide concentration in the source material }(\mathrm{pCi} / \mathrm{kg}) ; \text { and } \\
8,760= & \text { time conversion factor (number of hours per year) }(\mathrm{h} / \mathrm{yr}) .
\end{aligned}
$$


For surface, line, and point sources, the release rate of a principal radionuclide $n$ into the compartment $i$ is calculated by:

$$
\begin{array}{ll}
I_{S i}^{n}= & t<T_{R} \\
0 & t \geq T_{R},
\end{array}
$$

where

$$
\begin{aligned}
f_{R} & =\text { removable fraction of the source material; } \\
f & =\text { fraction of removed material that becomes indoor dust; } \\
T_{R} & =\text { time to remove material from the source }(\mathrm{d}) ; \\
Q_{s}^{n} & =\text { total radionuclide activity in the source (pCi); and } \\
24 & =\text { time conversion factor (number of hours per day) }(\mathrm{h} / \mathrm{d})
\end{aligned}
$$

The indoor air concentration, $C^{n}{ }_{i}$, of each principal radionuclide $n$ at each compartment $i$ of the building is calculated by using the indoor air quality model discussed in Appendix A.

\section{D.2 INHALATION DOSE}

The committed effective dose equivalent $D^{n}{ }_{i h}$, due to the inhalation of radionuclide $n$ in the indoor air of compartment $i$, can be calculated by the following equation:

$$
D_{i h}^{n}=\left(365 F_{i n} F_{i}\right) \operatorname{IR} C_{i}^{n} D C F_{h}^{n},
$$

where

$$
\begin{aligned}
D_{i h}^{n}= & \text { effective dose equivalent due to inhalation of radionuclide } n \text { in } \\
& \text { compartment } i(\mathrm{mrem} / \mathrm{yr}) ; \\
365= & \text { time conversion factor (number of days per year) }(\mathrm{d} / \mathrm{yr}) ; \\
F_{i n}= & \text { fraction of time spent indoors (dimensionless); }
\end{aligned}
$$




$$
\begin{aligned}
F_{i}= & \text { fraction of indoor time that is spent at compartment } i \\
& \text { (dimensionless); } \\
I R= & \text { inhalation rate }\left(\mathrm{m}^{3} / \mathrm{d}\right) ; \\
C^{n}= & \text { concentration of radionuclide } n \text { in the indoor air of compartment } \\
& i\left(\mathrm{pCi} / \mathrm{m}^{3}\right) ; \text { and } \\
D C F_{h}^{n}= & \text { inhalation dose conversion factor for radionuclide } n(\mathrm{mrem} / \mathrm{pCi}) .
\end{aligned}
$$

The dose conversion factor $D C F_{h}^{n}$ is discussed in Section D.3.

The total dose from full occupancy of the building is evaluated as a sum of the dose at each compartment $i$. That is:

$$
D_{t h}^{n}=\sum_{i=1}^{3}\left(D_{i h}^{n}\right)=\left(365 F_{i n} I R D C F_{h}^{n}\right) \sum_{i=1}^{3}\left(F_{i} C_{i}^{n}\right) .
$$

\section{D.3 DOSE CONVERSION FACTORS}

The default inhalation dose conversion factors used in the RESRAD-BUILD code are the same as those used in the RESRAD code (Yu et al. 1993). Values of dose conversion factors for inhalation were taken from a U.S. Department of Energy (1988) report and are listed in Table D.1. Similar values are given in a U.S. Environmental Protection Agency report (Eckerman et al. 1988). The values listed in Table D.1 are for dust particles with an activity median aerodynamic diameter (AMAD) of $1 \mu \mathrm{m}$. Values for different inhalation classes are also listed in Table D.1. The inhalation class for inhaled radioactive material is defined according to the material's rate of clearance from the lung. The three inhalation classes $\mathrm{D}, \mathrm{W}$, and $\mathrm{Y}$ correspond to retention half-times of less than 10 days, 10 to 100 days, and greater than 100 days, respectively. If the inhalation class for a radionuclide is not known, the largest dose conversion factor for that radionuclide should be used. The default value for a radionuclide used in the RESRAD-BUILD code is the largest dose conversion 
TABLE D.1 Committed Effective Dose Equivalent Conversion Factors $\left(D C F^{n}{ }_{h}\right)$ for Inhalation ${ }^{a}$

\begin{tabular}{|c|c|c|c|c|c|}
\hline Radionuclide $^{b}$ & $\begin{array}{l}\text { Inhalation } \\
\text { Class }\end{array}$ & $\begin{array}{c}D C F^{n}{ }_{h} \\
\text { (mrem/pCi) }\end{array}$ & Radionuclide $^{\mathrm{b}}$ & $\begin{array}{l}\text { Inhalation } \\
\text { Class }\end{array}$ & $\begin{array}{c}D C F^{n}{ }^{h} \\
(\mathrm{mrem} / \mathrm{p} \mathrm{Ci})\end{array}$ \\
\hline $\mathrm{H}-3$ & $\left(\mathrm{H}_{2} \mathrm{O}\right)^{\mathrm{c}}$ & $6.3 \times 10^{-8}$ & Cs-137+D & $\mathrm{D}$ & $3.2 \times 10^{-5}$ \\
\hline \multirow[t]{3}{*}{ C-14 } & $(\text { organic })^{\mathrm{c}}$ & $2.1 \times 10^{-6}$ & $\mathrm{Ce}-144+\mathrm{D}$ & W & $1.9 \times 10^{-4}$ \\
\hline & $(\mathrm{CO})^{\mathrm{c}}$ & $2.9 \times 10^{-9}$ & & $\mathrm{Y}$ & $3.5 \times 10^{-4}$ \\
\hline & $\left(\mathrm{CO}_{2}\right)^{\mathrm{c}}$ & $2.4 \times 10^{-8}$ & $\mathrm{Pm}-147$ & $\mathrm{~W}$ & $2.5 \times 10^{-5}$ \\
\hline $\mathrm{Na}-22$ & $\mathrm{D}^{\mathrm{d}^{2}}$ & $8.0 \times 10^{-6}$ & & $\mathrm{Y}$ & $3.4 \times 10^{-5}$ \\
\hline \multirow[t]{2}{*}{$\mathrm{Al}-26$} & $\mathrm{D}$ & $7.9 \times 10^{-5}$ & Sm-147 & W & $7.1 \times 10^{-2}$ \\
\hline & $\mathrm{W}$ & $5.9 \times 10^{-5}$ & $\mathrm{Sm}-151$ & $\mathrm{~W}$ & $2.9 \times 10^{-5}$ \\
\hline \multirow[t]{2}{*}{ Cl-36 } & $\mathrm{D}$ & $2.1 \times 10^{-6}$ & Eu-152 & $\mathrm{W}$ & $2.2 \times 10^{-4}$ \\
\hline & $\mathrm{W}$ & $2.0 \times 10^{-5}$ & Eu-154 & W & $2.6 \times 10^{-4}$ \\
\hline $\mathrm{K}-40$ & $\mathrm{D}$ & $1.2 \times 10^{-5}$ & Eu-155 & $\mathrm{W}$ & $3.9 \times 10^{-5}$ \\
\hline $\mathrm{Ca}-41$ & $\mathrm{~W}$ & $1.3 \times 10^{-6}$ & Gd-152 & $\mathrm{D}$ & $2.4 \times 10^{-1}$ \\
\hline \multirow[t]{2}{*}{$M n-54$} & $\mathrm{D}$ & $5.4 \times 10^{-6}$ & Gd-152 & $\mathrm{W}$ & $61 \times 10^{-2}$ \\
\hline & $\mathrm{W}$ & $6.4 \times 10^{-6}$ & Gd-153 & $\mathrm{D}$ & $2.1 \times 10^{-5}$ \\
\hline \multirow[t]{2}{*}{$\mathrm{Fe}-55$} & $\mathrm{D}$ & $2.6 \times 10^{-6}$ & & $\mathrm{~W}$ & $8.4 \times 10^{-6}$ \\
\hline & $\mathrm{W}$ & $1.2 \times 10^{-6}$ & $\mathrm{Au}-195$ & D & $1.1 \times 10^{-6}$ \\
\hline \multirow[t]{2}{*}{$\mathrm{Co}-57$} & $\mathrm{~W}$ & $1.8 \times 10^{-6}$ & & $\mathrm{~W}$ & $3.5 \times 10^{-6}$ \\
\hline & $\mathrm{Y}$ & $7.5 \times 10^{-6}$ & & $\mathrm{Y}$ & $1.2 \times 10^{-5}$ \\
\hline \multirow[t]{2}{*}{$\mathrm{Co}-60$} & $\mathrm{~W}$ & $3.0 \times 10^{-5}$ & Tl-204 & $\mathrm{D}$ & $2.3 \times 10^{-6}$ \\
\hline & $\mathrm{Y}$ & $1.5 \times 10^{-4}$ & $\mathrm{~Pb}-210$ & $\mathrm{D}$ & $2.1 \times 10^{-2}$ \\
\hline \multirow[t]{3}{*}{ Ni-59 } & $\mathrm{D}$ & $1.3 \times 10^{-6}$ & $\mathrm{Bi}-207$ & $\mathrm{D}$ & $2.9 \times 10^{-6}$ \\
\hline & $\mathrm{W}$ & $7.0 \times 10^{-7}$ & & W & $1.4 \times 10^{-5}$ \\
\hline & $(\text { vapor })^{c}$ & $2.7 \times 10^{-6}$ & $\mathrm{Ra}-226+\mathrm{D}$ & W & $7.9 \times 10^{-3}$ \\
\hline \multirow[t]{3}{*}{ Ni-63 } & $\mathrm{D}$ & $3.0 \times 10^{-6}$ & $\mathrm{Ra}-228+\mathrm{D}$ & $W$ & $4.5 \times 10^{-3}$ \\
\hline & $\mathrm{W}$ & $1.9 \times 10^{-6}$ & $\mathrm{Ac}-227+\mathrm{D}$ & $\mathrm{D}$ & 6.7 \\
\hline & $(\text { vapor })^{c}$ & $6.3 \times 10^{-6}$ & & W & 1.7 \\
\hline $\mathrm{Zn}-65$ & $\mathrm{Y}$ & $1.8 \times 10^{-5}$ & & $\mathrm{Y}$ & 1.2 \\
\hline \multirow[t]{2}{*}{$\mathrm{Ge}-68+\mathrm{D}$} & D & $1.4 \times 10^{-6}$ & Th-228+D & $\mathrm{W}$ & $2.5 \times 10^{-1}$ \\
\hline & W & $4.9 \times 10^{-5}$ & & $\mathrm{Y}$ & $3.1 \times 10^{-1}$ \\
\hline \multirow[t]{2}{*}{ Sr-90+D } & D & $2.3 \times 10^{-4}$ & Th-229+D & W & 2.0 \\
\hline & $\mathrm{Y}$ & $1.3 \times 10^{-3}$ & & $\mathrm{Y}$ & 1.7 \\
\hline \multirow[t]{2}{*}{$\mathrm{Nb}-94$} & W & $2.6 \times 10^{-5}$ & Th-230 & $\mathrm{W}$ & $3.2 \times 10^{-1}$ \\
\hline & $\mathrm{Y}$ & $3.3 \times 10^{-4}$ & & $\mathrm{Y}$ & $2.6 \times 10^{-1}$ \\
\hline \multirow{2}{*}{ Tc-99 } & $\mathrm{D}$ & $8.4 \times 10^{-7}$ & Th-232 & $\mathrm{W}$ & 1.6 \\
\hline & W & $7.5 \times 10^{-6}$ & & $\mathrm{Y}$ & 1.1 \\
\hline \multirow{3}{*}{$\mathrm{Ru}-106+\mathrm{D}$} & $\mathrm{D}$ & $5.7 \times 10^{-5}$ & $\mathrm{~Pa}-231$ & W & 1.3 \\
\hline & W & $9.3 \times 10^{-5}$ & & $\mathrm{Y}$ & $8.6 \times 10^{-1}$ \\
\hline & $\mathrm{Y}$ & $4.4 \times 10^{-4}$ & U-232 & $\mathrm{D}$ & $1.2 \times 10^{-2}$ \\
\hline \multirow[t]{3}{*}{ Ag-108m+D } & $\mathrm{D}$ & $2.8 \times 10^{-5}$ & & W & $1.3 \times 10^{-2}$ \\
\hline & $\mathrm{W}$ & $1.9 \times 10^{-5}$ & & $\mathrm{Y}$ & $6.7 \times 10^{-1}$ \\
\hline & $\mathrm{Y}$ & $2.0 \times 10^{-4}$ & $\mathrm{U}-233$ & $\mathrm{D}$ & $2.7 \times 10^{-3}$ \\
\hline \multirow{3}{*}{$\mathrm{Ag}-110 \mathrm{~m}+\mathrm{D}$} & $\mathrm{D}$ & $3.8 \times 10^{-5}$ & & $\mathrm{~W}$ & $7.1 \times 10^{-3}$ \\
\hline & $\mathrm{W}$ & $2.7 \times 10^{-5}$ & & $\mathrm{Y}$ & $1.3 \times 10^{-1}$ \\
\hline & $\mathrm{Y}$ & $5.3 \times 10^{-5}$ & U-234 & D & $2.7 \times 10^{-3}$ \\
\hline \multirow[t]{3}{*}{ Cd-109 } & $\mathrm{D}$ & $1.0 \times 10^{-4}$ & & $\mathrm{~W}$ & $7.1 \times 10^{-3}$ \\
\hline & $\mathrm{W}$ & $3.6 \times 10^{-5}$ & & $\mathrm{Y}$ & $1.3 \times 10^{-1}$ \\
\hline & $\mathrm{Y}$ & $4.2 \times 10^{-5}$ & $\mathrm{U}-235+\mathrm{D}$ & $\mathrm{D}$ & $2.5 \times 10^{-3}$ \\
\hline \multirow[t]{2}{*}{ Sb-125 } & $\mathrm{D}$ & $3.2 \times 10^{-6}$ & & W & $6.7 \times 10^{-3}$ \\
\hline & $\mathrm{W}$ & $1.1 \times 10^{-5}$ & & $\mathrm{Y}$ & $1.2 \times 10^{-1}$ \\
\hline $\mathrm{I}-129$ & $\mathrm{D}$ & $1.8 \times 10^{-4}$ & $\mathrm{U}-236$ & $\mathrm{D}$ & $2.5 \times 10^{-3}$ \\
\hline Cs-134 & $\mathrm{D}$ & $4.7 \times 10^{-5}$ & & $\mathrm{~W}$ & $6.7 \times 10^{-3}$ \\
\hline $\mathrm{Cs}-135$ & $\mathrm{D}$ & $4.5 \times 10^{-6}$ & & $\mathrm{Y}$ & $1.2 \times 10^{-1}$ \\
\hline
\end{tabular}


TABLE D.1 (Cont.)

\begin{tabular}{|c|c|c|c|c|c|}
\hline Radionuclide $^{\mathbf{b}}$ & $\begin{array}{l}\text { Inhalation } \\
\text { Class }\end{array}$ & $\begin{array}{c}D C F^{n}{ }_{h} \\
(\mathrm{mrem} / \mathrm{pCi})\end{array}$ & Radionuclide $^{b}$ & $\begin{array}{c}\text { Inhalation } \\
\text { Class }\end{array}$ & $\underset{(\mathrm{mrem} / \mathrm{pCi})}{D C F^{n}}$ \\
\hline \multirow[t]{3}{*}{$U-238+D$} & D & $2.4 \times 10^{-3}$ & Pu-242 & $\mathrm{W}$ & $4.8 \times 10^{-1}$ \\
\hline & W & $6.2 \times 10^{-3}$ & & $\mathrm{Y}$ & $3.1 \times 10^{-1}$ \\
\hline & $\mathrm{Y}$ & $1.2 \times 10^{-1}$ & $\mathrm{Pu}-244+\mathrm{D}$ & $\mathrm{W}$ & $4.8 \times 10^{-1}$ \\
\hline $\mathrm{Np}-237+\mathrm{D}$ & W & $4.9 \times 10^{-1}$ & & $\mathrm{Y}$ & $3.1 \times 10^{-1}$ \\
\hline \multirow{2}{*}{ Pu-238 } & $\mathrm{W}$ & $4.6 \times 10^{-1}$ & Am-241 & $\mathrm{W}$ & $5.2 \times 10^{-1}$ \\
\hline & $\mathrm{Y}$ & $3.0 \times 10^{-1}$ & $\mathrm{Am}-243+\mathrm{D}$ & $\mathrm{W}$ & $5.2 \times 10^{-1}$ \\
\hline \multirow{2}{*}{$\mathrm{Pu}-239$} & W & $5.1 \times 10^{-1}$ & $\mathrm{Cm}-243$ & W & $3.5 \times 10^{-1}$ \\
\hline & $\mathrm{Y}$ & $3.3 \times 10^{-1}$ & $\mathrm{Cm}-244$ & W & $2.7 \times 10^{-1}$ \\
\hline \multirow{2}{*}{$\mathrm{Pu}-240$} & W & $5.1 \times 10^{-1}$ & $\mathrm{Cm}-248$ & W & 1.9 \\
\hline & $\mathrm{Y}$ & $3.3 \times 10^{-1}$ & Cf-252 & $\mathrm{W}$ & $1.2 \times 10^{-1}$ \\
\hline $\mathrm{Pu}-241+\mathrm{D}$ & $\bar{W}$ & $1.0 \times 10^{-2}$ & & $\mathrm{Y}$ & $1.3 \times 10^{-1}$ \\
\hline $\mathrm{Pu}-241+\mathrm{D}$ & $\mathrm{Y}$ & $5.7 \times 10^{-3}$ & & & \\
\hline
\end{tabular}

a Inhalation factors are for an AMAD of $1 \mu \mathrm{m}$.

b Dose conversion factors for entries labeled by " $+\mathrm{D}$ " are aggregated dose conversion factors for intake of a radionuclide together with radionuclides of the associated decay chain in secular equilibrium.

c Gaseous material.

d The three inhalation classes D, W, and Y correspond to retention half-times of less than 10 days, 10 to 100 days, and greater than 100 days, respectively.

factor for that radionuclide. If a different value of $D C F^{n}{ }_{h}$ is needed, it can be modified by choosing the "Modify Library" option from the RESRAD-BUILD main menu.

\section{D.4 REFERENCES}

Eckerman, K.F., et al., 1988, Limiting Values of Radionuclide Intake and Air Concentration and Dose Conversion Factors for Inhalation, Submersion, and Ingestion, EPA-520/1-88-020, Federal Guidance Report No. 11, prepared by Oak Ridge National Laboratory, Oak Ridge, Tenn., for U.S. Environmental Protection Agency, Office of Radiation Programs, Washington, D.C.

U.S. Department of Energy, 1988, Internal Dose Conversion Factors for Calculation of Dose to the Public, DOE/EH-0071, Assistant Secretary for Environment, Safety and Health, Washington, D.C. 
Yu, C., et al., 1993, Manual for Implementing Residual Radioactive Material Guidelines Using

RESRAD, Version 5.0, Working Draft for Comment, ANL/EAD/LD-2, Argonne National Laboratory, Argonne, Ill., Sept. 
$E-1$

APPENDIX E:

INGESTION OF RADIOACTIVE MATERIAL 
E-2 


\section{APPENDIX E:}

\section{INGESTION OF RADIOACTIVE MATERIAL}

The ingestion pathway considered in the RESRAD-BUILD code includes (1) inadvertent ingestion of removable (loose) material directly from the source and (2) inadvertent ingestion of radioactive dust particulates deposited onto surfaces or food within the compartments of the building.

\section{E.1 DIRECT INGESTION OF REMOVABLE MATERIAL}

The component of the effective dose equivalent, $D^{n}{ }_{l}$, due to the ingestion of loose material directly from the source in compartment $i$ containing radionuclide $n$, can be calculated by the following equations. For volume sources:

$$
D_{i l}^{n}=\left(8,760 F_{i n} F_{i}\right) E R C_{s}^{n} D C F_{g}^{n},
$$

where

$$
\begin{aligned}
D_{i l}^{n}= & \text { component of the effective dose equivalent, due to ingestion of } \\
& \text { loose }(l) \text { material directly from the source containing radionuclide } \\
& n \text { in compartment } i(\mathrm{mrem} / \mathrm{yr}) ; \\
8,760= & \text { time conversion factor (number of hours per year) }(\mathrm{h} / \mathrm{yr}) ; \\
F_{i n}= & \text { fraction of time spent indoors (dimensionless); } \\
F_{i}= & \text { fraction of indoor time spent at compartment } i \text { (dimensionless); } \\
E R= & \text { ingestion rate of loose material directly from the source }(\mathrm{g} / \mathrm{h}) ; \\
C^{n}= & \text { concentration of radionuclide } n \text { in the source material }(\mathrm{pCi} / \mathrm{g}) ; \\
& \text { and } \\
D C F_{g}^{n}= & \text { ingestion dose conversion factor related to radionuclide } n \\
& (\text { mrem } / \mathrm{pCi}) .
\end{aligned}
$$


For surface, line, and point sources, the dose due to ingestion of loose material can be calculated as:

$$
D_{i l}^{n}=\left(8,760 F_{i n} F_{i}\right) E R_{l} F_{R} Q_{s}^{n} D C F_{g}^{n} \text {, }
$$

where

$$
\begin{aligned}
F_{R}= & \text { removable fraction of the source material; } \\
E R_{l}= & \text { ingestion rate of loose material directly from the source as a fraction } \\
& \text { of the source per unit time }(1 / \mathrm{h}) ; \text { and } \\
Q^{n}= & \text { total radionuclide activity in the source }(\mathrm{pCi}) .
\end{aligned}
$$

\section{E.2 INGESTION OF DEPOSITED RADIOACTIVE DUST}

The component of the effective dose equivalent, $D^{n}{ }_{i d}$, due to the ingestion of radioactive dust particulates deposited onto surfaces of compartment $i$ containing radionuclide $n$, can be given by the following equation:

$$
D_{i d}^{n}=\left(8,760 F_{i n} F_{i}\right) S E R C_{d i}^{n} D C F_{g}^{n},
$$

where

$$
\begin{aligned}
D_{i d}^{n}= & \text { component of the effective dose equivalent, due to ingestion of } \\
& \text { deposited dust particulates containing radionuclide } n \text { in } \\
& \text { compartment } i(\mathrm{mrem} / \mathrm{yr}) ; \\
8,760= & \text { time conversion factor (number of hours per year) }(\mathrm{h} / \mathrm{yr}) ; \\
F_{i n}= & \text { fraction of time spent indoors (dimensionless); } \\
F_{i}= & \text { fraction of indoor time spent at compartment } i \text { (dimensionless); } \\
S E R= & \text { surface ingestion rate or the ingestion rate of dust particulates } \\
& \text { deposited onto horizontal surfaces }\left(\mathrm{m}^{2} / \mathrm{h}\right) ; \\
C_{d i}^{n}= & \text { surface concentration of radionuclide } n, \text { deposited onto horizontal } \\
& \text { surfaces of compartment } i\left(\mathrm{pCi} / \mathrm{m}^{2}\right) ; \text { and }
\end{aligned}
$$


$D C F_{g}^{n}=$ ingestion dose conversion factor for radionuclide $n(\mathrm{mrem} / \mathrm{pCi})$.

The total ingestion dose, $\mathrm{D}_{i}^{n}$, is evaluated as a sum of the dose contribution from both components listed above.

\section{E.3 DOSE CONVERSION FACTORS}

The default ingestion dose conversion factors used in the RESRAD-BUILD code are the same as those used in the RESRAD code ( $\mathrm{Yu}$ et al. 1993). Values of dose conversion factors for ingestion were taken from a U.S. Department of Energy (1988) report and are tabulated in Table E.1. Similar values are given in a U.S. Environmental Protection Agency report (Eckerman et al. 1988). Dose conversion factors depend on the chemical form, which determines the fraction $f_{1}$ of a radionuclide entering the gastrointestinal (GI) tract that reaches body fluids. Data on the appropriate fractions for different chemical forms are given in Publication 30 of the International Commission on Radiological Protection (ICRP) (ICRP 1979-1982). The dose conversion factors used in RESRAD-BUILD are the values corresponding to the largest values of $f_{1}$ in Table E.1. If the chemical form of a radionuclide is known and a different value of $D C F^{n}$ is needed, it can be modified by choosing the "Modify Library" option from the RESRAD-BUILD main menu. 
TABLE E.1 Committed Effective Dose Equivalent Conversion Factors $\left(D C F^{n}{ }_{g}\right)$ for Internal Radiation from Ingestion

\begin{tabular}{|c|c|c|c|c|c|}
\hline Radionuclide $^{a}$ & $f_{1}^{\mathrm{b}}$ & $\begin{array}{c}D C F^{n} \\
\left(\mathrm{mrem} / \mathrm{p}^{\mathrm{Ci}}\right) \\
\end{array}$ & Radionuclide $^{a}$ & $f_{1}^{\mathrm{b}}$ & $\begin{array}{c}\left.D C F^{n}{ }_{(\mathrm{mrem}} / \mathrm{p}^{\mathrm{C}} \mathrm{i}\right) \\
\text { (m) }\end{array}$ \\
\hline H-3 & 1.0 & $6.3 \times 10^{-8}$ & $\mathrm{~Pb}-210+\mathrm{D}$ & $2 \times 10^{-1}$ & $6.7 \times 10^{-3}$ \\
\hline C-14 & 1.0 & $2.1 \times 10^{-6}$ & Bi-207 & $5 \times 10^{-2}$ & $4.9 \times 10^{-6}$ \\
\hline $\mathrm{Na}-22$ & 1.0 & $1.2 \times 10^{-5}$ & $\mathrm{Ra}-226+\mathrm{D}$ & $2 \times 10^{-1}$ & $1.1 \times 10^{-3}$ \\
\hline $\mathrm{Al}-26$ & $1 \times 10^{-2}$ & $1.3 \times 10^{-5}$ & $\mathrm{Ra}-228+\mathrm{D}$ & $2 \times 10^{-1}$ & $1.2 \times 10^{-3}$ \\
\hline $\mathrm{Cl}-36$ & 1.0 & $3.0 \times 10^{-6}$ & $\mathrm{Ac}-227+\mathrm{D}$ & $1 \times 10^{-3}$ & $1.5 \times 10^{-2}$ \\
\hline $\mathrm{K}-40$ & 1.0 & $1.9 \times 10^{-5}$ & Th-228+D & $2 \times 10^{-4}$ & $7.5 \times 10^{-4}$ \\
\hline $\mathrm{Ca}-41$ & $3 \times 10^{-1}$ & $1.2 \times 10^{-6}$ & Th-229+D & $2 \times 10^{-4}$ & $4.3 \times 10^{-3}$ \\
\hline $\mathrm{Mn}-54$ & $1 \times 10^{-1}$ & $2.7 \times 10^{-6}$ & Th-230 & $2 \times 10^{-4}$ & $5.3 \times 10^{-4}$ \\
\hline $\mathrm{Fe}-55$ & $1 \times 10^{-1}$ & $5.8 \times 10^{-7}$ & Th-232 & $2 \times 10^{-4}$ & $2.8 \times 10^{-3}$ \\
\hline \multirow[t]{2}{*}{$\mathrm{Co}-57$} & $3 \times 10^{-1}$ & $1.1 \times 10^{-6}$ & $\mathrm{~Pa}-231$ & $1 \times 10^{-3}$ & $1.1 \times 10^{-2}$ \\
\hline & $5 \times 10^{-2}$ & $6.8 \times 10^{-7}$ & U-232 & $5 \times 10^{-2}$ & $1.3 \times 10^{-3}$ \\
\hline \multirow[t]{2}{*}{$\mathrm{Co}-60$} & $3 \times 10^{-1}$ & $2.6 \times 10^{-5}$ & & $2 \times 10^{-3}$ & $6.8 \times 10^{-5}$ \\
\hline & $5 \times 10^{-2}$ & $1.0 \times 10^{-5}$ & U-233 & $5 \times 10^{-2}$ & $2.7 \times 10^{-4}$ \\
\hline $\mathrm{Ni}-59$ & $5 \times 10^{-2}$ & $2.0 \times 10^{-7}$ & & $2 \times 10^{-3}$ & $2.5 \times 10^{-5}$ \\
\hline $\mathrm{Ni}-63$ & $5 \times 10^{-2}$ & $5.4 \times 10^{-7}$ & U-234 & $5 \times 10^{-2}$ & $2.6 \times 10^{-4}$ \\
\hline $\mathrm{Zn}-65$ & $5 \times 10^{-1}$ & $1.4 \times 10^{-5}$ & & $2 \times 10^{-3}$ & $2.5 \times 10^{-5}$ \\
\hline $\mathrm{Ge}-68+\mathrm{D}$ & $1 \times 10^{-1}$ & $1.4 \times 10^{-6}$ & $\mathrm{U}-235+\mathrm{D}$ & $5 \times 10^{-2}$ & $2.5 \times 10^{-4}$ \\
\hline \multirow[t]{2}{*}{$\mathrm{Sr}-90+\mathrm{D}$} & $3 \times 10^{-1}$ & $1.4 \times 10^{-4}$ & & $2 \times 10^{-3}$ & $2.6 \times 10^{-5}$ \\
\hline & $1 \times 10^{-2}$ & $2.2 \times 10^{-5}$ & U-236 & $5 \times 10^{-2}$ & $2.5 \times 10^{-4}$ \\
\hline $\mathrm{Nb}-94$ & $1 \times 10^{-2}$ & $5.1 \times 10^{-6}$ & & $2 \times 10^{-3}$ & $2.4 \times 10^{-5}$ \\
\hline Tc-99 & $8 \times 10^{-1}$ & $1.3 \times 10^{-6}$ & $\mathrm{U}-238+\mathrm{D}$ & $5 \times 10^{-2}$ & $2.5 \times 10^{-4}$ \\
\hline Ru-106+D & $5 \times 10^{-2}$ & $2.2 \times 10^{-5}$ & & $2 \times 10^{-3}$ & $3.8 \times 10^{-5}$ \\
\hline$A g-108 m+D$ & $5 \times 10^{-2}$ & $7.5 \times 10^{-6}$ & $\mathrm{~Np}-237+\mathrm{D}$ & $1 \times 10^{-3}$ & $3.9 \times 10^{-3}$ \\
\hline $\mathrm{Ag}-110 \mathrm{~m}+\mathrm{D}$ & $5 \times 10^{-2}$ & $1.1 \times 10^{-5}$ & $\mathrm{Pu}-238$ & $1 \times 10^{-3}$ & $3.8 \times 10^{-3}$ \\
\hline $\mathrm{Cd}-109$ & $5 \times 10^{-2}$ & $1.2 \times 10^{-5}$ & & $1 \times 10^{-5}$ & $5.4 \times 10^{-5}$ \\
\hline \multirow[t]{2}{*}{$\mathrm{Sb}-125+\mathrm{D}$} & $1 \times 10^{-1}$ & $3.2 \times 10^{-6}$ & $\mathrm{Pu}-239$ & $1 \times 10^{-3}$ & $4.3 \times 10^{-3}$ \\
\hline & $1 \times 10^{-2}$ & $3.4 \times 10^{-6}$ & & $1 \times 10^{-5}$ & $5.8 \times 10^{-5}$ \\
\hline $\mathrm{I}-129$ & 1.0 & $2.8 \times 10^{-4}$ & $\mathrm{Pu}-240$ & $1 \times 10^{-3}$ & $4.3 \times 10^{-3}$ \\
\hline Cs-134 & 1.0 & $7.4 \times 10^{-5}$ & & $1 \times 10^{-5}$ & $5.8 \times 10^{-5}$ \\
\hline Cs-135 & 1.0 & $7.1 \times 10^{-6}$ & $\mathrm{Pu}-241+\mathrm{D}$ & $1 \times 10^{-3}$ & $8.6 \times 10^{-5}$ \\
\hline $\mathrm{Cs}-137+\mathrm{D}$ & 1.0 & $5.0 \times 10^{-5}$ & & $1 \times 10^{-5}$ & $9.2 \times 10^{-7}$ \\
\hline $\mathrm{Ce}-144+\mathrm{D}$ & $3 \times 10^{-4}$ & $2.0 \times 10^{-5}$ & $\mathrm{Pu}-242$ & $1 \times 10^{-3}$ & $4.1 \times 10^{-3}$ \\
\hline Pm-147 & $3 \times 10^{-4}$ & $9.5 \times 10^{-7}$ & & $1 \times 10^{-5}$ & $5.6 \times 10^{-5}$ \\
\hline Sm-147 & $3 \times 10^{-4}$ & $1.8 \times 10^{-4}$ & $\mathrm{Pu}-244+\mathrm{D}$ & $1 \times 10^{-3}$ & $4.0 \times 10^{-3}$ \\
\hline Sm-151 & $3 \times 10^{-4}$ & $3.4 \times 10^{-7}$ & & $1 \times 10^{-5}$ & $3.8 \times 10^{-5}$ \\
\hline Eu-152 & 1. $\times 10^{-3}$ & $6.0 \times 10^{-6}$ & $\mathrm{Am}-241$ & $1 \times 10^{-3}$ & $4.5 \times 10^{-3}$ \\
\hline Eu-154 & 1. $\times 10^{-3}$ & $9.1 \times 10^{-6}$ & $\mathrm{Am}-243+\mathrm{D}$ & $1 \times 10^{-3}$ & $4.5 \times 10^{-3}$ \\
\hline Eu-155 & 1. $\times 10^{-3}$ & $1.3 \times 10^{-6}$ & $\mathrm{Cm}-243$ & $1 \times 10^{-3}$ & $2.9 \times 10^{-3}$ \\
\hline Gd-152 & $3 \times 10^{-4}$ & $1.5 \times 10^{-4}$ & $\mathrm{Cm}-244$ & $1 \times 10^{-3}$ & $2.3 \times 10^{-3}$ \\
\hline Gd-153 & $3 \times 10^{-4}$ & $1.1 \times 10^{-6}$ & $\mathrm{Cm}-248$ & $1 \times 10^{-3}$ & $1.6 \times 10^{-2}$ \\
\hline $\mathrm{Au}-195$ & 1. $\times 10^{-1}$ & $1.1 \times 10^{-6}$ & Cf-252 & $1 \times 10^{-3}$ & $9.4 \times 10^{-4}$ \\
\hline Tl-204 & 1.0 & $3.2 \times 10^{-6}$ & & & \\
\hline
\end{tabular}

a Dose conversion factors for entries labeled by " $+D^{*}$ are aggregated dose conversion factors for intake of a radionuclide together with radionuclides of the associated decay chain in secular equilibrium.

b Fraction of a stable element entering the GI tract that reaches body fluids. 


\section{E.4 REFERENCES}

Eckerman, K.F., et al., 1988, Limiting Values of Radionuclide Intake and Air Concentration and Dose Conversion Factors for Inhalation, Submersion, and Ingestion, EPA-520/1-88-020, Federal Guidance Report No. 11, prepared by Oak Ridge National Laboratory, Oak Ridge, Tenn., for U.S. Environmental Protection Agency, Office of Radiation Programs, Washington, D.C.

International Commission on Radiological Protection, 1979-1982, Limits for Intakes of Radionuclides by Workers, a report of Committee 2 of the International Commission on Radiological Protection, adopted by the Commission in July 1978, ICRP Publication 30, Part 1 (and Supplement), Part 2 (and Supplement), Part 3 (and Supplements A and B), and Index, Annals of the ICRP, Pergamon Press, New York, N.Y.

U.S. Department of Energy, 1988, Internal Dose Conversion Factors for Calculation of Dose to the Public, DOE/EH-0071, Assistant Secretary for Environment, Safety and Health, Washington, D.C.

Yu, C., et al., 1993, Manual for Implementing Residual Radioactive Material Guidelines Using RESRAD, Version 5.0, Draft ANL/EAD/LD-2, Argonne National Laboratory, Argonne, Ill., Sept. 


$$
\text { E-8 }
$$




\section{APPENDIX F:}

EXTERNAL RADIATION EXPOSURE 
F-2 


\section{APPENDIX F:}

\section{EXTERNAL RADIATION EXPOSURE}

The external radiation exposure model is used to calculate the deep effective doses

from (1) direct external exposure to the sources, (2) external exposure to deposited material, and (3) external exposure to radioactive dust in the indoor air (air submersion).

Two direct exposure models are based on the geometrical type of source. The model for area and volume sources is based on an infinite plane source and a semi-infinite slab source, respectively, then applying two geometrical factors. One factor accounts for the limited area of the source, the perpendicular displacement between the source and receptor, and the shielding effect of a cover material or shielding material between the receptor and the source. The source is always assumed to be either a disk, in the surface contamination case, or cylindrical, in the volume contaminated case. The other geometrical factor accounts for the possible off-centered placement of the receptor relative to the axis of the disk or cylinder. The point and line contamination models use a simple dose integral method.

\section{F.1 EXTERNAL DOSE FROM CONTAMINATED AREA SOURCE}

The external dose from exposure to an area source containing radionuclide $n$ in compartment $i, D^{n}{ }_{i A}$, is expressed as:

$$
D_{i A}^{n}=8,760 F_{i n} F_{i} C_{S A}^{n} D C F_{a}^{n} \frac{\sum_{j} y_{n j} H A_{A}\left(E_{n j}\right) d\left(E_{n j}\right)}{\sum_{j} y_{n j} d\left(E_{n j}\right)}
$$

where

$$
\begin{aligned}
8,760 & =\text { time conversion factor }(\mathrm{h} / \mathrm{yr}) \\
F_{i n} & =\text { fraction of time spent indoors; } \\
F_{i} & =\text { fraction of time spent at compartment } i
\end{aligned}
$$


$C_{S A}^{n}=$ area source concentration of radionuclide $n\left(\mathrm{pCi} / \mathrm{cm}^{2}\right)$;

$D C F^{n}{ }_{a}=$ dose conversion factor for radionuclide $n$ for an infinite plane source with the receptor $1 \mathrm{~m}$ from the plane;

$y_{n j}=$ yield for gamma $j$ from radionuclide $n$;

$E_{n j}=$ energy for gamma $j$ from radionuclide $n$;

$d\left(E_{n j}\right)=$ unit dose rate for energy $\left(E_{n j}\right)$ for an infinite plane with the receptor $1 \mathrm{~m}$ from the plane;

$H=$ horizontal displacement factor; and

$A_{A}\left(E_{n j}\right)=$ area factor, which depends on the energy of the gamma, the area of the disk, the amount of shielding, and the distance of the receptor from the plane of the disk.

The horizontal displacement factor, $H$, depends only on the radius of the disk, $r$, the distance from the receptor to the plane of the disk, $t_{\alpha}$, and the distance from the receptor to the axis of the disk, $x$, shown in Figure F.1 (Jaeger et al. 1968):

$$
H=\frac{\ln \left(\left[\left(t_{a}^{2}+r^{2}-x^{2}+\sqrt{r^{4}+2 r^{2}\left(t_{a}^{2}-x^{2}\right)+\left(t_{a}^{2}+x^{2}\right)^{2}}\right] /\left(2 t a a^{2}\right)\right)\right.}{\ln \left(1+\frac{r^{2}}{t_{a}^{2}}\right)}
$$

The area factor, $A_{A}$, can be derived by considering the point kernal dose integral $I\left(r, t_{\mathrm{a}}, t_{\mathrm{c}}\right)$ over the source considering the radius of the disk, $r$, the distance from the receptor 


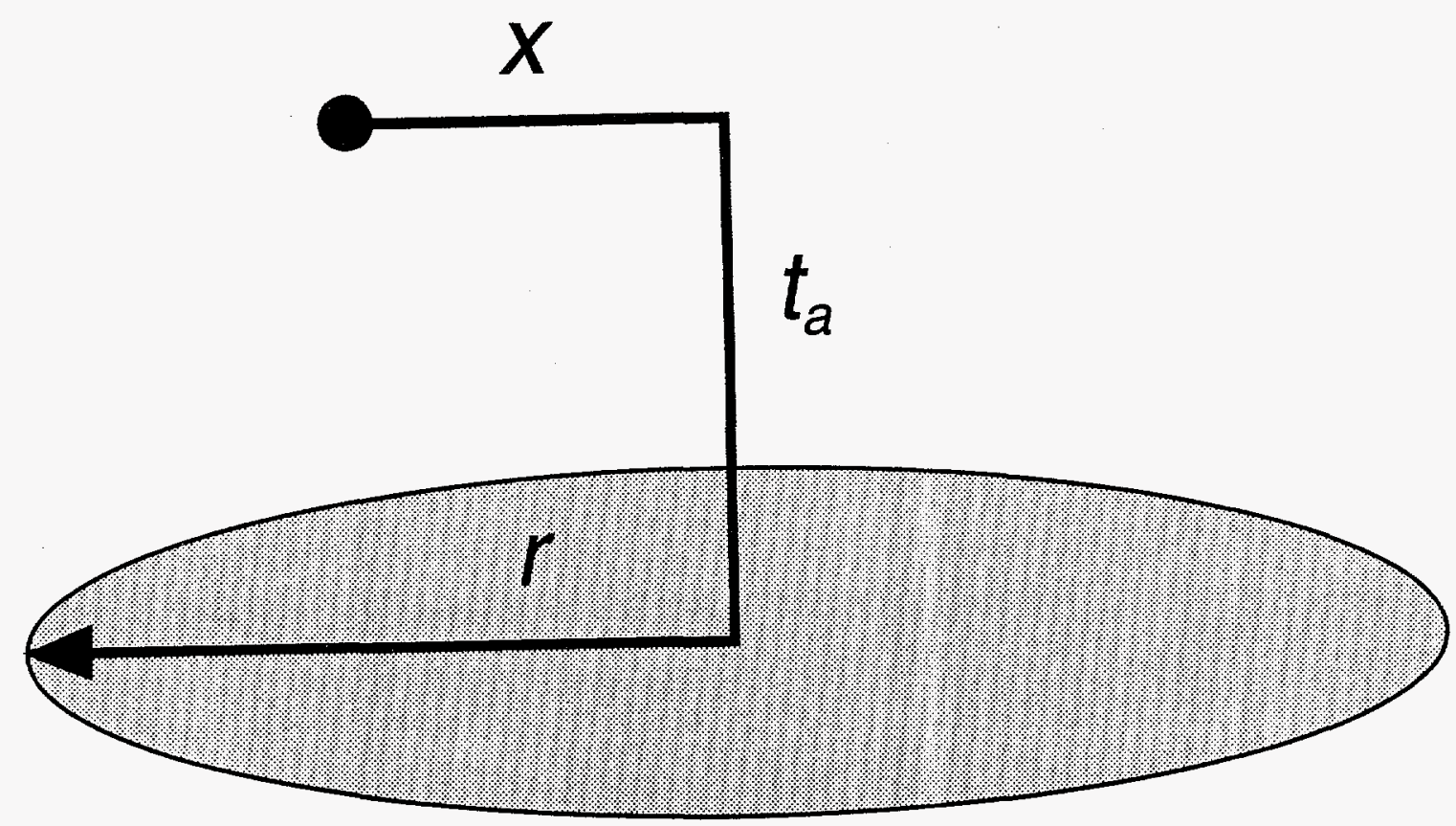

FIGURE F.1 Geometry for the Horizontal Displacement Factor

to the plane of the disk, $t_{\alpha}$, and the thickness of the shielding material, $t_{c}$. The area factor is the ratio of the dose integrals for the case considered and the reference case:

$$
A_{A}=\frac{I\left(r, t_{a}, t_{c}\right)}{I(\infty, 1 \text { meter, } 0.0)}
$$

where the dose integral, $I\left(r, t_{\alpha}, t_{c}\right)$, is given by:

$$
I\left(r, t_{a}, t_{c}\right)=\int_{z_{0}}^{z_{F}} e^{-z} B(z) \frac{d z}{z}
$$

where

$$
\begin{aligned}
& z_{0}=\mu_{a} t_{a}+\mu_{c} t_{c} ; \\
& z_{F}=z_{0} \frac{\sqrt{\left(t_{a}+t_{c}\right)^{2}+r^{2}}}{t_{a}+t_{c}} ; \\
& \mu_{a}=\text { attenuation coefficient for air; }
\end{aligned}
$$


$\mu_{c}=$ attenuation coefficient for the cover material; and

$B(z)=$ buildup factor (G-P Method) for length measured in mean free paths, $z$.

The shielding material thickness, $t_{c}$, includes the receptor-source shielding thickness and any uncontaminated volume layers in the source material between the contaminated layer and the receptor.

\section{F.2 EXTERNAL DOSE FROM CONTAMINATED VOLUME SOURCE}

The external dose from exposure to a volume source containing radionuclide $n$ in compartment $i, D^{n}{ }_{i \mathrm{~V}}$, is expressed as:

$$
\begin{gathered}
D_{i V}^{n}=8,760 F_{i n} F_{i} C_{s V}^{n} D C F_{v}^{n} \frac{\sum_{j} y_{n j} H A_{V}\left(E_{n j}\right) d\left(E_{n j}\right)\left[1-e^{-f\left(E_{n j} t_{s}\right)}\right]}{\sum_{j} y_{n j} d\left(E_{n j}\right)}, \\
f\left(E_{n j}, t\right)=\quad \alpha_{1}\left(E_{n j}\right) \mu_{s} t, \quad 0<\mu t<0.5 \\
\alpha_{2}\left(E_{n j}\right) \mu_{s} t+\beta_{2}\left(\mu_{s} t\right)^{0.5}, \quad 0.5<\mu t,
\end{gathered}
$$

where

$$
\begin{aligned}
C_{s V}^{n}= & \text { volume source concentration of radionuclide } n\left(\mathrm{pCi} / \mathrm{cm}^{3}\right) ; \\
D C F_{v}^{n}= & \text { dose conversion factor for radionuclide } n \text { for a semi-infinite } \\
& \text { slab source with the receptor } 1 \mathrm{~m} \text { from the plane; } \\
d\left(E_{n j}\right)= & \text { unit dose rate for energy }(E) \text { for a semi-infinite slab with the } \\
& \text { receptor } 1 \mathrm{~m} \text { from the plane; }
\end{aligned}
$$


$A_{V}\left(E_{n j}\right)=$ volume source area factor, which depends on the energy of the gamma, the area of the disk, the amount of shielding, the thickness of the cylinder, and the distance of the receptor from the plane of the disk;

$f\left(E_{n j}, t\right)=$ finite thickness coefficient, which is a function of the gamma energy and thickness of the source;

$\mu_{s}=$ attenuation coefficient of the source material; and

$\alpha_{1}, \alpha_{2}, \beta_{2}=$ energy-dependent coefficients (Chen 1991).

The area factor can be derived in a similar way to the area factor for the area source with the extra consideration of the finite thickness of the source cylinder, $t_{s}$ :

$$
A_{V}=\frac{I\left(r, t_{a}, t_{c}, t_{s}\right)}{I\left(\infty, 1 \text { meter, } 0.0, t_{s}\right)},
$$

where the dose integral is given by:

$$
I\left(r, t_{a}, t_{c}, t_{s}\right)=\int_{0}^{t_{s}} \int_{z_{0}}^{z_{F}} e^{-z} B(z) \frac{d z}{z} d t
$$

where

$$
\begin{aligned}
& z_{0}=\mu_{a} t_{a}+\mu_{c} t_{c}+\mu_{s} t, \text { and } \\
& z_{F}=z_{0} \frac{\sqrt{\left(t_{a}+t_{c}+t\right)^{2}+r^{2}}}{t_{a}+t_{c}+t}
\end{aligned}
$$




\section{F.3 EXTERNAL DOSE FROM CONTAMINATED POINT SOURCE}

The model for point sources is simply expressed considering the energy of the radiation and attenuation. The external dose from exposure to a point source containing radionuclide $n$, in compartment $i, D^{n}{ }_{i P}$, is:

$$
D_{i P}^{n}=8,760 F_{i n} F_{i} C_{s P}^{n} \sum_{j} y_{n j} E_{n j} B\left(\mu_{a} t_{a}\right) d\left[\frac{\mu_{e n}\left(E_{n j}\right)}{\rho}\right]_{a i r} \frac{e^{-\mu_{a} t_{a}-\mu_{c} t_{c}}}{4 \pi t_{a}^{2}}
$$

where

$$
\begin{aligned}
C_{s P}^{n} & =\text { total activity of radionuclide } n \text { in the source }(\mathrm{pCi}) ; \\
d & =\text { unit dose rate per energy absorption; and } \\
{\left[\frac{\mu_{e n}\left(E_{n j}\right)}{\rho}\right]_{a i r} } & =\text { mass energy absorption coefficient in air. }
\end{aligned}
$$

\section{F.4 EXTERNAL DOSE FROM CONTAMINATED LINE SOURCE}

The model for line sources differs from that of the point source in the more complicated geometrical factor. The external dose from exposure to a line source in compartment $i$, containing radionuclide $n, D^{n}{ }_{i L}$, is expressed as:

$$
\begin{gathered}
D_{i L}^{n}=8,760 F_{i n} F_{i} C_{s L}^{n} \sum_{j} y_{n j} E_{n j} B\left(z^{\prime}\right) d\left[\frac{\mu_{e n}\left(E_{n j}\right)}{\rho}\right]_{a i r} A_{L} \\
z^{\prime}=\mu_{a} \sqrt{t_{a}^{2}+\left(\frac{x_{1}+x_{2}}{2}\right)^{2}} \\
A_{L}=e^{-\mu_{c} t_{c}} \int_{x_{1}}^{\frac{e^{-\mu_{a}} \sqrt{x^{2}+t_{a}^{2}}}{4 \pi\left(x^{2}+t_{a}^{2}\right)}} d x
\end{gathered}
$$


where

$$
\begin{aligned}
C_{s L}^{n}= & \text { line source concentration of radionuclide } n(\mathrm{pCi} / \mathrm{m}) \\
t_{a}= & \text { perpendicular distance to receptor; and } \\
x_{1}, x_{2}= & \text { distances between the foot of the perpendicular from the } \\
& \text { receptor to the line source and each end of the line source. }
\end{aligned}
$$

These geometrical parameters are shown in Figure F.2 and are calculated on the basis of the input geometrical parameters of the source and the location of the receptor.

\section{F.5 EXTERNAL DOSE FROM CONTAMINATED DUST IN INDOOR AIR}

The air submersion external dose, $D^{n}{ }_{i, s u b}$, from exposure to indoor contaminated dust in the air is calculated by using the following equation:

$$
D_{i, s u b}^{n}=8,760 F_{i n} F_{i} C_{i}^{n} D C F_{s u b}^{n}
$$

where

$$
\begin{aligned}
D_{i, s u b}^{n}= & \text { air submersion effective dose equivalent from } \\
& \text { radionuclide } n \text { in compartment } i(\mathrm{mrem} / \mathrm{yr}) ; \\
C_{i}^{n}= & \text { concentration of radionuclide } n \text { in the indoor air of } \\
& \text { compartment } i\left(\mathrm{pCi} / \mathrm{m}^{3}\right) ; \text { and } \\
D C F_{s u b}^{n}= & \text { air submersion dose conversion factor for } \\
& \text { radionuclide } n\left(\mathrm{mrem} / \mathrm{yr} \text { per } \mathrm{pCi} / \mathrm{m}^{3}\right) .
\end{aligned}
$$

The $D C F_{s u b}^{n}$ is for a semi-infinite cloud source; no correction (reduction) for the finite indoor air volume was performed in the RESRAD-BUILD code. 


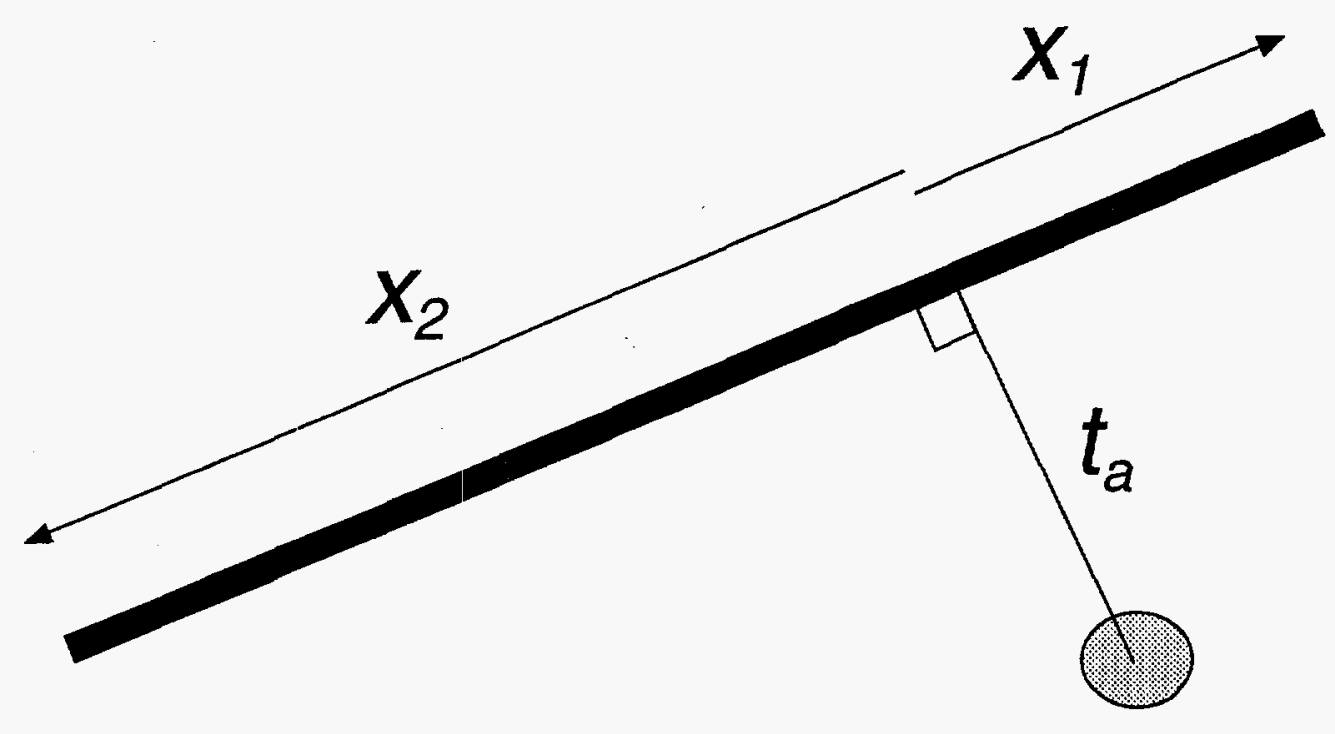

FIGURE F.2 Geometry in the Line Source Model

\section{F.6 DOSE CONVERSION FACTORS}

Values of dose conversion factors for external exposure were taken from a U.S. Environmental Protection Agency report (Eckerman and Ryman 1993). Table F.1 lists the dose conversion factors for the surface (infinite plane) source, the infinite depth volume source, and the air submersion exposure.

\section{F.7 REFERENCES}

Chen, S.Y., 1991, "Calculation of Effective Dose-Equivalent Responses for External Exposure from Residual Photon Emitters in Soil," Health Physics 60(3).

Eckerman, K.F., and J.C. Ryman, 1993, External Exposure to Radionuclides in Air, Water, and Soil, Exposure-to-Dose Coefficients for General Application, Based on the 1987 Federal Radiation Protection Guidance, Federal Guidance Report No. 12, prepared by Oak Ridge National Laboratory, Oak Ridge, Tenn., for the U.S. Environmental Protection Agency.

Jaeger, R.G., et al., 1968, Engineering Compendium on Radiation Shielding, Springer-Verlag, New York, N.Y. 
TABLE F.1 Effective Dose Equivalent Conversion Factors for External Exposure

\begin{tabular}{|c|c|c|c|}
\hline Radionuclide & $\begin{array}{c}\text { Surface }^{\mathrm{a}} \\
(\mathrm{mrem} / \mathrm{yr}) /\left(\mathrm{pCi} / \mathrm{m}^{2}\right)\end{array}$ & $\begin{array}{c}\text { Volume } \mathrm{e}^{\mathrm{b}} \\
(\mathrm{mrem} / \mathrm{yr}) /\left(\mathrm{pCi} / \mathrm{m}^{3}\right)\end{array}$ & $\begin{array}{c}\text { Submersion }^{\mathrm{c}} \\
(\mathrm{mrem} / \mathrm{yr}) /\left(\mathrm{pCi} / \mathrm{m}^{3}\right)\end{array}$ \\
\hline H-3 & 0 & 0 & $3.87 \times 10^{-8}$ \\
\hline C-14 & $1.88 \times 10^{-9}$ & $8.42 \times 10^{-12}$ & $2.62 \times 10^{-8}$ \\
\hline $\mathrm{Na}-22$ & $2.46 \times 10^{-4}$ & $8.56 \times 10^{-6}$ & $1.26 \times 10^{-2}$ \\
\hline Al-26 & $2.91 \times 10^{-4}$ & $1.09 \times 10^{-5}$ & $1.59 \times 10^{-2}$ \\
\hline $\mathrm{Cl}-36$ & $7.87 \times 10^{-8}$ & $1.50 \times 10^{-9}$ & $2.61 \times 10^{-6}$ \\
\hline $\mathrm{K}-40$ & $1.71 \times 10^{-5}$ & $6.52 \times 10^{-7}$ & $9.42 \times 10^{-4}$ \\
\hline $\mathrm{Ca}-41$ & 0 & 0 & 0 \\
\hline$M n-54$ & $9.50 \times 10^{-5}$ & $3.23 \times 10^{-6}$ & $4.79 \times 10^{-3}$ \\
\hline $\mathrm{Fe}-55$ & 0 & 0 & 0 \\
\hline Co-57 & $1.35 \times 10^{-5}$ & $3.14 \times 10^{-7}$ & $6.56 \times 10^{-4}$ \\
\hline $\mathrm{Co}-60$ & $2.75 \times 10^{-4}$ & $1.02 \times 10^{-5}$ & $1.47 \times 10^{-2}$ \\
\hline $\mathrm{Ni}-59$ & 0 & 0 & 0 \\
\hline Ni-63 & 0 & 0 & 0 \\
\hline $\mathrm{Zn}-65$ & $6.47 \times 10^{-5}$ & $2.32 \times 10^{-6}$ & $3.39 \times 10^{-3}$ \\
\hline $\mathrm{Ge}-68+\mathrm{D}$ & $1.10 \times 10^{-4}$ & $3.52 \times 10^{-6}$ & $5.36 \times 10^{-3}$ \\
\hline Sr-90+D & $6.56 \times 10^{-7}$ & $1.54 \times 10^{-8}$ & $2.31 \times 10^{-5}$ \\
\hline $\mathrm{Nb}-94$ & $1.79 \times 10^{-4}$ & $6.06 \times 10^{-6}$ & $9.01 \times 10^{-3}$ \\
\hline Tc-99 & $9.13 \times 10^{-9}$ & $7.86 \times 10^{-11}$ & $1.90 \times 10^{-7}$ \\
\hline $\mathrm{Ru}-106+\mathrm{D}$ & $2.48 \times 10^{-5}$ & $8.08 \times 10^{-7}$ & $1.22 \times 10^{-3}$ \\
\hline Ag-108m+D & $1.87 \times 10^{-4}$ & $6.04 \times 10^{-6}$ & $9.14 \times 10^{-3}$ \\
\hline Ag-110m+D & $3.10 \times 10^{-4}$ & $1.08 \times 10^{-5}$ & $1.59 \times 10^{-2}$ \\
\hline Cd-109 & $2.63 \times 10^{-6}$ & $9.21 \times 10^{-9}$ & $3.44 \times 10^{-5}$ \\
\hline $\mathrm{Sb}-125+\mathrm{D}$ & $4.97 \times 10^{-5}$ & $1.53 \times 10^{-6}$ & $2.36 \times 10^{-3}$ \\
\hline $\mathrm{I}-129$ & $3.02 \times 10^{-6}$ & $8.11 \times 10^{-9}$ & $4.45 \times 10^{-5}$ \\
\hline Cs-134 & $1.78 \times 10^{-4}$ & $5.93 \times 10^{-6}$ & $8.86 \times 10^{-3}$ \\
\hline Cs-135 & $3.90 \times 10^{-9}$ & $2.40 \times 10^{-11}$ & $6.61 \times 10^{-8}$ \\
\hline $\mathrm{Cs}-137+\mathrm{D}$ & $6.49 \times 10^{-5}$ & $2.14 \times 10^{-6}$ & $3.19 \times 10^{-3}$ \\
\hline $\mathrm{Ce}-144+\mathrm{D}$ & $6.83 \times 10^{-6}$ & $2.03 \times 10^{-7}$ & $3.29 \times 10^{-4}$ \\
\hline Pm-147 & $3.99 \times 10^{-9}$ & $3.14 \times 10^{-11}$ & $8.11 \times 10^{-8}$ \\
\hline $\mathrm{Sm}-147$ & 0 & 0 & 0 \\
\hline $\mathrm{Sm}-151$ & $5.89 \times 10^{-10}$ & $6.17 \times 10^{13}$ & $4.22 \times 10^{-9}$ \\
\hline Eu-152 & $1.29 \times 10^{-4}$ & $4.39 \times 10^{-6}$ & $6.61 \times 10^{-3}$ \\
\hline Eu-154 & $1.39 \times 10^{-4}$ & $4.81 \times 10^{-6}$ & $7.18 \times 10^{-3}$ \\
\hline Eu-155 & $6.90 \times 10^{-6}$ & $1.14 \times 10^{-7}$ & $2.91 \times 10^{-4}$ \\
\hline Gd-152 & 0 & 0 & 0 \\
\hline Gd-153 & $1.24 \times 10^{-5}$ & $1.53 \times 10^{-7}$ & $4.34 \times 10^{-4}$ \\
\hline $\mathrm{Au}-195$ & $9.17 \times 10^{-6}$ & $1.30 \times 10^{-7}$ & $3.76 \times 10^{-4}$ \\
\hline Tl-204 & $1.73 \times 10^{-7}$ & $2.54 \times 10^{-9}$ & $6.54 \times 10^{-6}$ \\
\hline $\mathrm{Pb}-210+\mathrm{D}$ & $4.14 \times 10^{-7}$ & $3.82 \times 10^{-9}$ & $1.43 \times 10^{-5}$ \\
\hline $\mathrm{Bi}-207$ & $1.73 \times 10^{-4}$ & $5.87 \times 10^{-6}$ & $8.82 \times 10^{-3}$ \\
\hline $\mathrm{Ra}-226+\mathrm{D}$ & $1.94 \times 10^{-4}$ & $7.00 \times 10^{-6}$ & $1.04 \times 10^{-2}$ \\
\hline $\mathrm{Ra}-228+\mathrm{D}$ & $1.09 \times 10^{-4}$ & $3.74 \times 10^{-6}$ & $5.59 \times 10^{-3}$ \\
\hline Ac- $227+\mathrm{D}$ & $4.53 \times 10^{-5}$ & $1.26 \times 10^{-6}$ & $2.16 \times 10^{-3}$ \\
\hline Th-228+D & $1.65 \times 10^{-4}$ & $6.39 \times 10^{-6}$ & $9.41 \times 10^{-3}$ \\
\hline
\end{tabular}


TABLE F.1 (Cont.)

\begin{tabular}{lccc}
\hline Radionuclide & $\begin{array}{c}\text { Surface } \\
(\mathrm{mrem} / \mathrm{yr}) /\left(\mathrm{pCi} / \mathrm{m}^{2}\right)\end{array}$ & $\begin{array}{c}\text { Volume }^{\mathrm{b}} \\
(\mathrm{mrem} / \mathrm{yr}) /\left(\mathrm{pCi} / \mathrm{m}^{3}\right)\end{array}$ & $\begin{array}{c}\text { Submersion } \\
(\mathrm{mrem} / \mathrm{yr}) /\left(\mathrm{pCi} / \mathrm{m}^{3}\right)\end{array}$ \\
\hline Th-229+D & $3.68 \times 10^{-5}$ & $9.87 \times 10^{-7}$ & $1.72 \times 10^{-3}$ \\
Th-230+D & $8.78 \times 10^{-8}$ & $7.57 \times 10^{-10}$ & $2.04 \times 10^{-6}$ \\
Th-232 & $6.45 \times 10^{-8}$ & $3.26 \times 10^{-10}$ & $1.02 \times 10^{-6}$ \\
Pa-231 & $4.76 \times 10^{-6}$ & $1.19 \times 10^{-7}$ & $2.01 \times 10^{-4}$ \\
U-232 & $1.18 \times 10^{-7}$ & $5.65 \times 10^{-10}$ & $1.66 \times 10^{-6}$ \\
U-233 & $8.38 \times 10^{-8}$ & $8.75 \times 10^{-10}$ & $1.91 \times 10^{-6}$ \\
U-234 & $8.75 \times 10^{-8}$ & $2.52 \times 10^{-10}$ & $8.93 \times 10^{-7}$ \\
U-235+D & $1.95 \times 10^{-5}$ & $4.74 \times 10^{-7}$ & $9.03 \times 10^{-4}$ \\
U-236 & $7.61 \times 10^{-8}$ & $1.35 \times 10^{-10}$ & $5.86 \times 10^{-7}$ \\
U-238+D & $3.53 \times 10^{-6}$ & $9.51 \times 10^{-8}$ & $1.60 \times 10^{-4}$ \\
Np-237+D & $2.62 \times 10^{-5}$ & $6.88 \times 10^{-7}$ & $1.21 \times 10^{-3}$ \\
Pu-238 & $9.80 \times 10^{-8}$ & $9.48 \times 10^{-11}$ & $5.71 \times 10^{-7}$ \\
Pu-239 & $4.29 \times 10^{-8}$ & $1.85 \times 10^{-10}$ & $4.96 \times 10^{-7}$ \\
Pu-240 & $9.40 \times 10^{-8}$ & $9.18 \times 10^{-11}$ & $5.56 \times 10^{-7}$ \\
Pu-241+D & $6.07 \times 10^{-10}$ & $1.18 \times 10^{-11}$ & $2.56 \times 10^{-8}$ \\
Pu-242 & $7.80 \times 10^{-8}$ & $8.01 \times 10^{-11}$ & $4.69 \times 10^{-7}$ \\
Pu-244+D & $3.88 \times 10^{-5}$ & $1.26 \times 10^{-6}$ & $1.90 \times 10^{-3}$ \\
Am-241 & $3.22 \times 10^{-6}$ & $2.74 \times 10^{-8}$ & $9.57 \times 10^{-5}$ \\
Am-243+D & $2.53 \times 10^{-5}$ & $5.60 \times 10^{-7}$ & $1.15 \times 10^{-3}$ \\
Cm-243 & $1.46 \times 10^{-5}$ & $3.65 \times 10^{-7}$ & $6.88 \times 10^{-4}$ \\
Cm-244 & $1.03 \times 10^{-7}$ & $7.89 \times 10^{-11}$ & $5.74 \times 10^{-7}$ \\
Cm-248 & $7.02 \times 10^{-8}$ & $5.50 \times 10^{-11}$ & $3.97 \times 10^{-7}$ \\
Cf-252 & $8.45 \times 10^{-8}$ & $1.10 \times 10^{-10}$ & $5.92 \times 10^{-7}$ \\
\hline
\end{tabular}

a Surface factors represent infinite thinness.

b Volume factors represent infinite depth.

c Submersion factors represent air submersion. 